\title{
WestVirginiaUniversity
}

THE RESEARCH REPOSITORY @ WVU

Graduate Theses, Dissertations, and Problem Reports

2015

\section{The correlation of chin prominence and esthetics}

Nicholas Maddux

Follow this and additional works at: https://researchrepository.wvu.edu/etd

\section{Recommended Citation}

Maddux, Nicholas, "The correlation of chin prominence and esthetics" (2015). Graduate Theses,

Dissertations, and Problem Reports. 6137.

https://researchrepository.wvu.edu/etd/6137

This Thesis is protected by copyright and/or related rights. It has been brought to you by the The Research Repository @ WVU with permission from the rights-holder(s). You are free to use this Thesis in any way that is permitted by the copyright and related rights legislation that applies to your use. For other uses you must obtain permission from the rights-holder(s) directly, unless additional rights are indicated by a Creative Commons license in the record and/ or on the work itself. This Thesis has been accepted for inclusion in WVU Graduate Theses, Dissertations, and Problem Reports collection by an authorized administrator of The Research Repository @ WVU. For more information, please contact researchrepository@mail.wvu.edu. 


\title{
CORRELATION OF CHIN PROMINENCE AND ESTHETICS
}

\author{
Nicholas Maddux D.D.S.
}

\author{
A THESIS \\ Submitted to: \\ The School of Dentistry \\ At West Virginia University \\ In partial fulfillment of the requirements \\ For the degree of \\ Master of Science \\ In \\ Orthodontics
}

Tim Tremont D.M.D., M.S. Advisor

Peter Ngan, D.M.D., Chair

Chris Martin, D.D.S., M.S.

Richard Jurevic, D.M.D, M.S.

West Virginia University

Department of Orthodontics

Morgantown, West Virginia 


\title{
The Correlation of Chin Prominence and Facial Esthetics
}

Nicholas Maddux, D.D.S., Dr. Timothy Tremont D.M.D., Dr. Peter Ngan, D.M.D, Dr. Chris Martin, D.D.S., Dr. Richard Jurevic, D.M.D.

\begin{abstract}
In part I, a sample of pre-treatment lateral cephalograms collected consecutively was analyzed to look for correlation between soft tissue and hard tissue chin measurements. In part II a survey was constructed to investigate the effects of changes in chin prominence on perceived facial profile attractiveness. Materials \& Methods: (Part I) 105 cephalograms of patients in the permanent dentition, 12 years old or greater, were analyzed with a series of hard tissue and soft tissue measurements. The sample was also grouped based on skeletal class and category. (Part II) A facial profile photograph was obtained from one female subject. The chin prominence was morphed in $1 \mathrm{~mm}$ increments forward and backward to create 14 new images (15 total). A second group was created by cropping these 15 images to only include the chin and lower lip. Orthodontists and non-orthodontists were recruited for a survey and asked to rate the attractiveness of both series of images. Results: (Part I) Chin soft tissue thickness, Pog-Pog', showed weak correlation with N-Me ( $R=0.24)$, Sn'-Me (R=0.21), Pog'-GALL (-0.42), Pog-GALL (0.29), and TVL-Pog' (-0.40). There was no significant difference in average chin soft tissue thickness when the sample was grouped by skeletal class or category. (Part II) For the survey, when comparing orthodontist vs. non-orthodontists, there was no significant difference in the ratings of chin profile alone or the whole face profile. When comparing men versus women, there was no significant difference in rating the whole face, but there was significant difference in the ratings of the chin alone. There was also no significant difference when comparing ratings of the chin alone to the corresponding whole face images. Conclusions: 1 ) There is only weak correlation between chin soft tissue thickness and skeletal measurements. 2) Chin soft tissue thickness is highly variable. 3 ) There is no difference in soft tissue chin thickness based on skeletal class or category. 4) Perceived attractiveness of the profile is sensitive to millimeter changes in chin prominence. 5) Orthodontists and non-orthodontists agree on attractiveness. 6) Male and females agree on profile attractiveness but differ on chin attractiveness.
\end{abstract}




\section{CONTENTS}

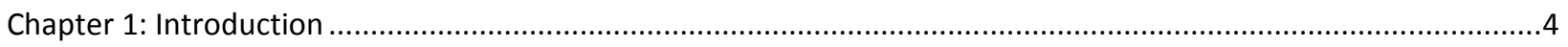

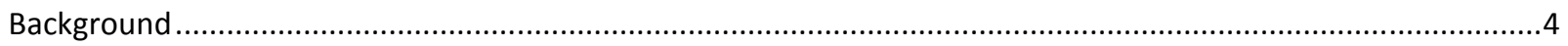

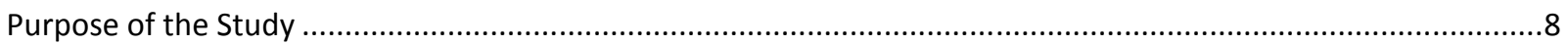

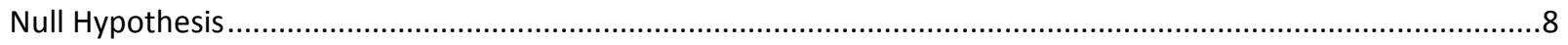

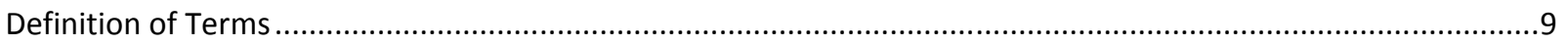

Assumptions …

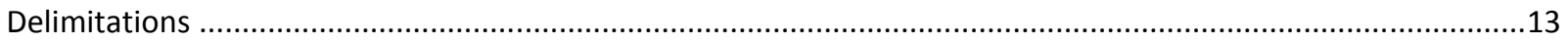

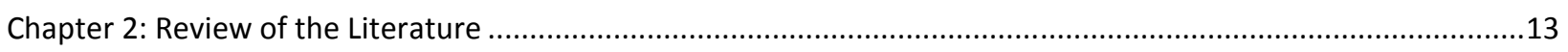

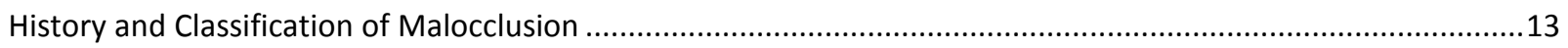

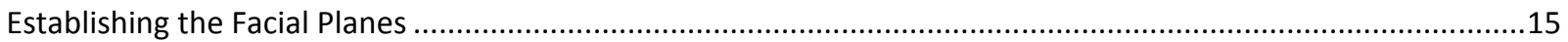

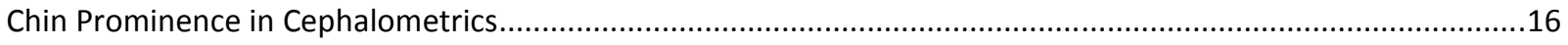

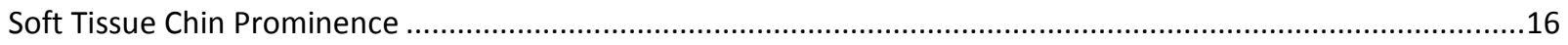

Soft Tissue Changes Resulting From Surgical Advancement …....................................................................17

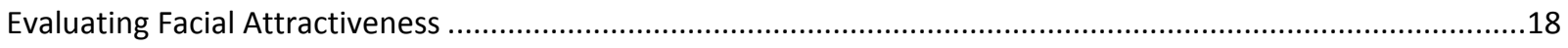

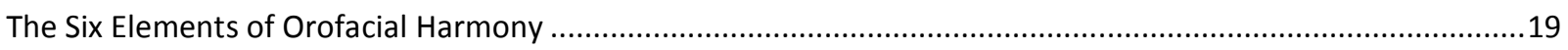

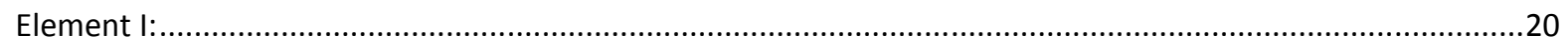

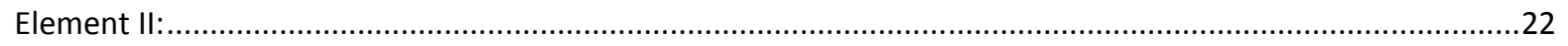

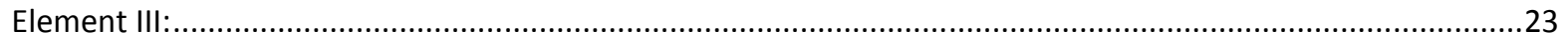

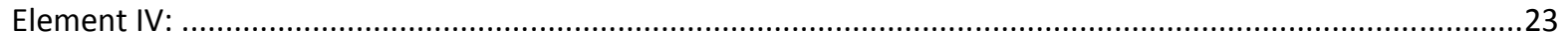

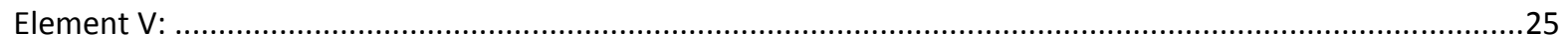

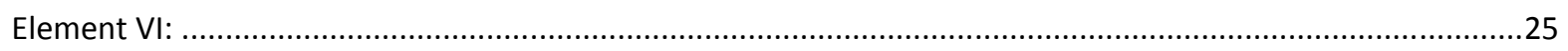

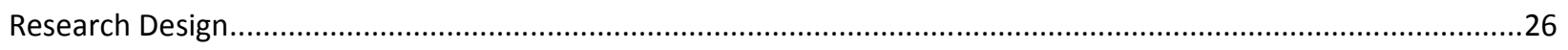

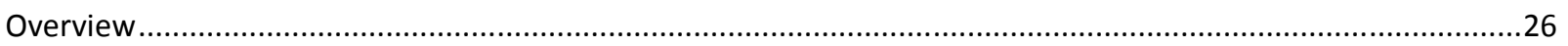

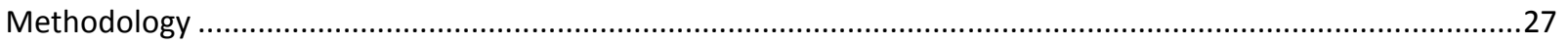




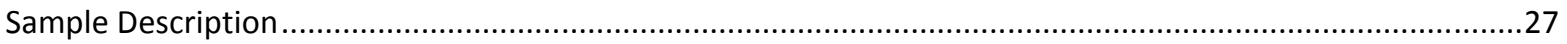

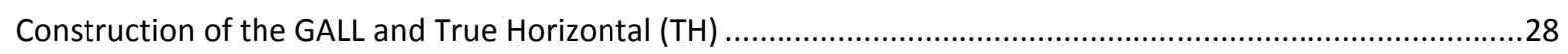

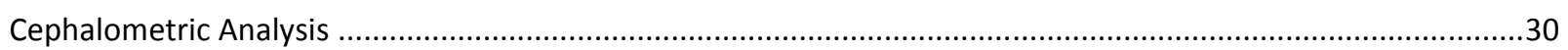

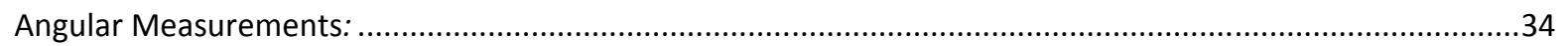

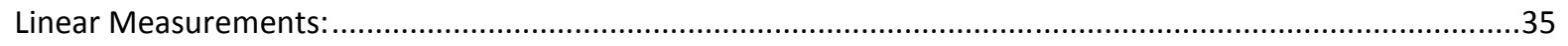

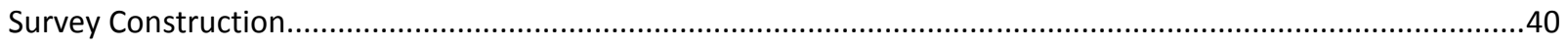

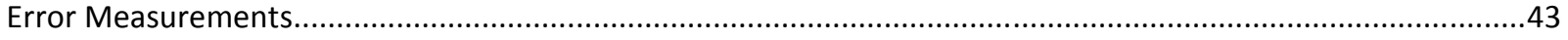

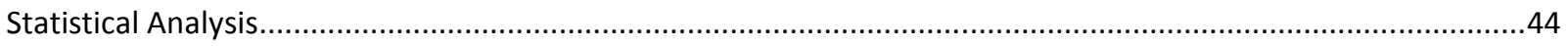

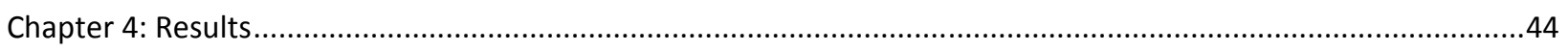

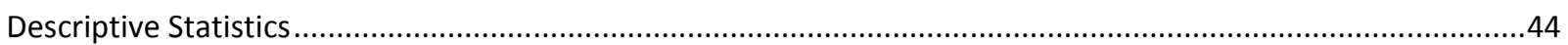

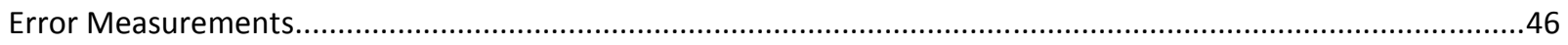

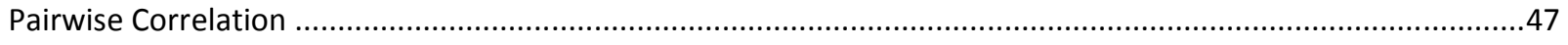

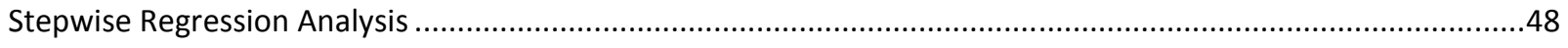

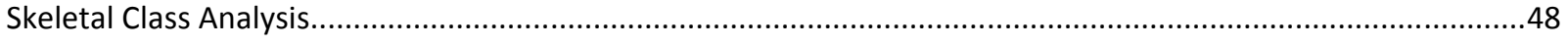

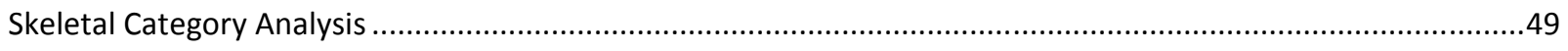

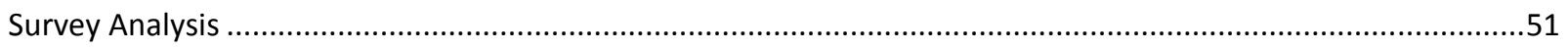

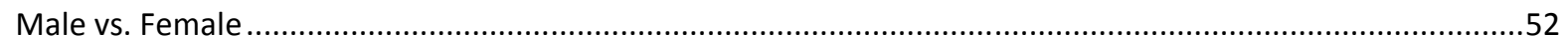

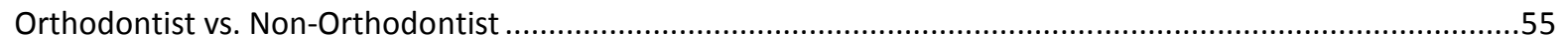

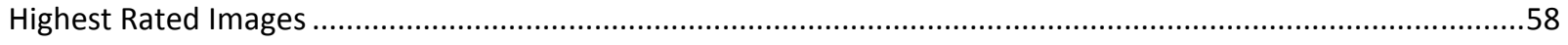

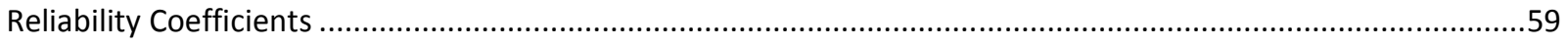

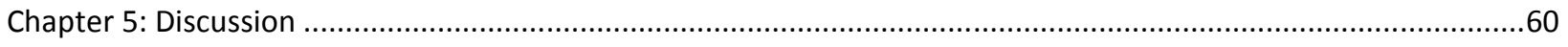

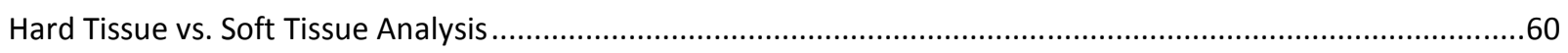

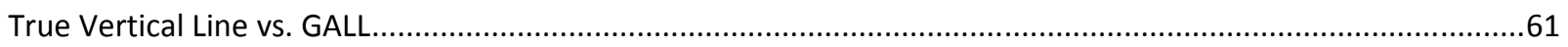

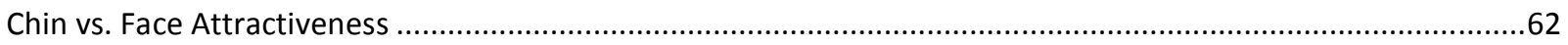

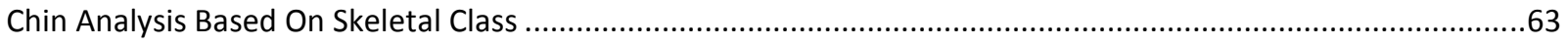

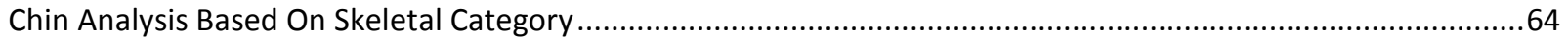

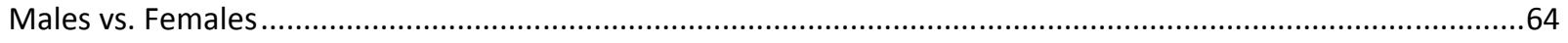


Orthodontists vs. Non-Orthodontists

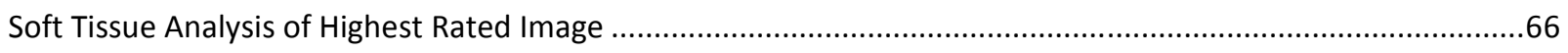

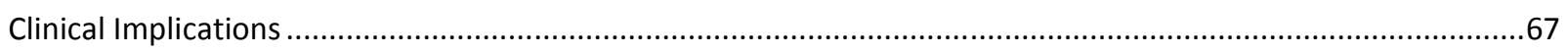

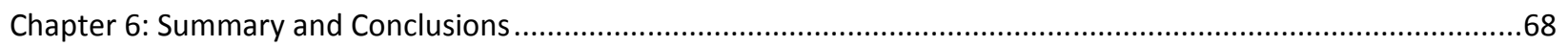

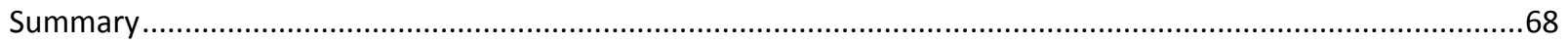

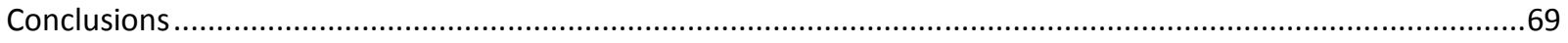

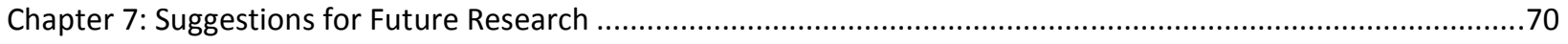

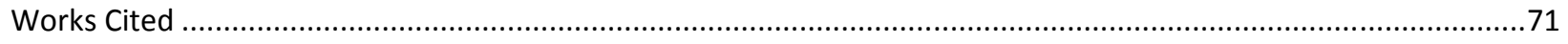

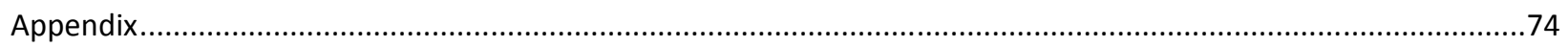

\section{CHAPTER 1: INTRODUCTION}

\section{BACKGROUND}

The chin is a feature unique to humans. There is a wide range of chin morphology seen throughout the world. There is a link between facial profile and attractiveness. This profile can be greatly affected by chin prominence. The chin can be altered slightly by orthodontics alone, but greatly in combination with surgery. Proper understanding of the relationship between the chin and facial esthetics allows clinicians to properly diagnose and correct skeletal discrepancies.

Over the past century, there have been many theories of why humans have chins. In 1954, DuBrul and Sicher suggested that the chin served to buttress the symphysis against medial transverse bending caused by the lateral pterygoid muscles. Then in 1977, White 
hypothesized that the chin was associated with resistance to labial compression at the symphysis causing "wishboning." There have been many theories following trying to link the mechanical stresses applied to the mandible and the presence of the chin. With the advances made in computer technology research evaluating the stresses and strains on the mandible during function have been conducted. The results show no significant advantage of mandibles with chin prominence and mandibles without ${ }^{1}$. Ichim et. Al also found that having a chin serves no masticatory benefit over mandibles without chins ${ }^{2}$. Therefore, evolution of the chin is independent of biomechanical demands of the symphysis.

The question is then raised, why do humans have chins? More recent theories propose chins are a result of differential growth. Marshall et. Al suggests that chin development is due in part to differential jaw growth and dentoaveolar movements. This means the mandibular symphysis can be divided into two regions, the upper and lower symphyseal regions. It is possible that these two regions act independently of one another resulting in the variability of chin shapes seen throughout the population. The upper symphyseal region is affected greatly by the interaction of the upper and lower dentition, while the lower is more an extension of the body of the mandible ${ }^{3}$.

The advent of cephalometrics enabled researchers and clinicians to assess craniofacial characteristics. Downs was the first to propose a cephalometric analysis designed to evaluate the dentoskeletal profile. The Down's analysis stimulated a plethora of cephalometric analyses to evaluate characteristics of the craniofacial skeleton and aid in orthodontic diagnosis and treatment planning. These analyses measured relative to internal landmarks and reference 
planes that were shown to be inherently unreliable for orthodontic treatment planning. The sella-nasion plane and Frankfort horizontal plane exhibit a large amount of variability as measured to the horizontal plane in both natural head position and natural head orientation. The amount of variability in the prominence of these planes between individuals suggests that measurements to evaluate craniofacial characteristics will be unreliable. Longitudinal growth studies have shown that the soft tissue profile does not directly reflect changes in the underlying hard tissue profile. In addition, many came to realize that treating patients to dentoskeletal norms does not guarantee an esthetic soft tissue outcome. Thus, several authors have proposed measurements by which to analyze the soft tissue profile in repose. These include Holdaways' H-angle, Merrifield's Z-angle, Ricket's E-line, Steiner's S-line, and Arnett's Soft Tissue Cephalometric Analysis.

In orthodontics, facial landmarks are used to evaluate the dimensions of the face. These measurements can then be related to facial esthetics. There have been many measurements used to analyze the chin. Khosravanifard et. Al used a vertical line dropped down from Glabella. They determined that the ideal prominence for the chin is within one millimeter behind this line ${ }^{4}$. Soft tissue landmarks and measurements are helpful in quantifying facial features in an attempt to define attractiveness.

Another question that arises, do clinicians and laypeople agree on what is considered attractive? Maple et. Al altered the position of the mandible in the horizontal and vertical dimensions. Their results showed that laypeople, orthodontists and oral surgeons all agreed on 
facial attractiveness ${ }^{5}$. The groups of laypeople and clinicians can then be combined to create a larger sample.

In the past, some researchers have used silhouettes instead of photographs to evaluate chin prominence. This is an attempt to minimize other variables that could affect attractiveness and bias. Using this approach, a SNB of 78 degrees was determined to be most attractive ${ }^{6}$. Naini et. Al came to the conclusion that surgery to correct protrusions greater the six millimeters and retrusions greater than ten millimeters were suggested ${ }^{7}$. Unfortunately, it has been shown that people rate silhouettes differently than photographs. Silhouettes with flatter profiles then normal were preferred among raters ${ }^{8}$. Therefore, photographs should be preferred over silhouettes for this study.

Further research evaluating chin esthetics is needed. Correlations found from an in depth study of cephalometric measurements can lead to a better understanding of why there is such wide variability of chin morphology. Furthermore, by determining the extant and magnitude changes in chin prominence have on facial esthetics clinicians will be better able to diagnose and treat their patients. 
The objectives of this study are:

1. To investigate the relationship between chin prominence in the sagittal plane and perceived attractiveness.

2. To investigate any correlation of hard tissue and soft tissue chin measurements.

3. To investigate any correlation of perceived attractiveness of the chin alone and perceived attractiveness of facial profile.

\section{NULL HYPOTHESIS}

1. Hard tissue lateral cephalometric measurements do not correlate with soft tissue chin thickness.

2. There is no difference in soft tissue chin thickness based on skeletal class or category.

3. There is no correlation with the soft tissue chin prominence and perceived attractiveness.

4. There is no difference between perceived attractiveness of chin prominence alone and full facial profile.

5. There is no difference between judged attractiveness perceived by orthodontists and non-orthodontists.

6. There is no difference between judged attractiveness perceived by males and females. 
Adjusted natural head position - the clinician's judgment of the subject's natural head position when the patient is looking at a distant point at eye level, synonymous to natural head orientation and upright head position

Anatomical forehead - the exposed skin from the hairline (or where the hairline once was) to glabella

Basal bone - the osseous tissue of the maxilla and mandible that does not include the alveolar process.

Centric relation - the maxillomandibular relationship in which the condyles articulate with the thinnest avascular portion of their respective disks with the complex in the most anteriorsuperior position against the shapes of the articular eminencies.

Clinical forehead - the portion of the forehead that is related more with the face than the scalp. For straight foreheads, it is between trichion and glabella. For rounded or angular foreheads, it is between superion and glabella.

DALL (dentition's anterior limit line) - a line that parallels the head's frontal plane and passes through the maxillary incisor's facial axis (FA) point.

Element I- the position in which a tooth is centered in basal bone with proper inclination for optimal occlusion 
Element II - the anteroposterior position of the maxilla and mandible judged as optimal based on the FA point of an Element I maxillary incisor that touches the GALL and is coupled with an Element I mandibular incisor in the Key I position.

FA point (tooth) - the point on the facial axis of the clinical crown that is midway between the gingival and occlusal borders.

FALL (forehead's anterior limit line) - a line that parallels the head's frontal plane and passes through the FFA point.

FALL-DALL - the difference between the FALL and DALL measured in millimeters. A negative number will correspond to a DALL that is posterior to the FALL. A positive number will correspond to a DALL that is anterior to the FALL. Zero will indicate that the FALL and DALL coincide.

FFA point (forehead facial axis point) - the midpoint of the clinical forehead that is between superion and glabella for round and angular foreheads and is between trichion and glabella for straight foreheads.

GALL (goal anterior limit line) - a line that parallels the head's frontal plane and represents the optimal anterior border for the FA point of an Element I maxillary incisor. This line passes through the FFA point when the forehead inclination is $\pm 7^{\circ}$. For every degree the forehead has an inclination beyond $7^{\circ}$, the GALL passes through a line that is $0.6 \mathrm{~mm}$ anterior to the FFA point; without exceeding the glabella point. 
Glabella - a point on the frontal bone that lies above nasion and between the eyebrows; the most inferior border of the clinical forehead.

Gonion - A point on the angle of the mandible formed by bisecting the angle formed by lines drawn tangent to the posterior ramus and the inferior border of the mandible.

Hard Tissue Chin Prominence - the projection of the mandibular symphysis in the sagittal plane

Key I-Interarch relationships - (1) the mesiobuccal cusp of the maxillary first molar occludes in the mesio-buccal groove of the mandibular first molar; (2) the distal marginal ridge of the maxillary first molar occludes on the mesial marginal ridge of the mandibular first molar; (3) the mesiolingual cusp of the maxillary first molar occludes in the central fossa of the mandibular first molar; (4) the buccal cusps of the maxillary premolars rest in the embrasures of the mandibular premolars; (5) the lingual cusps of the maxillary premolars rest in the fossae of the mandibular premolars; (6) the maxillary incisors overlap the mandibular incisors and the midlines of the maxillary and mandibular arch are coincident.

Natural Head Orientation - the head orientation of the subject perceived by the clinician, based on general experience, as the natural head position in a standing, relaxed body and head posture, when the subject is looking at a distant point at eye level. Same as Adjusted Natural Head position and upright head position.

Natural Head position - a standardized and reproducible orientation of the head when the subject is focusing on a distant point at eye level. 
Occlusal Plane - The occlusal plane defined by as Andrews as a line connecting the distal marginal ridge of the maxillary first premolar and the distal marginal ridge of the maxillary first molar.

Soft Tissue Chin Prominence - the projection of the external chin tissue in the sagittal plane.

Superion - the point on the angular or round forehead that, in profile, represents the superior boundary of the clinical forehead.

The FP Gauge ${ }^{\mathrm{TM}}$ (The Facial-Plane Gauge ${ }^{\mathrm{TM}}$ ) - A measuring device developed by Dr. Timothy Tremont to accurately judge the FALL-DALL measurement.

Trichion - The superior border of the anatomical forehead that is rounded or angular in shape.

WALA ridge - a band of soft tissue immediately superior to the mucogingival junction in the mandible.

\section{ASSUMPTIONS}

1. The lateral cephalometric radiographs are taken with the mandible in centric relation.

2. The GALL, as determine by the FALL-DALL measurement and forehead inclination, represents a true vertical reference plane.

3. The FALL-DALL measurement was accurately recorded with the patient positioned in the adjusted natural head position. 
4. The occlusal plane, as identified in this study, is an accurate representation of the line of occlusion and can be accurately identified.

5. Survey participants rated pictures without bias.

\section{DELIMITATIONS}

1. The FALL-DALL measurement will be determined utilizing a novel measuring device (The FP Gauge $\left.{ }^{\mathrm{TM}}\right)$.

2. All landmark identification and cephalometric measurements will be completed by a single investigator.

\section{CHAPTER 2: REVIEW OF THE LITERATURE}

\section{HISTORY AND CLASSIFICATION OF MALOCCLUSION}

Orthodontics has been around for thousands of years. Archeologists have found ancient Egyptian remains with metal bands wrapped around their teeth, believed to have been used for tooth alignment. Primitive orthodontic appliances were found in Greek and Etruscan belongings. Hippocrates (460-377 BC), in $400 \mathrm{BC}$ described irregularities of the teeth. He wrote, "... others have strongly arched palates thus teeth are disposed to irregularity, crowding, one on the other." 
The first orthodontic appliance was created in 1723 by Pierre Fauchard. It was an expansion arch called the Bandeau. Fauchard is called the "Father of Modern Dentistry". The first orthodontic text was published by Norman Kingsley. His book, Oral Deformities, took aim at etiology, diagnosis and treatment planning in orthodontics. Kingsley was also known for the use of occipital traction to correct incisor protrusion as well as in the treatment of cleft lip and palate. The orthodontist goals during this period of time were focused on tooth alignment and facial proportions ${ }^{9}$.

Edward H. Angle, the "Father of Modern Orthodontics", was a true pioneer in the field of orthodontics. He was the one who pushed for orthodontics to be recognized as a specialty. He founded the first post-graduate orthodontic educational program (Angle School of Orthodontia, 1900), the first orthodontic society (currently known as the American Association of Orthodontists) and the first orthodontic journal (The American Orthodontist, 1907). He held numerous patents which include the Edgewise Appliance (1925).

Dental Cosmos, published in 1899, was when the Angle molar classification was first introduced. The Angle classification system relates the mesiobuccal cusp tip of the maxillary first molar to the mesiobuccal groove of the mandibular first molar. The system consists of four distinct classes: normal Class I occlusion, Class I malocclusion, Class II malocclusion and Class III malocclusion. A Class I malocclusion is defined as a normal molar relationship, whereby the mesiobuccal cusp tip of the maxillary first molars occludes in the mesiobuccal groove of the mandibular first molar, with the presence of tooth malpositions and/or rotations. A Class II malocclusion is defined as a distal position of the mandibular first molar relative to the 
maxillary first molar. A Class III malocclusion consists of a mesial position of the mandibular first molar relative to the maxillary first molar. Angle was a strong proponent of non-extraction treatment plans. He believed in using elastics to correct to Class I occlusion regardless of the effects on facial esthetics. The Angle classification is still the most widely accepted system in use today.

\section{ESTABLISHING THE FACIAL PLANES}

The first step to cephalometric analysis is often establishing a reference plane. One of the first planes used was Frankfurt Horizontal. While this may coincide with a true horizontal plane in some cases, research has shown Frankfurt horizontal to range +9 to -7 degrees ${ }^{10}$. This led to use of Sella-Nasion in the Down's Analysis. It has been shown that there is no statistically significant difference in variability between Frankfurt Horizontal and the Sella-Nasion line, thus intracranial reference lines have been found to be unreliable ${ }^{11}$.

Extracranial reference planes have been proposed for both cephalometric and soft tissue analysis. Natural Head posture has been shown to be a repeatable, stable position ${ }^{12}$. Dr. Larry Andrews suggests the use of the FALL, a vertical plane established from an adjusted upright head posture. This line along with the inclination of the forehead is used to determine the GALL, which defines the ideal position for the facial surface of the upper incisor. Upright head posture is the basis for Dr. Arnett's True Vertical, a vertical line dropped from subnasale. 
From this line measurements to landmarks can be made to quantify their position. Dr. Arnett has developed ranges of normal for numerous landmarks of the face ${ }^{13}$. Upright head posture is a proven reliable way to define facial planes.

\section{CHIN PROMINENCE IN CEPHALOMETRICS}

Lateral cephalometrics are a useful tool in analyzing hard tissue structures in the sagittal plane. Most measurements quantifying chin prominence use the landmark pogonion, which has been shown to be a very repeatable, reliable landmark ${ }^{14}$. Measurements such as Down's facial angle (NPg to FH) and angle of convexity (NA to APg) do not specifically address chin prominence, more so mandibular position. Holdaway's ratio (L1-NB : Pg-NB) defines the ideal placement of the lower incisor based in regard to pogonion prominence as a one to one ratio ${ }^{15}$. Andrews Six Elements defines chin prominence as ideal when a line perpendicular to the occlusal plane and tangent to the facial axis of a lower central incisor with ideal inclination is also tangent to pogonion.

\section{SOFT TISSUE CHIN PROMINENCE}

Due to variability and unreliability of hard tissue structures to predict soft tissue thickness, cephalometric measurements alone tell only part of the story. Reference lines such 
as Rickett's E-Plane and Steiner's S-Line address the harmony of the nose, lip, and chin. In orthodontics, the lips can be greatly affected by the proclination and retraction of incisors. Arnett takes it as step farther by giving normal ranges for numerous facial landmarks including soft tissue pogonion. The normal range for the in females is $-4.5 \mathrm{~mm}$ to $-0.7 \mathrm{~mm}$ and males 5.3mm to $-1.7 \mathrm{~mm}$ from Arnett's True Vertical Line dropped down from subnasale ${ }^{16}$.

\section{SOFT TISSUE CHANGES RESULTING FROM SURGICAL ADVANCEMENT}

Both surgical advancement of the mandible and genioplasties have soft tissue effects. Soft tissue changes resulting from a mandibular advancement can be consistently predicted with a 1:1 ratio in both anteroposterior and vertical dimensions. With addition of a genioplasty soft tissue measured at both pogonion and B point before and after surgery have been showed to have a 0.9:1 mean ratio of soft tissue to hard tissue relationship, but with an average difference between hard and soft tissue movement of $\pm 2.6 \mathrm{~mm}$. The lower lip's response to advancement is also variable, especially with a genioplasty. On average it can be expected to

see $0.5: 1 \mathrm{~mm}$ ratio ${ }^{17}$. Veltkamp et. Al also concluded that although low lip and chin response to mandibular advancement and genioplasty is multifactorial, it can be accurately and reliably predicted $^{18}$. 
Facial esthetics can be greatly affected by orthodontic treatment. Facial attractiveness is multifactorial, influenced by complexion, hair-style and color, and eye color. Despite their significance, these factors cannot be controlled by the clinician. Therefore, the orthodontist is focused on achieving dentofacial harmony. A study by Spyropoulos and Halazonetis ${ }^{19}$ attempted to evaluate the relative importance of the soft tissue profile in ratings of facial attractiveness. Profile photographs of twenty female orthodontic patients were scanned, digitized and morphed to conform to the average outline of the original twenty photographs. Ratings of facial attractiveness were assessed on the twenty original photographs, the twenty morphed photographs, and three additional photographs that represented the average outline, each with a different hairstyle. The authors concluded that soft tissue outline form did influence ratings of facial attractiveness. The morphed images were rated higher than the nonmorphed images. However, the improvement in the rating was not as high as the composite images. Therefore, the authors concluded that there are factors in addition to profile form that influence perceptions of facial attractiveness ${ }^{19}$.

Harmony can be related to the divine proportion, also called the golden ratio (1.618:1)

20. This universal proportion can be seen everywhere in nature. One study evaluated the divine proportion and ratings of facial attractiveness in fifty females, deemed to have acceptable profiles. None of the subjects matched the golden ratio, but those considered most attractive 
were closer to the "ideal divine proportion." Beauty may be in the eye of the beholder, but proportions clearly play an integral part in perceived attractiveness ${ }^{21}$.

\section{THE SIX ELEMENTS OF OROFACIAL HARMONY}

The Andrews ${ }^{\circledR}$ Six Elements Orthodontic Philosophy ${ }^{\text {TM }} 22$ is a complete analysis that provides a thorough diagnosis and leads to a custom treatment plan. The Six Elements of Orofacial Harmony" is defined by Lawrence F. Andrews as "six characteristics (within dentistry's milieu) that are essential for optimal orofacial health and appearance"22. The six characteristics include Element I: dental arch shape and length; Element II: anteroposterior jaw positions; Element III: buccolingual jaw positions; Element IV: superoinferior jaw positions; Element V: pogonion prominence and Element VI: dental occlusion. Andrews established a set of objectives, goals, landmarks and referents to define the optimality of each element. The Six Elements $^{\mathrm{TM}}$ allows for a comprehensive classification system representing both the position of the teeth and the jaws. Andrews suggests that each Element be "uniquely correct for each person"22. This classification system differs from traditional analyses; in that the position of the jaws and teeth are not based on cephalometric norms.

Inclusion of the lateral smiling profile is unique to Six Elements treatment planning. Andrews noted that a relationship exists between the forehead position and inclination and the AP position of the maxillary central incisor in patients with harmonious profiles. This relationship can be used to construct a frontal plane, the Goal Anterior Limit Line (GALL), to 
judge the optimal AP position of the jaws. A recent study confirmed that $91 \%$ of the individuals with a good to excellent facial profile fall within the GALL and FA point of the forehead. Schlosser et al. ${ }^{2}$ reported on the rating of facial attractiveness using the position of the maxillary central incisors with reference to the forehead. These studies support the use of the forehead to determine the AP position of the maxilla; which is fundamental to the Six Elements classification system.

Below is a brief summary of each Element. For a comprehensive guide to the Six Elements of Orofacial Harmony, please refer to the Andrews ${ }^{\circledR}$ Foundation course syllabus ${ }^{22}$.

ELEMENT I:

Element I covers the shape of teeth and how they should fit together. Teeth should be positioned with proper inclination, roots centered in basal bone and a level core line depth (curve of Spee between $0-2.5 \mathrm{~mm}$ ). The dental arch shape of the mandible is determined by evaluating the bucco-lingual distance between each tooth's facial-axis (FA) point and the WALA Ridge. The WALA ridge is the ridge of soft tissue directly superior to the mucogingival junction and is suggested to approximate the center of rotation of each tooth. The buccolingual distance between the FA point and the WALA ridge progressively decreases from posterior to anterior. The distance averages $2.2 \mathrm{~mm}$ at the second molar and $0.1 \mathrm{~mm}$ at the central incisor. A recent study by Ronay et al. has corroborated the relationship between the tooth's FA point and the WALA ridge. The shaping of arch wires to the WALA ridge not only allows the mandibular arch form to be unique for each patient, but is proposed to ensure a stable position 
relative to the periodontium. The maxillary arch form is then established based on the mandibular arch form.

The occlusal plane is key to determining incisor inclination. The occlusal plane must first be identified on the lateral cephalogram. The Andrews template is then utilized to determine the proper inclination of the maxillary and mandibular central incisors with the roots centered in basal bone. The template incisor inclination relative to the occlusal plane ensures an optimal inclination $\left(7^{\circ}\right.$ for the maxillary incisor and $-1^{\circ}$ for the mandibular incisor) relative to the dental arch's perimeter line.

A piece of acetate overlay is placed over the maxilla and secured. The occlusal plane and outline of the maxilla is traced on the acetate overlay. The occlusal plane of the Andrews template is superimposed on the occlusal plane of the patient, and the Element I maxillary incisor is drawn once the template incisor is centered in maxillary basal bone. A second piece of acetate paper is then placed over the body of the mandible. The occlusal plane, outline of the mandible and the Element I mandibular incisor is also traced as described for the maxilla. Measurement of the distance between the FA point of the original incisor and the Element I incisor is recorded.

Core discrepancy is another essential part of Element I. Calculations must be made to determine the effects that leveling the curve of Spee, uprighting the molars, expanding the maxilla and proclining/retroclining the incisors will create on the core discrepancy. These effects are then recorded as the interim core discrepancy (ICD). For example, leveling the curve of Spee will require space within the arch and thus will ultimately decrease the space available 
within the arch and decrease the ICD. Proclining incisors to an optimal Element I position, centered in basal bone will increase the space available within the arch and increase the ICD. A negative ICD indicates crowding, whereas a positive ICD indicates spacing. The ICD is valuable information to help determine the treatment plan.

ELEMENT II:

Element II defines the anteroposterior positions of the maxilla and mandible. The Goal Anterior Limit Line (GALL) represents the frontal plane of the head, and is identified based on an evaluation of the forehead shape and inclination. Three forehead shapes predominate; straight, round and angular. The forehead points, trichion, superion, glabella and the foreheads facial axis point, are identified for the patient based on forehead shape. The distance between the face anterior limit line (FALL) and the dentition's anterior limit line (DALL) is evaluated clinically with the patient in the upright head position and recorded. The FALL is a line passing through the FFA point of the forehead that parallels the frontal plane of the head. The DALL is a line passing through the FA point of the maxillary incisor that parallels the frontal plane of the head. The angular measurement determined by the forehead inclination (superion and/or trichion to glabella) relative to the FALL is recorded. The FALL is equivalent to the GALL with a forehead inclination between $-7^{\circ}$ to $+7^{\circ}$. For every degree beyond the range $-7^{\circ}$ to $+7^{\circ}$, the GALL lies $0.6 \mathrm{~mm}$ anterior to the FALL, without exceeding glabella.

When the FA point of an Element I maxillary incisor is on the GALL, the maxilla is consider optimal Element II. The maxilla can be classified as red (prognathic) or black 
(retrognathic) by measuring the distance from the maxillary incisor FA point to the GALL. An optimal Element II mandible is determined relative to an optimal Element II maxilla, with the teeth in an Element I position and a Key I dental relationship. The mandible can be classified as red (prognathic) or black (retrognathic) by measuring the distance from the optimal Element I and Element II maxillary incisor to the Element I mandibular incisor.

ELEMENT III:

Element III is evaluates the transverse dimension. The WALA ridge helps define the ideal mandibular transverse dimension which then is used to evaluate the maxilla. If a discrepancy exists, the maxilla can be orthopedically or surgically expanded to match the mandibular width. The cusp-cusp and fossa-fossa distances are measured within the maxilla and mandible with the teeth in an Element I position. The distance between FA point of the mandibular posterior teeth and WALA ridge, is used to determine the Element I tooth position. For instance, if the mandibular posterior teeth are inclined to the lingual, the amount of uprighting should be incorporated into the fossa-fossa transverse mandibular measurements. Andrews states that the transverse measurement of FA point to FA point should be 2 to $4 \mathrm{~mm}$ greater in the maxillary arch than the mandibular arch.

ELEMENT IV:

Element IV evaluates the vertical dimension. The measurement from glabella to subnasale (midfacial height) should equal the measurements from subnasal to menton (lower 
facial height) and condylion to gonion (ramus height). Andrews separates the vertical jaw position, Element IV, into anterior and posterior components within each jaw. The anterior maxilla Element IV is defined as optimal based on appropriate maxillary incisor display in repose. The FA point of the maxillary incisor should be at the same level as the inferior border of the maxillary lip in repose. The anterior mandible Element IV is defined as optimal when the distance from the FA point of the mandibular incisor to hard-tissue menton is equal to one-half the distance of the midfacial height. The posterior maxilla Element IV is considered optimal when the anterior maxilla and mandible are optimal and there is an absence of an anterior or posterior open bite. The posterior mandible Element IV is considered optimal when the ramus height equals midfacial height. The extent of deviation from optimal should be recorded.

To determine the extent that the anterior maxilla Element IV deviates from optimal, the acetate overlay should be released and moved up or down, ensuring that the occlusal plane remains parallel to the original, until the FA point of the maxillary incisor is level with the inferior border of the maxillary lip. If the acetate is moved down the distance is recorded as negative and if moved up the distance is recorded as positive.

To determine the extent that the anterior mandible Element IV deviates from optimal the difference between one-half the midfacial height and the mandibular incisor FA point to menton is recorded. If the anterior mandible is less than or greater than the midfacial height this number is recorded as a negative number or positive number, respectively. The anterior mandible Element IV can be corrected surgically. 
To determine the extent of deviation from optimal for the posterior Element IV, the mandibular acetate overlay should be extended to include the condyle. The overlay should then be rotated until the amount of incisor overbite is corrected. The maxillary overlay should be released and the occlusal planes should then be superimposed. The distance of the original posterior position to the new position should be recorded.

The relationship between the anterior and posterior Element IV of the maxilla thus establishes the inclination of the occlusal plane. However, Andrews does not designate an optimal inclination for the occlusal plane.

\section{ELEMENT V:}

Element $\mathrm{V}$ concerns an evaluation of hard-tissue pogonion prominence. Element $\mathrm{V}$ is defined as optimal based on a pogonion prominence that lies on a line $90^{\circ}$ to the occlusal plane that passes through the FA point of the Element I mandibular incisor. The amount of deviation anterior or posterior to this line is recorded as positive or negative, respectively.

ELEMENT VI:

The Six Keys to Optimal Occlusion is the basis for Element VI. When all six keys are present, with the mandible in centric relation and functional excursions include canine disclusion, Element VI is considered optimal. In 1967, Lawrence F. Andrews published The Six Keys to Normal Occlusion ${ }^{22}$, which he later referred to as the Six Keys to Optimal Occlusion. Andrews studied 120 dental casts with optimal occlusions to assess if there were any universal 
characteristics. Within these casts variability did exist, however, the constancy of features are defined as Key; I) correct interarch relationships; II) correct crown angulation; III) correct crown inclination; IV) absence of rotations; V) tight contacts; and VI) a flat curve of Spee. The characteristics which define an optimal occlusion are now widely accepted.

Andrews' study of optimal dental casts established the basis from which he developed the fully programmed Straight Wire Orthodontic Appliance. Introduction of the preadjusted appliance in conjunction with advances in material science, such as development of nickel titanium wire, revolutionized contemporary orthodontic treatment.

\section{RESEARCH DESIGN}

\section{OVERVIEW}

IRB approval for the use of human research subjects was obtained prior to the start of this study (Appendix A). A lateral cephalometric radiograph was captured with a Planmeca EX 3000 film based machine. The radiographs were then scanned using an Epson Scan Ink scanner at 300 dpi. The FALL-DALL measurement was obtained from their treatment records. The radiographs were digitized using Dolphin Imaging Software Version 10.5. The radiographs were printed out in a 1:1 ratio on high quality photo paper. All linear measurements were measured with a Kobalt 6 inch Electronic Caliper and recorded to the nearest $0.01 \mathrm{~mm}$. All angular 
measurements were measured with the 1996 Lawrence F. Andrews Foundation protractor and recorded to the nearest degree.

Based on data from Dr. Holly Eppard's study ${ }^{23}$, the sample of 105 was divided into three anteroposterior groups (Class I, II, and III) according to the ANB angle. Class I subjects were those with an ANB angle from 0-5 degrees. Class II subjects were those with and ANB angle $>5$ degrees. Class III subjects were those with an ANB angle $<0$ degrees.

The sample was also divided into three anteroposterior groups (Category I, II, and III) based on jaw base differences evaluated with the Six Elements measurements (Element II Maxilla and Element II Mandible). Category I subjects were those with jaw positions within $2 \mathrm{~mm}$ of each other. Category II subjects were those with an Element II mandible, in relation to the maxilla, positioned posterior by more than $2 \mathrm{~mm}$. Category III subjects were those with an Element II mandible, in relation to the maxilla, positioned anterior by more than $2 \mathrm{~mm}$.

\section{METHODOLOGY}

SAMPLE DESCRIPTION

105 patients were randomly selected from the private orthodontic practice of Dr. Timothy Tremont, White Oak, PA. Subject selection was based on the following:

\section{Inclusion Criteria:}

- Any patient 12 years of age or greater in the permanent dentition. 
- A pretreatment lateral cephalometric radiograph taken prior to orthodontic treatment.

\section{Exclusion Criteria:}

- Presence of any craniofacial anomalies; eg: Cleft lip and palate.

- Absence of maxillary and/or mandibular first molars.

- Presence of an obvious transverse (right to left) cant of the maxilla which would make accurate identification of the occlusal plane difficult.

- Presence of obvious mentalis strain on the lateral cephalometric radiograph.

- Inability to visual soft-tissue profile on the lateral cephalometric radiograph.

- Any previous orthodontic treatment.

CONSTRUCTION OF THE GALL AND TRUE HORIZONTAL (TH)

The patient was placed in the upright head position and the lateral smiling profile was used to clinically determine the FALL-DALL measurement. This measurement was confirmed utilizing a novel device, The FP Gauge ${ }^{\mathrm{TM}}$. The FALL-DALL measurement and lateral cephalometric radiograph were obtained from the patient record. The GALL was then constructed on the lateral cephalometric radiograph as described by Andrews. The angular measurement determined by the forehead inclination (superion and/or trichion to glabella) relative to the FALL was calculated. The FALL is equivalent to the GALL with a forehead 
inclination between $-7^{\circ}$ to $+7^{\circ}$. For every degree beyond the range $-7^{\circ}$ to $+7^{\circ}$, the GALL lies 0.6 $\mathrm{mm}$ anterior to the FALL, without exceeding glabella. The GALL represents a true frontal plane with the patient in the adjusted natural head position. True horizontal (TH) was constructed from a line drawn perpendicular to the GALL.

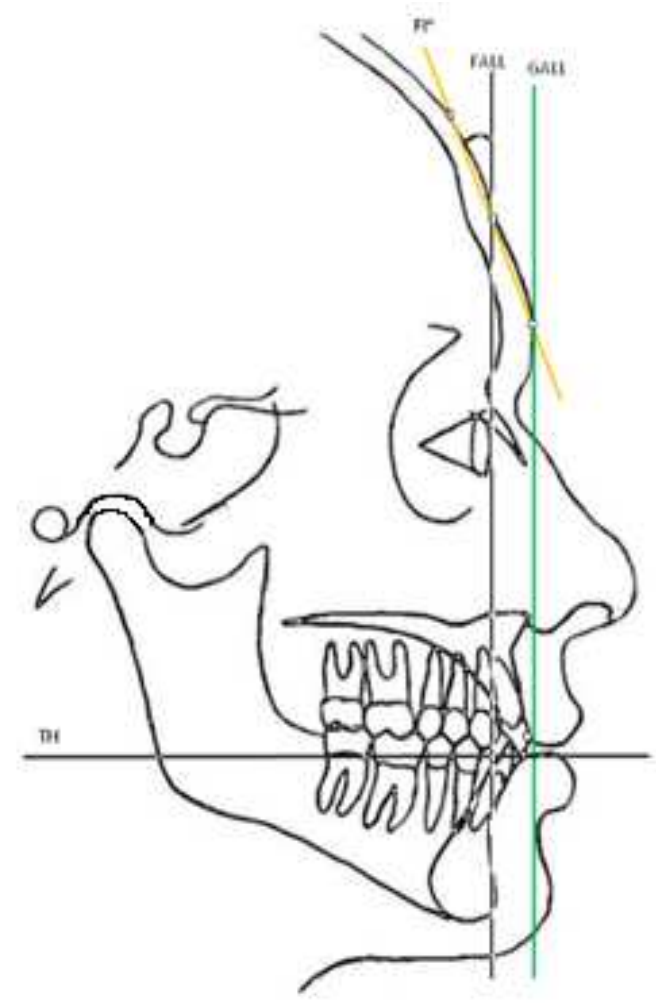

Fig. 1: Construction of the GALL and True Horizontal (TH) 
Landmark Identification:

The lateral cephalometric radiograph was used for analysis of the cephalometric variables. Landmark identification (Fig. 2 and Fig. 3), tracings and measurements were completed by a single investigator.

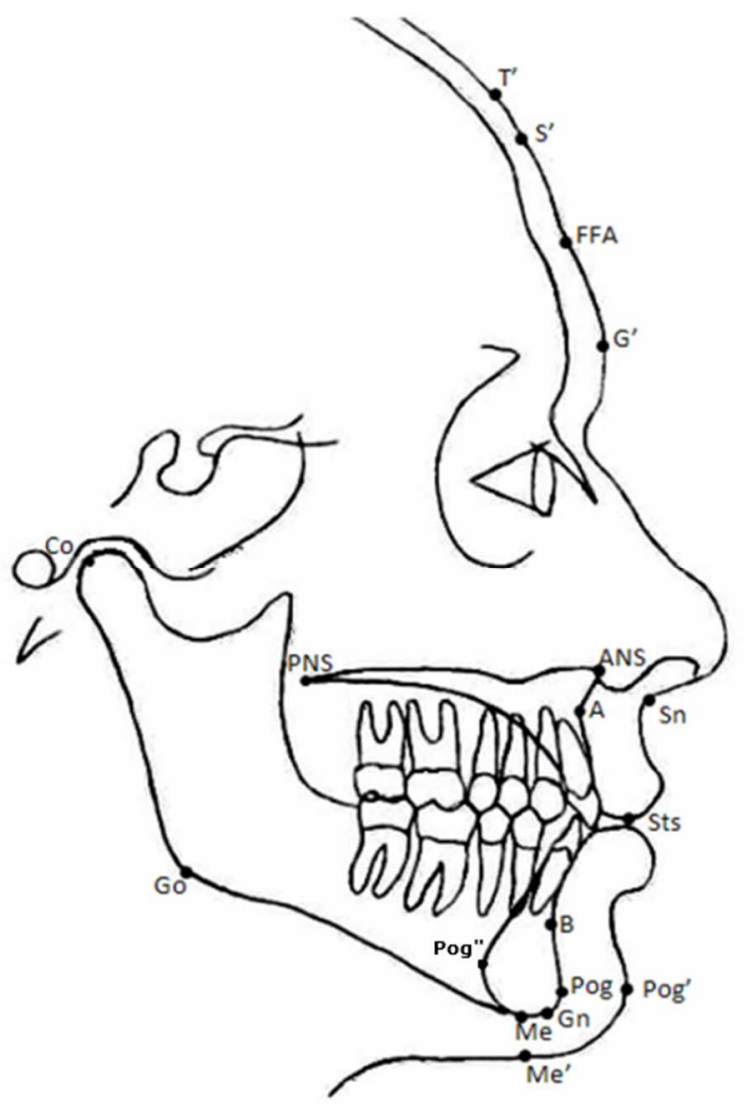

Fig. 2: Hard and Soft Tissue Cephalometric Landmarks 


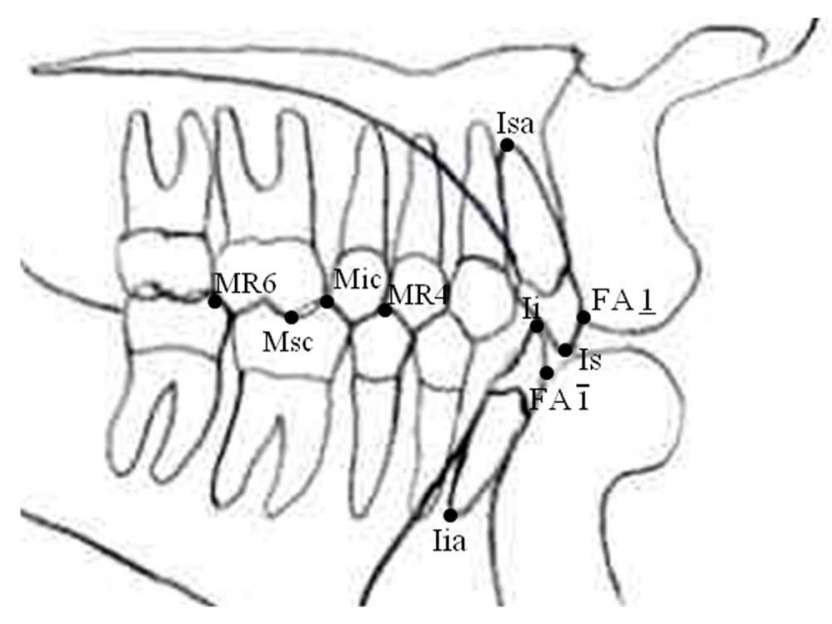

Fig. 3: Dental Cephalometric Landmarks

Six Elements Measurements:

The cephalometric analysis included a measurement of several of Andrew's Six

Elements. For an overview of these measurements please refer to table 1 below.

Table 1: Six Elements Measurements

\begin{tabular}{ll}
\hline Variable & Definition \\
\hline \hline IV Md Ant & $\begin{array}{l}\text { The vertical position of the anterior mandible. Measured as the vertical distance } \\
\text { from the FA point of the Element I mandibular central incisor to Me. }\end{array}$ \\
V & $\begin{array}{l}\text { Pogonion Position. The distance between Pog to a line formed tangent to the FA } \\
\text { pt of an Element I mandibular central incisor and perpendicular to the occlusal } \\
\text { plane. }\end{array}$
\end{tabular}


Element IV Md Ant is the vertical position of the anterior mandible. It was measured as the vertical distance from the FA point of the Element I mandibular central incisor to Me. (Fig. 7)

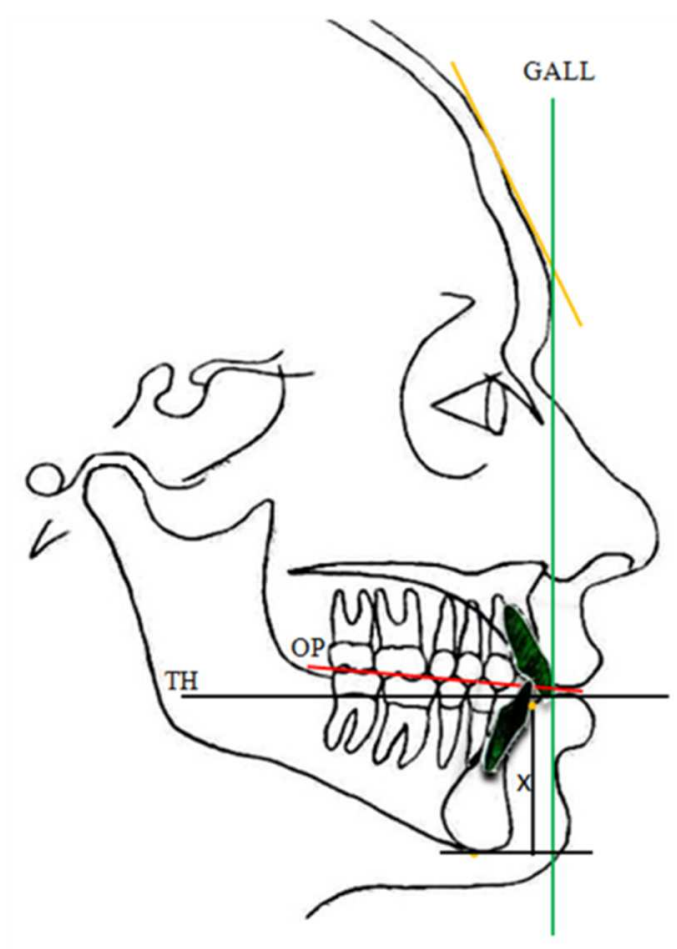

Fig. 7: Illustration of Element IV Mandibular Anterior 
Element $\mathrm{V}$ is the pogonion prominence, and is a measure of the prominence of the hard tissue chin. It was measured as the distance between Pog to a line formed tangent to the FA pt of an Element I mandibular central incisor and perpendicular to the occlusal plane. (Fig. 8)
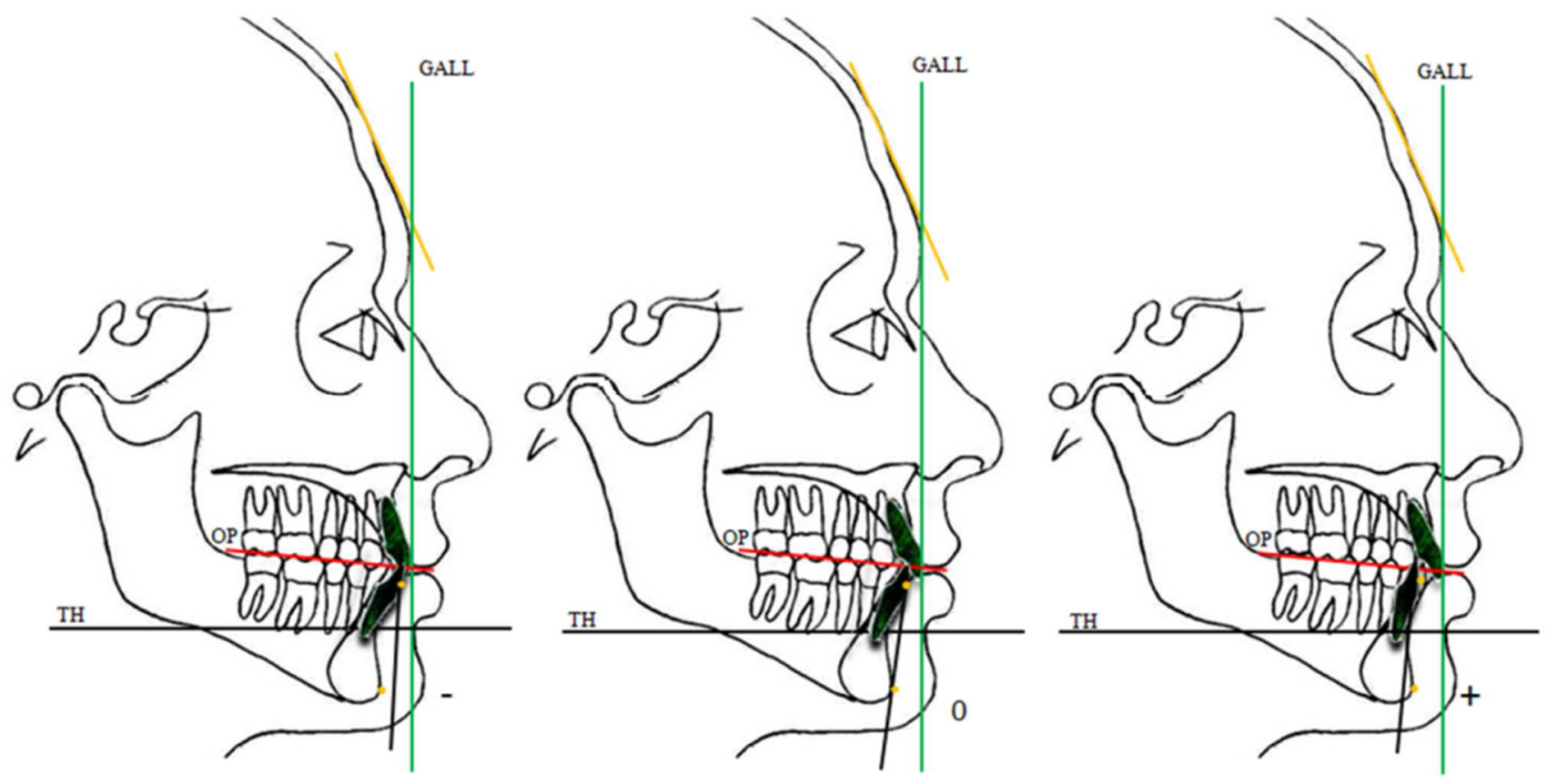

Fig. 8: Illustration of Element $\mathrm{V}$ 
ANGULAR MEASUREMENTS:

The angular cephalometric measurements (Table 2) were measured utilizing (C) 1996 Lawrence F. Andrews Foundation protractor, and recorded to the nearest 0.5 . . These measurements included the inclinations of the $\mathrm{OP}$ and $\mathrm{MP}^{\circ}$ were measured relative to $\mathrm{TH}$. (Fig. 10A) In addition the gonial angle (Goㅇ), lower incisor to mandibular plane (L1-Mp), and lower Element I incisor to mandibular plane (L1'-Mp) was measured (Fig. 9 A,B). The reference planes measured relative to $\mathrm{TH}(\mathrm{MPo}, \mathrm{Op}$ ㅇ) were assigned a positive value for a clockwise rotation (anterior end of plane is inferior) and a negative value for an anticlockwise rotation. SNNo was assigned a positive value for an anticlockwise rotation.
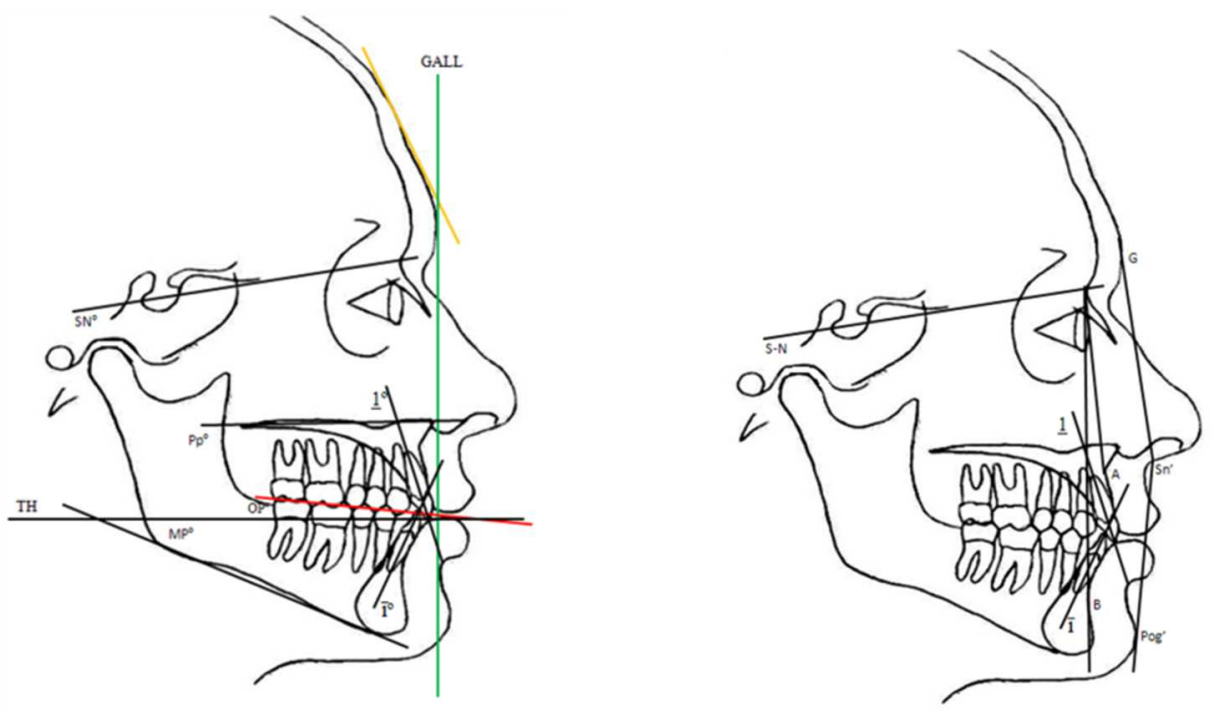

Fig. 9: Angular measurements 
Table 2: Angular Cephalometric Variables

\begin{tabular}{|l|l|}
\hline Variable & Definition \\
\hline $\mathbf{M P}^{\circ}$ & $\begin{array}{l}\text { Inclination of the mandibular plane measured relative } \\
\text { to TH }\end{array}$ \\
\hline $\mathbf{O p}^{\circ}$ & $\begin{array}{l}\text { Inclination of the occlusal plane measured relative to } \\
\text { TH }\end{array}$ \\
\hline $\mathbf{G o}^{\circ}$ & $\begin{array}{l}\text { The gonial angle measured as the angle of a line } \\
\text { tangent to the posterior ramus and the mandibular } \\
\text { plane }\end{array}$ \\
\hline $\mathbf{L 1}^{\circ} \mathbf{M P} \mathbf{O}^{\circ}$ & $\begin{array}{l}\text { Inclination of long axis of the mandibular incisor to } \\
\text { mandibular plane }\end{array}$ \\
\hline $\mathbf{L 1}^{\prime}-\mathbf{M P}^{\circ}$ & $\begin{array}{l}\text { Inclination of long axis of an Element I mandibular } \\
\text { incisor to mandibular plane }\end{array}$ \\
\hline
\end{tabular}

LINEAR MEASUREMENTS:

The linear cephalometric measurements (Table 3) were measured using a Kobalt 6 inch Electronic Caliper and recorded to the nearest $0.01 \mathrm{~mm}$. Soft and hard tissue vertical facial heights were recorded (Fig. 10). Pogonion has been shown to be a very reliable landmark ${ }^{14}$. The anteroposterior prominence of the hard tissue and soft tissue chin was measured relative to Andrew's GALL (Fig. 12) and Arnett's TVL (Fig. 13); Pog'-GALL, Pog-GALL, TVL-Pog. The thickness of the symphysis was measured from Pog-Pog". The vertical eruption of the mandibular central incisors were recorded; MP-L1 (Fig. 14). Overbite was measured from Maxillary incisor tip to mandibular incisor tip. A negative number reflects an opebite. 


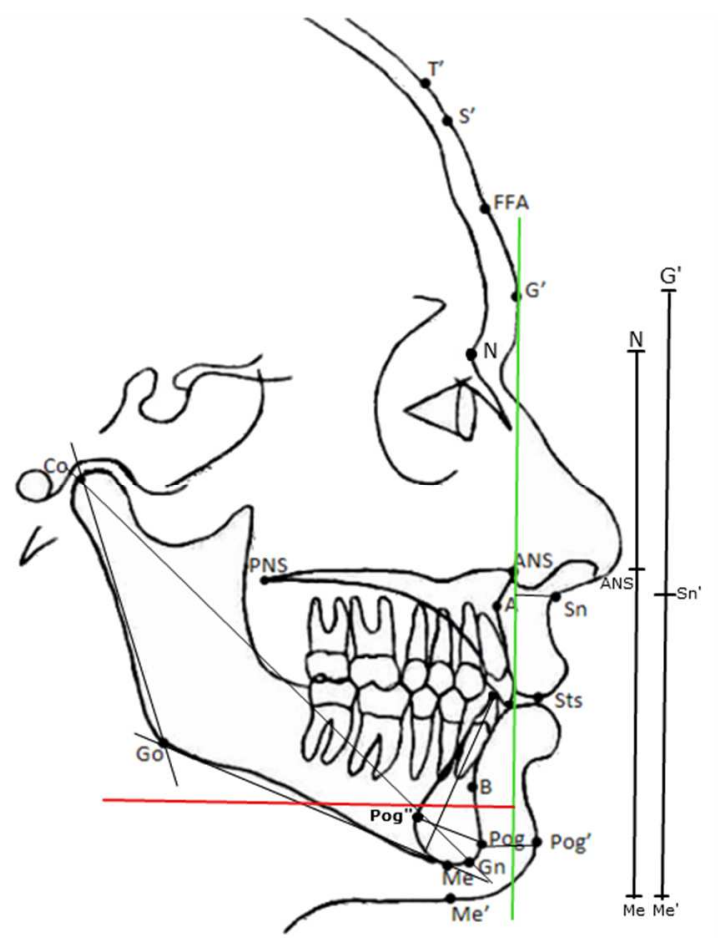

Figure 10: Linear Measurements

Table 3: Linear Measurements

\begin{tabular}{|l|l|}
\hline Variable & Definition \\
\hline Soft Tissue & \\
\hline G'$^{-} \mathbf{M e}$ & Soft tissue total facial height \\
\hline G'-Sn' $^{\prime}$ & Soft tissue upper anterior facial height \\
\hline Sn'-Me' & Soft tissue lower anterior facial height \\
\hline & $\begin{array}{l}\text { Anteroposterior prominence of hard tissue pogonion. } \\
\text { Pog-GALL }\end{array}$ \\
\hline
\end{tabular}




\begin{tabular}{|c|c|}
\hline Pog'-GALL & $\begin{array}{l}\text { Anteroposterior prominence of soft tissue pogonion. } \\
\text { The distance in millimeters of soft tissue pogonion }\end{array}$ \\
\hline TVL-Pog' & $\begin{array}{l}\text { Anteroposterior prominence of soft tissue pogonion } \\
\text { measured as a linear distance to Arnett's TVL }\end{array}$ \\
\hline Pog-Pog' & $\begin{array}{l}\text { Anterorposterior soft tissue chin thickness at } \\
\text { pogonion }\end{array}$ \\
\hline Sn'-GALL & Anteroposterior distance of Sn' to GALL line \\
\hline \multicolumn{2}{|l|}{ Hard Tissue } \\
\hline N-ANS & Hard tissue upper anterior facial height \\
\hline $\mathrm{N}-\mathrm{Me}$ & Hard tissue total facial height \\
\hline ANS-Me & Hard tissue lower anterior facial height \\
\hline Co-Go & Posterior facial height as defined by Andrews \\
\hline Co-GN & $\begin{array}{l}\text { Mandibular length measured from condylion to } \\
\text { gnathion }\end{array}$ \\
\hline Pog-Pog" & Symphyseal thickness parallel to mandibular plane \\
\hline \multicolumn{2}{|l|}{ Dental } \\
\hline Mp-L1 & $\begin{array}{l}\text { Vertical height of the mandibular central incisor } \\
\text { measured as a linear distance from the mandibular } \\
\text { plane }\end{array}$ \\
\hline U1-L1 & $\begin{array}{l}\text { Vertical overbite measured pependicular to occlusal } \\
\text { plane }\end{array}$ \\
\hline L1'-Pog & $\begin{array}{l}\text { Distance measured parellel to mandibular plance of } \\
\text { pogonion to a line dropped perpendicular to the } \\
\text { occlusal plane that is tangent with the FA of the } \\
\text { mandibular incisor in Element I position }\end{array}$ \\
\hline L"-Pog & $\begin{array}{l}\text { Distance measured parellel to mandibular plance of } \\
\text { pogonion to a line dropped perpendicular to the } \\
\text { occlusal plane that is tangent with the FA of the } \\
\text { mandibular incisor in a position } 90 \text { degrees to the } \\
\text { occlusal plane }\end{array}$ \\
\hline
\end{tabular}




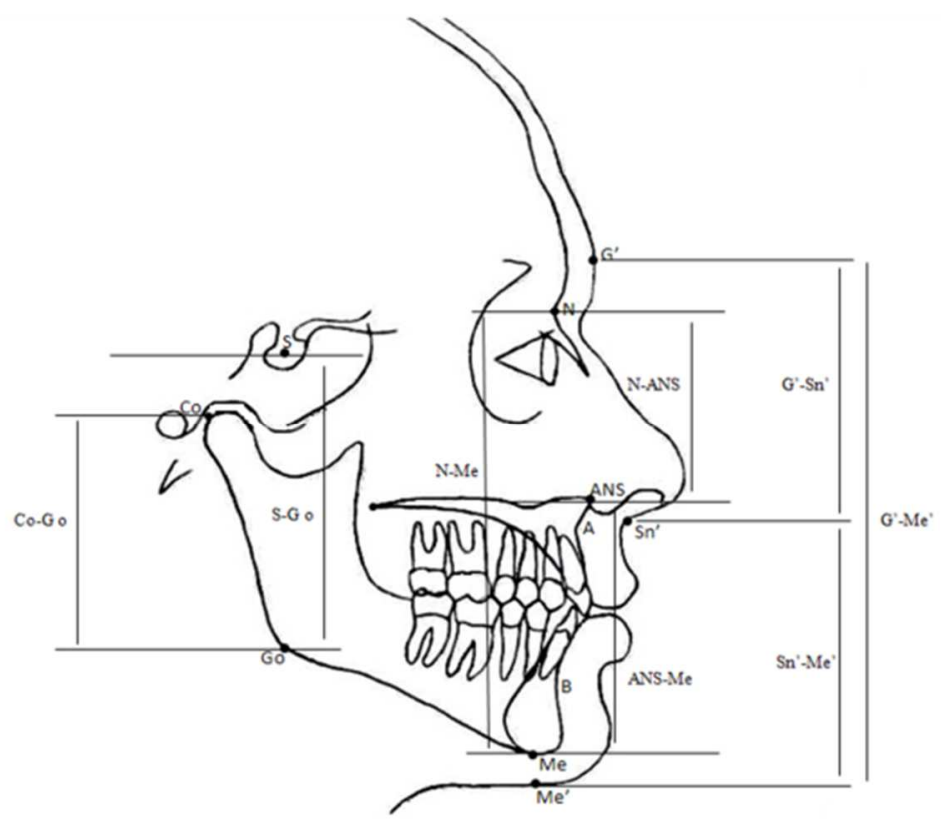

Fig. 11: Vertical Facial Heights
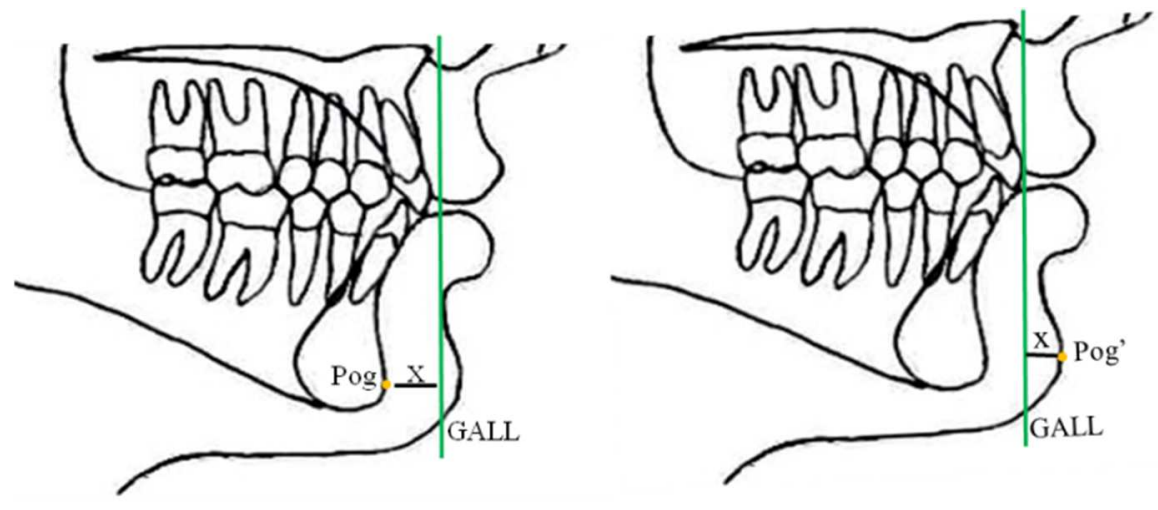

Fig. 12: Chin Prominence Measurement to the GALL 


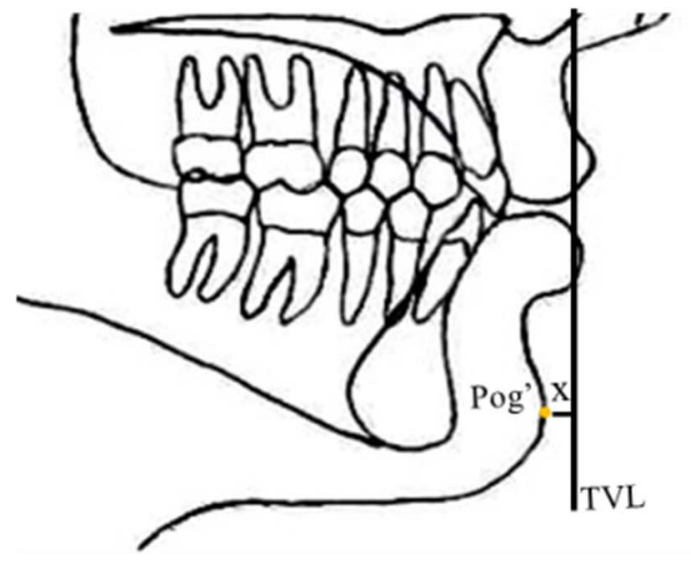

Fig. 13: Soft Tissue Chin Measurement to TVL

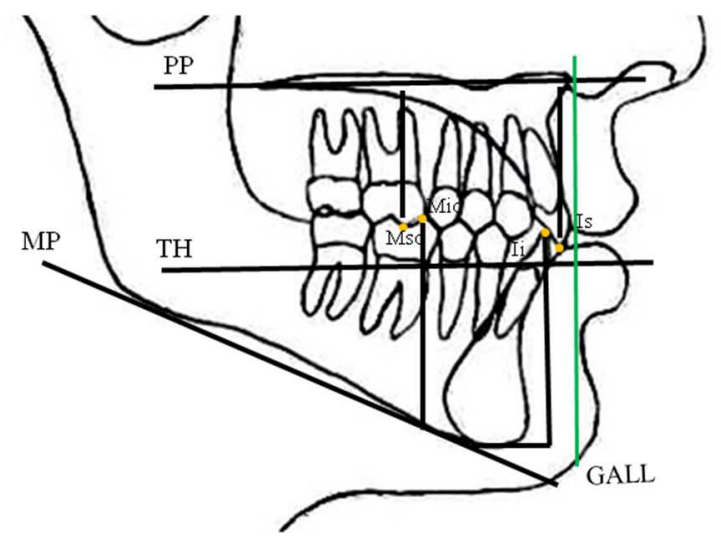

Fig. 14: Vertical Eruption 


\section{SURVEY CONSTRUCTION}

A survey was constructed to evaluate the effect of chin prominence on facial esthetics. A subject was chosen that was considered to have a generally attractive profile. The photo was taken with a Nikon D90 Digital camera with the patients head in the adjusted upright head position. The patient held a millimeter ruler parallel to the floor beneath her chin while the photo was taken for scaling. Using Adobe Photoshop, the photo was converted to black and white to avoid any bias from skin complexion. Then the photo was edited to morph the chin prominence forward and back in $1 \mathrm{~mm}$ increments in the midsagital plane. The lower lip position was left unchanged. A range of fifteen photos was created. To form a group of photos only including the lower lip and chin, these photos were cropped. The result is 15 photos including the entire the face (Fig. 15) and 15 photos including only the lower lip and chin (Fig. 16).

These photos were put into a slideshow using Microsoft PowerPoint. Within each respective group, profile and chin, the pictures were placed in random order. One random photo was repeated at the end of each group to test reliability (Total of 16 photos per group).

Survey participants were recruited within the WVU Dental Clinic at Suncrest Town Center. Participants had to be 18 or older. The survey was printed out with instructions. Each photo has an identification number that corresponds with a visual analog scale to rate perceived attractiveness. Raters were instructed to rate the 
attractiveness of the entire image using a visual analog scale (Fig. 17). The survey document can be found in the Appendix.
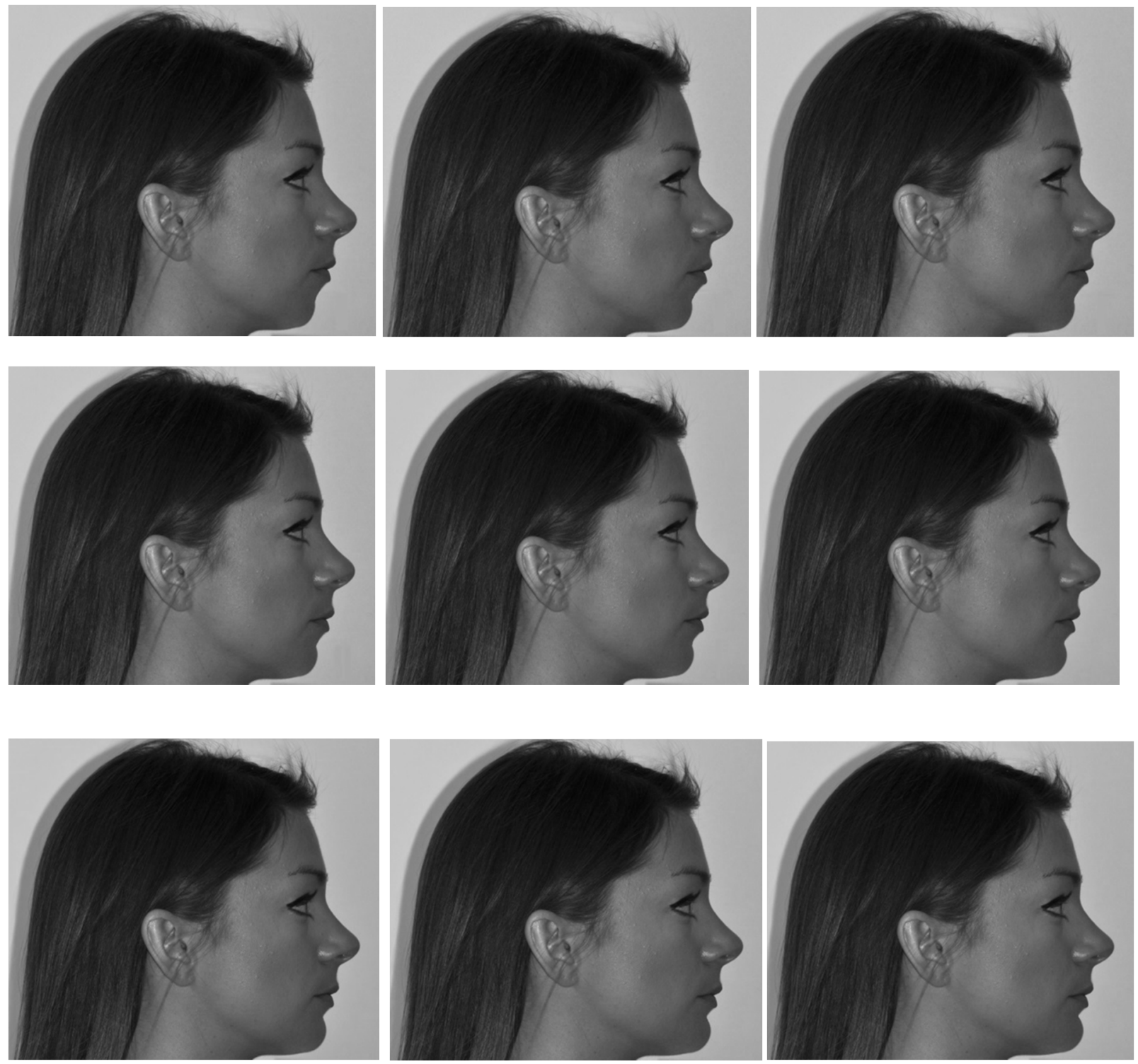

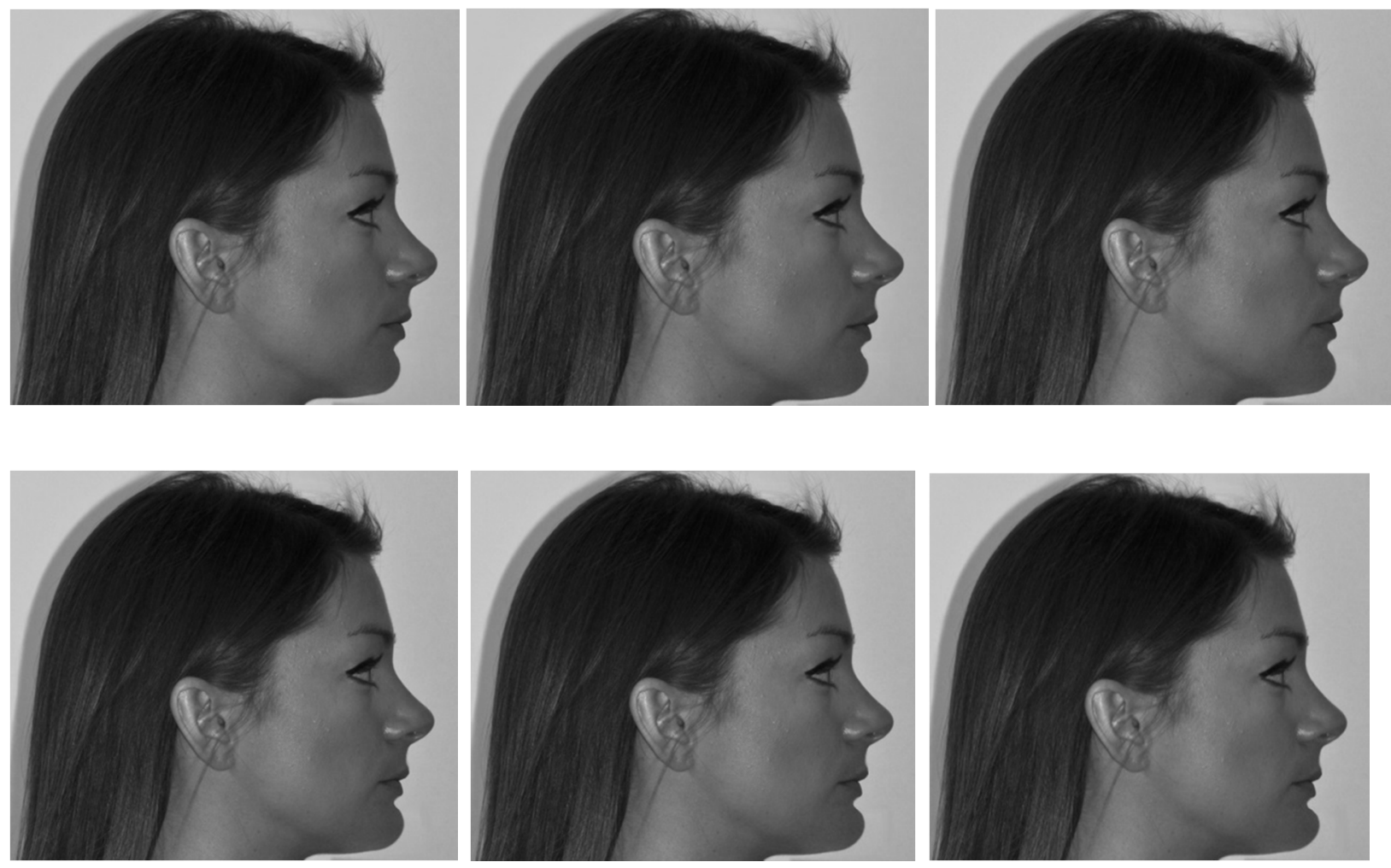

Figure 15: Face Images
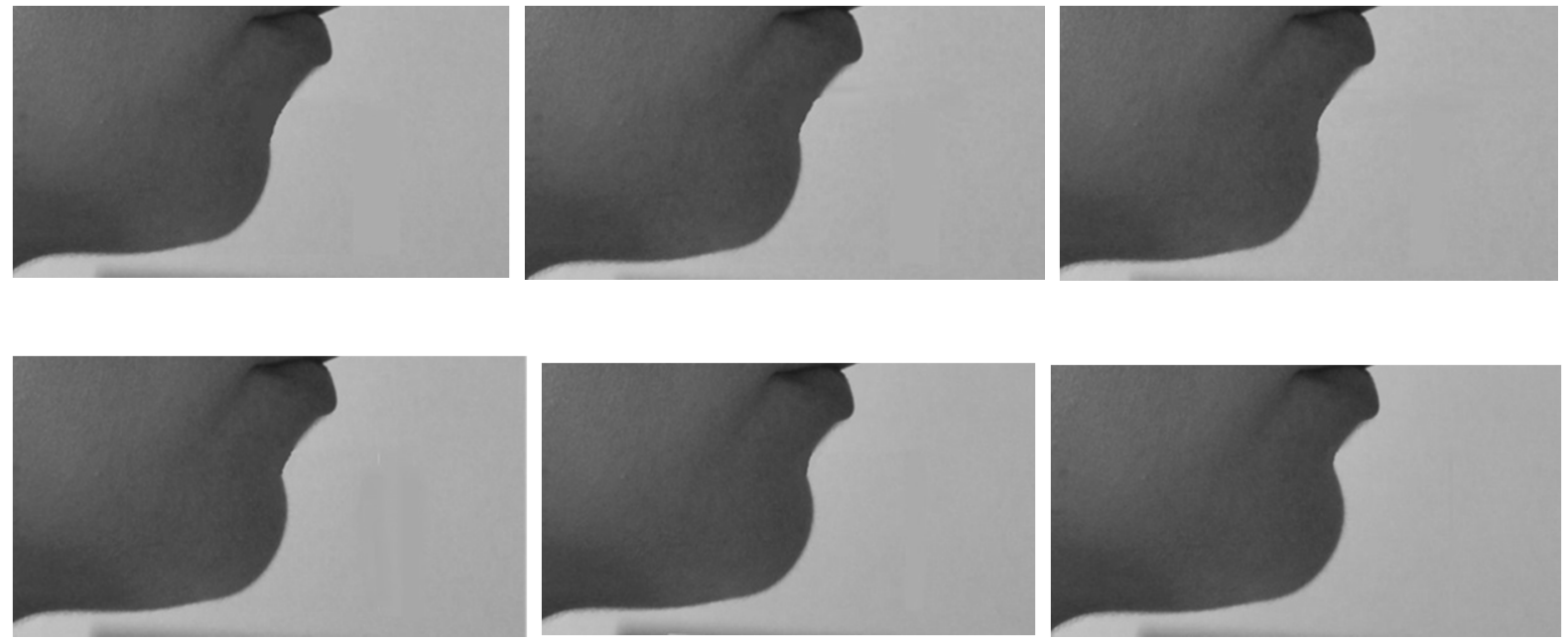

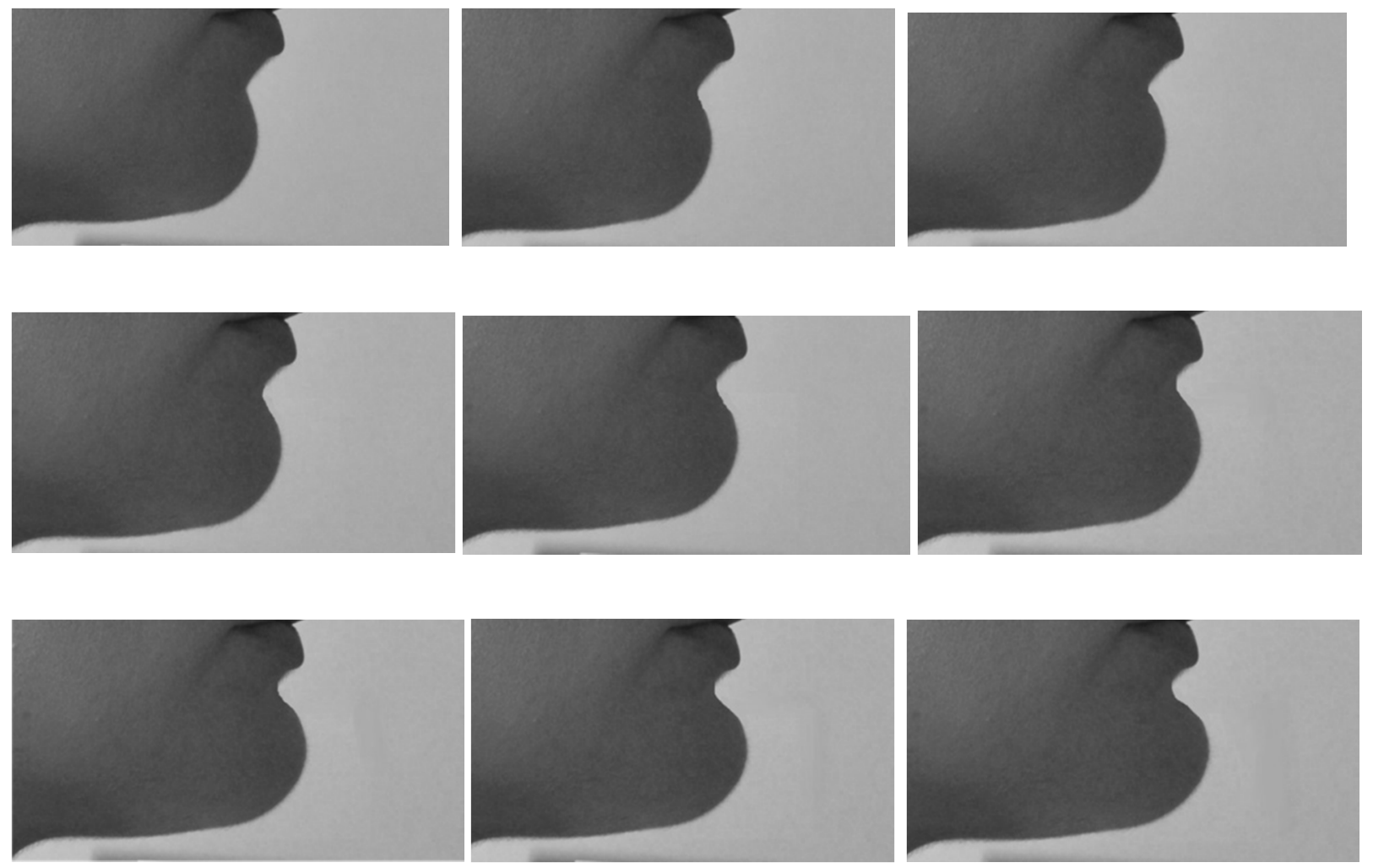

Figure 16: Chin Images

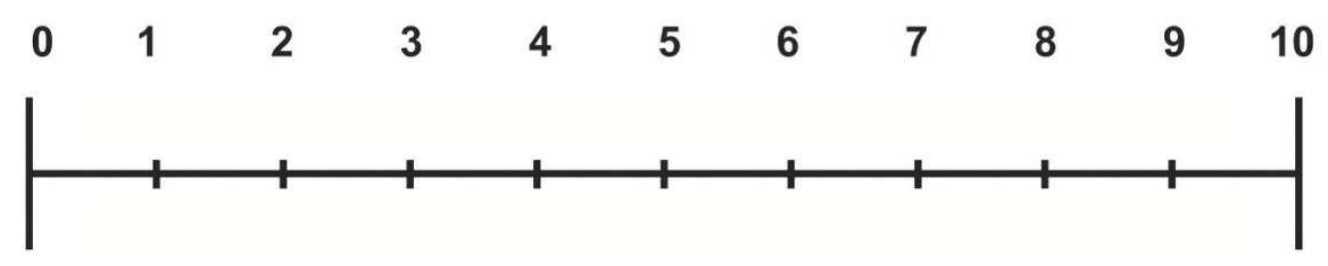

Less Attractive

More Attractive

Figure 17: Visual Analog Scale

All cephalometric measurements were repeated on ten subjects six weeks after initial measurements. The reliability of these measurements was analyzed by comparing 
the differences between the initial and repeated measurements. Coefficients of reliability and Cronbach's a were calculated.

For both chin and facial groups of photographs used in the survey, one photograph was repeated to test the reliability of the visual analog scale.

\section{STATISTICAL ANALYSIS}

The statistical analysis was carried about by the statistician (E.G.) using the JMP version 10 SAS Software. Pairwise correlation coefficients were calculated to quantitatively evaluate the relationship among the chin soft tissue thickness (Pog-Pog') and all linear, angular and Six Elements cephalometric variables. A stepwise regression analysis was used to determine the cephalometric variables that can be used to predict chin soft tissue thickness.

\section{CHAPTER 4: RESULTS}

\section{DESCRIPTIVE STATISTICS}

The study sample for the cephalometric portion consisted of 65 females and 40 males. The age distribution ranged from 10.1 to 53.8. Descriptive statistics were used to determine the mean, standard deviation, minimum and maximum for each of the linear, 
angular and Six Elements cephalometric variables (Table 4). The mean soft tissue thickness for the sample was $11.84 \mathrm{~mm}$ with a standard deviation of 2.2 .

Table 4: Descriptive Statistics

\begin{tabular}{|c|c|c|c|c|c|}
\hline & \multicolumn{5}{|c|}{ Descriptive Statistics of Pooled Data } \\
\hline & Mean & Std Dev & $\begin{array}{l}\text { Std Err } \\
\text { Mean }\end{array}$ & $\begin{array}{l}\text { Upper 95\% } \\
\text { Mean }\end{array}$ & $\begin{array}{l}\text { Lower95\% } \\
\text { Mean }\end{array}$ \\
\hline \multicolumn{6}{|l|}{ Linear } \\
\hline Pog-Pog' & 11.84 & 2.2 & 0.22 & 12.27 & 11.41 \\
\hline N-ANS & 50.32 & 3.46 & 0.34 & 51 & 49.64 \\
\hline ANS-Me & 61.57 & 5.63 & 0.56 & 62.68 & 60.47 \\
\hline $\mathrm{N}-\mathrm{Me}$ & 108.7 & 20.03 & 1.95 & 112.58 & 104.82 \\
\hline G'-Sn' & 62.91 & 4.45 & 0.44 & 63.78 & 62.03 \\
\hline Sn'-Me' & 65.67 & 6.1 & 0.6 & 66.86 & 64.46 \\
\hline G'-Me' & 124.9 & 22.98 & 2.24 & 129.34 & 120.45 \\
\hline Co-Go & 54.1 & 5.08 & 0.5 & 55.1 & 53.11 \\
\hline Pog'-GALL & 1.1 & 4.77 & 0.47 & 2.04 & 0.16 \\
\hline Pog-GALL & -9.2 & 7.31 & 0.72 & -7.77 & -10.64 \\
\hline TVL-Pog' & -6.11 & 6.08 & 0.6 & -4.92 & -7.3 \\
\hline MP-L1 & 38.41 & 3.47 & 0.34 & 39.1 & 37.73 \\
\hline Sn-GALL & 7.9 & 2.61 & 0.26 & 8.41 & 7.38 \\
\hline Co-Gn & 111.93 & 6.82 & 0.68 & 113.27 & 110.6 \\
\hline U1-L1 & 3.61 & 2.78 & 0.28 & 4.15 & 3.06 \\
\hline L1'-Pog & 2.06 & 1.57 & 0.16 & 2.37 & 1.75 \\
\hline L1"-Pog & 2.96 & 8.8 & 0.87 & 4.69 & 1.23 \\
\hline Pog-Pog" & 14.72 & 1.92 & 0.19 & 15.1 & 14.34 \\
\hline
\end{tabular}




\begin{tabular}{|l|r|r|r|r|r|} 
L1-Me & 39.13 & 3.65 & 0.36 & 39.85 & 38.42 \\
\hline Angular & \multicolumn{5}{|l|}{} \\
\hline Go $^{\circ}$ & 122.16 & 12.32 & 1.22 & 124.58 & 119.74 \\
\hline MP $^{\circ}$ & 24.54 & 14.74 & 1.46 & 27.44 & 21.65 \\
\hline Op $^{\circ}$ & 9.43 & 7.71 & 0.76 & 10.94 & 7.92 \\
\hline L1-MP $^{\circ}$ & 93.11 & 8.96 & 0.89 & 94.87 & 91.35 \\
\hline L1'-MP $^{\circ}$ & 90.09 & 4.17 & 0.41 & 90.91 & 89.27 \\
\hline
\end{tabular}

\section{ERROR MEASUREMENTS}

Reliability coefficients were analyzed to determine accuracy of the examiners measurements. All linear and angular measurements had high correlation $(>0.98)$ as seen in Table 5. For the data used from the previous study of Dr. Holly Eppard was shown to all have coefficients of reliability greater than $0.95{ }^{23}$. 


\section{Table 5: Reliability Coefficients}

\begin{tabular}{|l|r|r|r|}
\hline \multicolumn{4}{|c|}{ Reliability Coefficients } \\
\hline & \multicolumn{1}{|l}{$\begin{array}{l}\text { Avg Meas } \\
\text { Round 1 }\end{array}$} & \multicolumn{1}{l|}{$\begin{array}{l}\text { Avg Meas } \\
\text { Round 2 }\end{array}$} & Correlation \\
\hline Pog-Pog' & 12.43 & 12.53 & 0.990 \\
\hline U1-L1 & 3.83 & 3.68 & 0.994 \\
\hline L1'-Pog & 1.25 & 1.5 & 0.994 \\
\hline L1'-Pog & 1.815 & 1.815 & 0.999 \\
\hline L1-Me & 41.79 & 41.76 & 0.999 \\
\hline Sn-GALL & 7.94 & 7.85 & 0.983 \\
\hline Co-Gn & 113.01 & 112.84 & 0.999 \\
\hline Pog-Pog" & 15.75 & 15.41 & 0.998 \\
\hline L1-Mp & 96.1 & 96.5 & 0.997 \\
\hline L1'-Mp & 90.2 & 90.1 & 0.994 \\
\hline
\end{tabular}

\section{PAIRWISE CORRELATION}

Pairwise correlations were calculated to determine any relationship between variables.

The following variables in the area of interest showed correlation $(p=<0.05)$ : Pog-Pog' by NMe, Pog-Pog' by Sn'-Me', Pog-Pog' by Pog'-GALL, Pog-Pog' by Pog-GALL, and Pog-Pog' by TVLPog'. No angular measurements showed any correlation with Pog-Pog'. 
The stepwise regression analysis was conducted to examine for any further relationship between Pog-Pog' and the other cephalometric measurements. The analysis resulted in a fit involving the following variables: ANS-Me, Sn'-Me', TVL-Pog', and L1-Me. Since ANS-Me by Sn'-Me, ANS-Me by L1-Me, and L1-Me by Sn'-Me' are highly correlated there are multicollinearity in the fitted model. Then the models involving the uncorrelated variables are fitted. If Sn'-Me' and TVL-Pog' are used then $R^{2}=0.29$. If ANS-Me and TVL-Pog' are used then $R^{2}=0.18$. With Pog-Pog' as the dependent variable the result of the regression analysis was the following equation (best fit):

$$
\text { Pog-Pog' }=1.83+0.16\left(S^{\prime}-M e^{\prime}\right)+0.10(\text { TVL-Pog') }
$$

\section{SKELETAL CLASS ANALYSIS}

The sample was grouped based on skeletal class then compared. There was no significant difference in soft tissue chin thickness (Pog-Pog') between any of the groups. There was also no significant difference in symphyseal thickness (Pog-Pog") or Element $V(L 1$ '-Pog). There was significant difference seen between all groups in subnasale to the GALL (Sn'-GALL) and soft tissue chin prominence (Pog'-GALL). 
Table 6: Averages by Skeletal Class

\begin{tabular}{|l|r|r|r|}
\hline & \multicolumn{3}{|c|}{ Averages by Skeletal Class } \\
\hline & \multicolumn{1}{|c|}{ Class I } & \multicolumn{1}{l|}{ Class II } & \multicolumn{1}{l|}{ Class III } \\
\hline ANB & 2.64 & 7.17 & -3.05 \\
\hline Pog-Pog' & 11.81 & 12.06 & 11.55 \\
\hline Pog-Pog" & 14.66 & 15.11 & 14.17 \\
\hline Sn-GALL & 7.93 & 9.01 & 5.05 \\
\hline L1'-Pog & 2 & 2.04 & 2.51 \\
\hline U1-L1 & 3.75 & 4.4 & 0.9 \\
\hline Co-Gn & 112.52 & 108.9 & 115.58 \\
\hline L1-Me & 38.84 & 40.62 & 37.34 \\
\hline L1-MP & 93.32 & 96.81 & 83.09 \\
\hline L1'-MP & 90 & 90.77 & 89 \\
\hline Pog'-GALL & 1.47 & -1.87 & 5.96 \\
\hline Pog-GALL & -8.93 & -11.99 & -4.18 \\
\hline TVL-Pog' & -5.55 & -10.53 & 1.03 \\
\hline
\end{tabular}

\section{SKELETAL CATEGORY ANALYSIS}

The sample was grouped based on skeletal category then compared. There was no significant difference seen based on soft tissue chin thickness (Pog-Pog'). There was significant difference seen in symphyseal thickness (Pog-Pog") between Category I/ Category III and Category II/ Category III. There was no significant difference see in 
Element $V$ measurement (L1'-Pog). There was significant difference seen in subnasale to the GALL (Sn'-GALL) between Category I/Category III and Category II/ Category III. There was significant difference between all categories in soft tissue chin prominence (Pog'-GALL).

Table 7: Averages by Skeletal Category

\begin{tabular}{|c|c|c|c|}
\hline & \multicolumn{3}{|c|}{ Averages by Skeletal Category } \\
\hline & $\begin{array}{l}\text { Category } \\
\text { I }\end{array}$ & $\begin{array}{l}\text { Category } \\
\text { II }\end{array}$ & $\begin{array}{l}\text { Category } \\
\text { III }\end{array}$ \\
\hline ANB & 3.24 & 6.23 & -0.061 \\
\hline Pog-Pog' & 11.57 & 11.86 & 12.2 \\
\hline Pog-Pog" & 14.87 & 15.17 & 13.97 \\
\hline Sn-GALL & 8.41 & 8.47 & 6.47 \\
\hline L1'-Pog & 2.12 & 2.12 & 1.91 \\
\hline U1-L1 & 3.77 & 5.01 & 1.68 \\
\hline Co-Gn & 113.2 & 109.59 & 114.73 \\
\hline L1-Me & 38.55 & 41.01 & 37.69 \\
\hline L1-MP & 94.18 & 97.5 & 86.25 \\
\hline L1'-MP & 90.3 & 90.32 & 89.5 \\
\hline Pog'-GALL & 1.67 & -1.91 & 3.94 \\
\hline Pog-GALL & -9.89 & -11.21 & -5.78 \\
\hline TVL-Pog' & -6.49 & -9.48 & -1.48 \\
\hline
\end{tabular}


The data was collected and organized for evaluation. Image ratings were placed in order from least protrusive to most protrusive and labeled 1-15 for both chin and face groups. Averages were calculated for each image and plotted (Chart 1). The differences seen are not considered statistically significant $(p$ value $=0.17)($ Table 6$)$.

\section{Chart 1: Chin vs. Face Average Ratings}

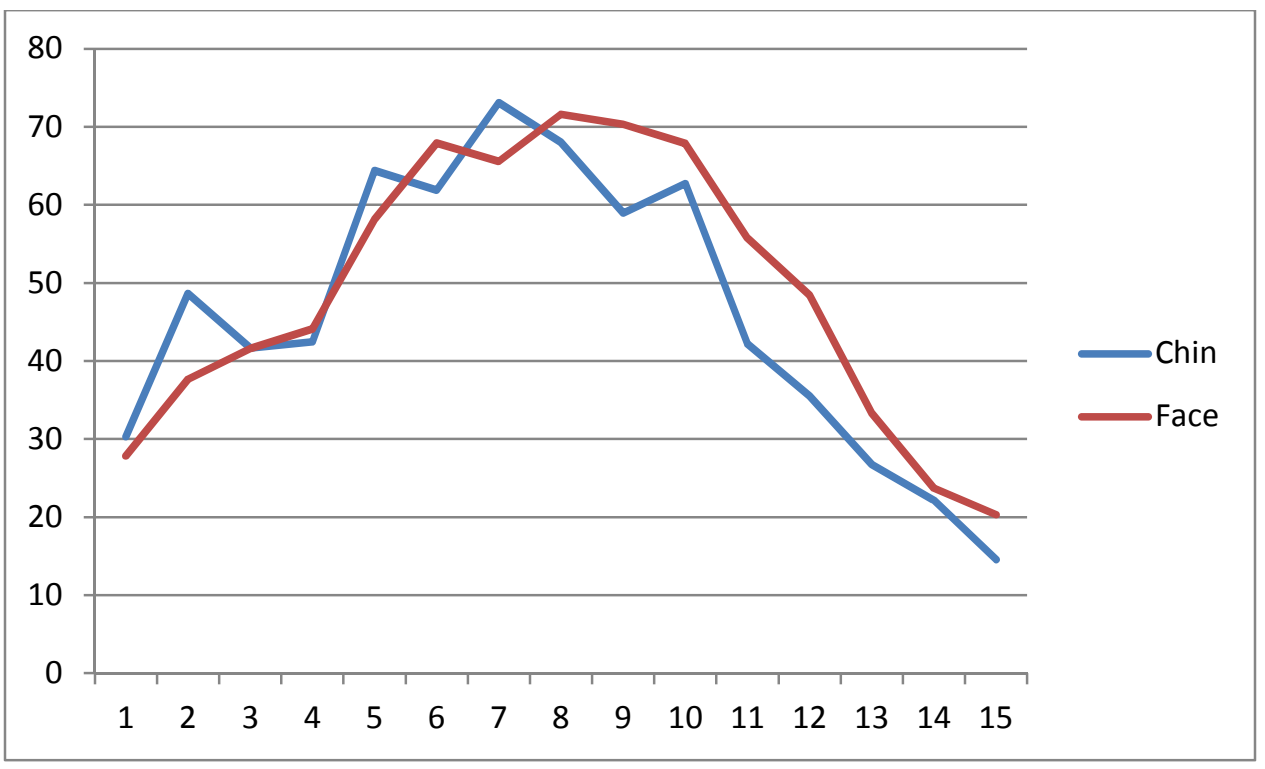




\section{Table 8: Whole Face vs. Chin}

\begin{tabular}{|l|r|l|r|}
\hline \multicolumn{4}{|l|}{ Whole Face vs. Chin } \\
\hline \multicolumn{4}{|l|}{} \\
\hline Whole Face & 48.95 & t-Ratio & 1.44 \\
\hline Chin & 46.2 & DF & 14 \\
\hline Mean Difference & 2.72 & Prob $>$ It & 0.17 \\
\hline Std Error & 1.89 & Prob $>t$ & 0.09 \\
\hline N & 15 & Prob $<t$ & 0.91 \\
\hline Correlation & 0.92 & & \\
\hline
\end{tabular}

MALE VS. FEMALE

The sample was broken down into male and female groups. The data was analyzed to see if there were any differences between male and female raters of the chin and face images (Chart 2,3). There was a statistically significant difference between male and female ratings of the chin images $(p$-value $=<.0001)($ Table 7$)$. There was no significant difference between male and female ratings of the face images ( $p$ value $=0.13)($ Table 8$)$. 


\section{Chart 2: Males vs. Females (Chin)}

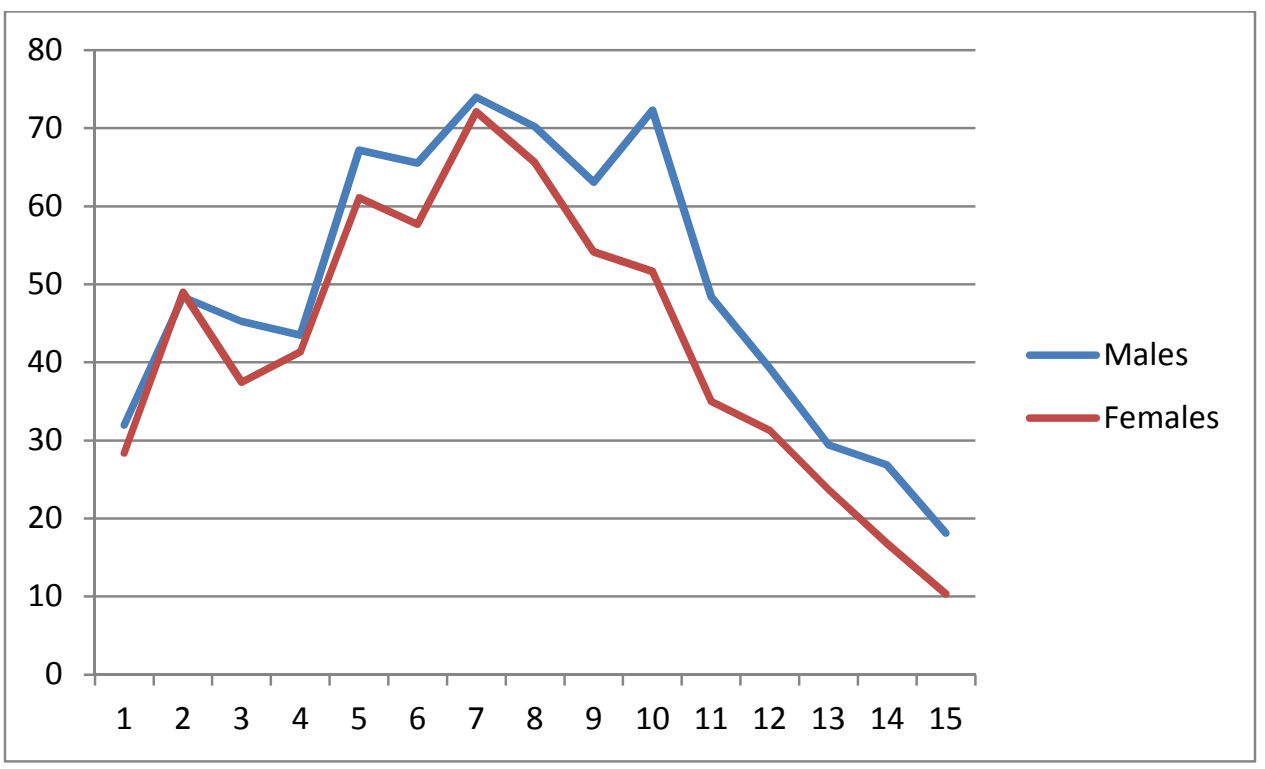

Table 9: Males vs. Females (Chin)

\begin{tabular}{|c|c|c|c|}
\hline \multicolumn{4}{|c|}{ Males vs. Females (Chin) } \\
\hline Females & 42.37 & t-Ratio & -5.41 \\
\hline Males & 49.54 & DF & 14 \\
\hline Mean Difference & -7.18 & Prob $>|t|$ & $<.0001$ \\
\hline Std Error & 1.33 & Prob $>t$ & 1 \\
\hline $\mathbf{N}$ & 15 & Prob $<\mathrm{t}$ & $<.0001$ \\
\hline on Correlati & 0.961 & & \\
\hline
\end{tabular}




\section{Chart 3: Males vs. Females (Face)}

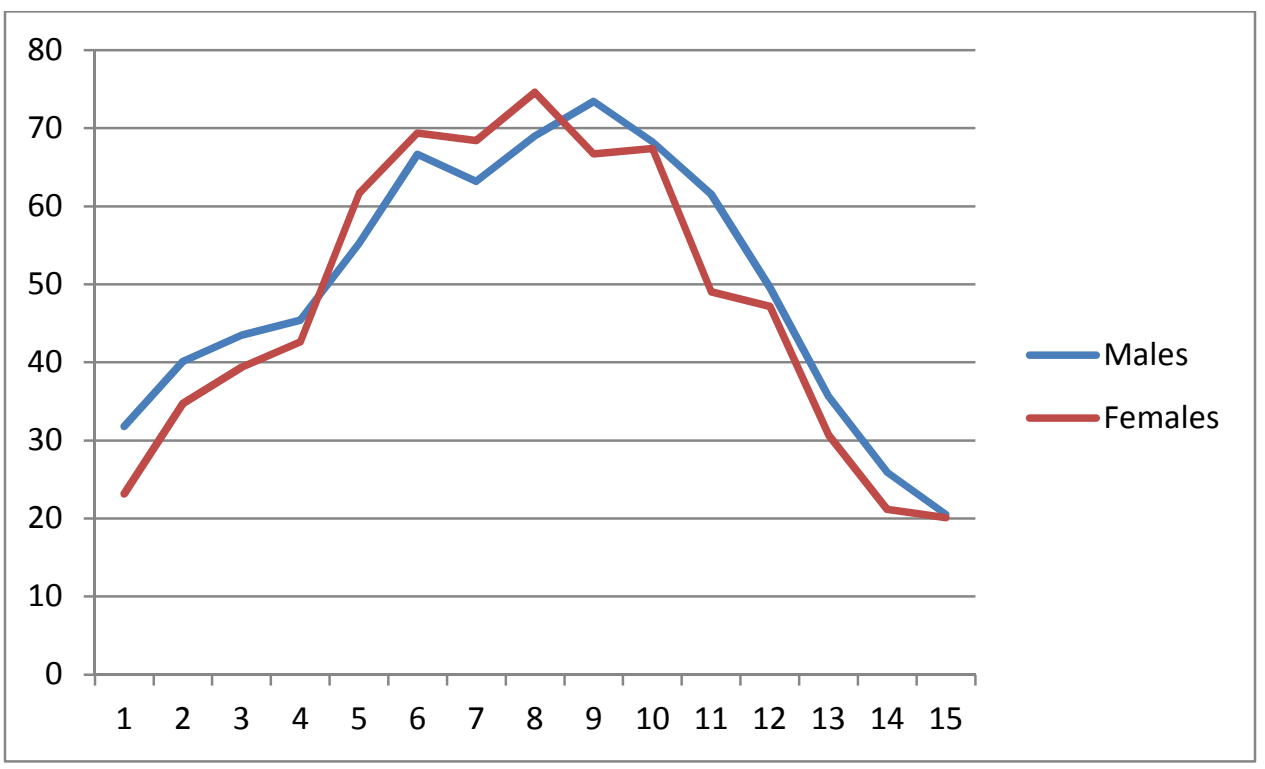

Table 10: Males vs. Females (Face)

\begin{tabular}{|l|r|l|r|}
\hline \multicolumn{3}{|c|}{ Males vs. Females (Face) } \\
\hline & \multicolumn{2}{|c|}{} \\
\hline Females & 47.74 & t-Ratio & -1.59 \\
\hline Males & 49.98 & DF & 14 \\
\hline Mean Difference & -2.23 & Prob $>$ It & 0.13 \\
\hline Std Error & & Prob $>t$ & 0.93 \\
\hline N & 15 & Prob $<t$ & 0.067 \\
\hline Correlation & 0.96 & & \\
\hline
\end{tabular}


The sample was broken down into orthodontist and non-orthodontist groups. The data was analyzed to determine if there was any difference in the way orthodontist and non-orthodontist view attractiveness (Chart 4,5). There was no significant difference in rating the chin images $(p$-value $=0.63)($ Table 9$)$. There was also no significant difference in rating the face images ( $p$-value $=0.12)($ Table 10$)$.

\section{Chart 4: Orthodontist vs. Non-Orthodontist (Chin)}

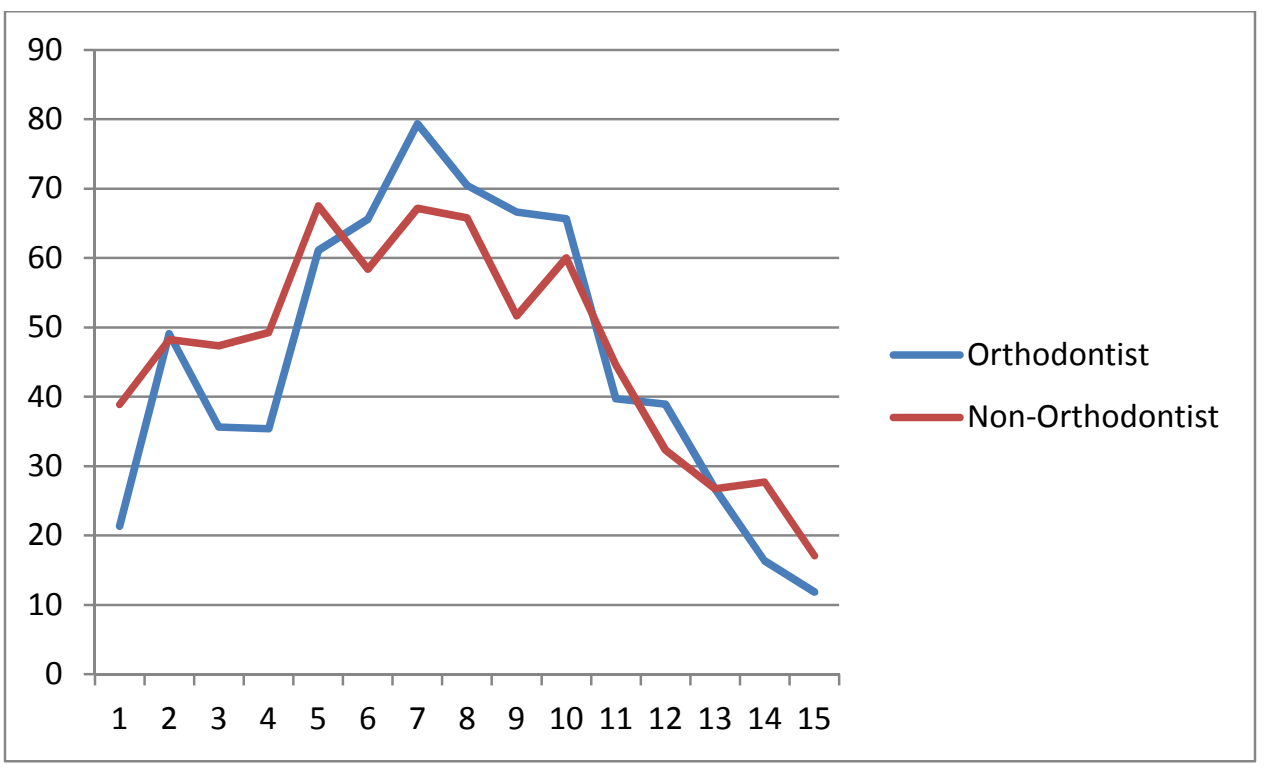




\section{Table 11: Orthodontist vs. Non-Orthodontist (Chin)}

\begin{tabular}{|l|r|l|r|}
\hline \multicolumn{4}{|l|}{ Orthodontist vs. Non-Orthodontist (Chin) } \\
\hline \multicolumn{4}{|l|}{} \\
\hline Non-Ortho & 46.84 & t-Ratio & 0.49 \\
\hline Ortho & 45.59 & DF & 14 \\
\hline Mean Difference & 1.24 & Prob $>$ It & 0.63 \\
\hline Std Error & 2.54 & Prob $>t$ & 0.32 \\
\hline N & 15 & Prob $<t$ & 0.68 \\
\hline Correlation & 0.91 & & \\
\hline
\end{tabular}

\section{Chart 5: Orthodontist vs. Non-Orthodontist (Face)}

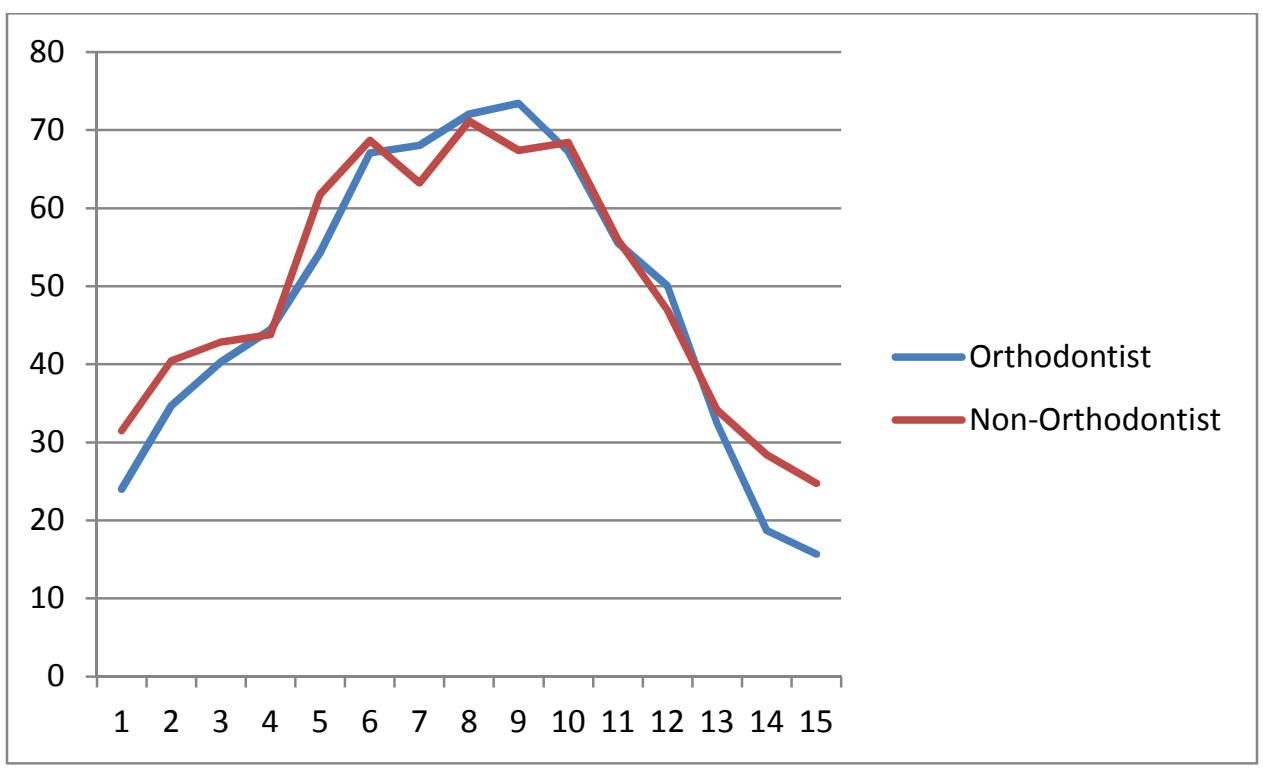


Table 12: Orthodontist vs. Non-Orthodontist (Face)

\begin{tabular}{|l|r|l|r|}
\hline \multicolumn{4}{|l|}{ Orthodontist vs. Non-Orthodontist (Face) } \\
\hline \multicolumn{4}{|l|}{} \\
\hline Non-Ortho & 49.97 & t-Ratio & 1.65 \\
\hline Ortho & 47.87 & DF & 14 \\
\hline Mean Difference & 2.09 & Prob $>$ Itl & 0.12 \\
\hline Std Error & 1.27 & Prob $>t$ & 0.06 \\
\hline N & 15 & Prob $<t$ & 0.94 \\
\hline Correlation & 0.98 & & \\
\hline
\end{tabular}

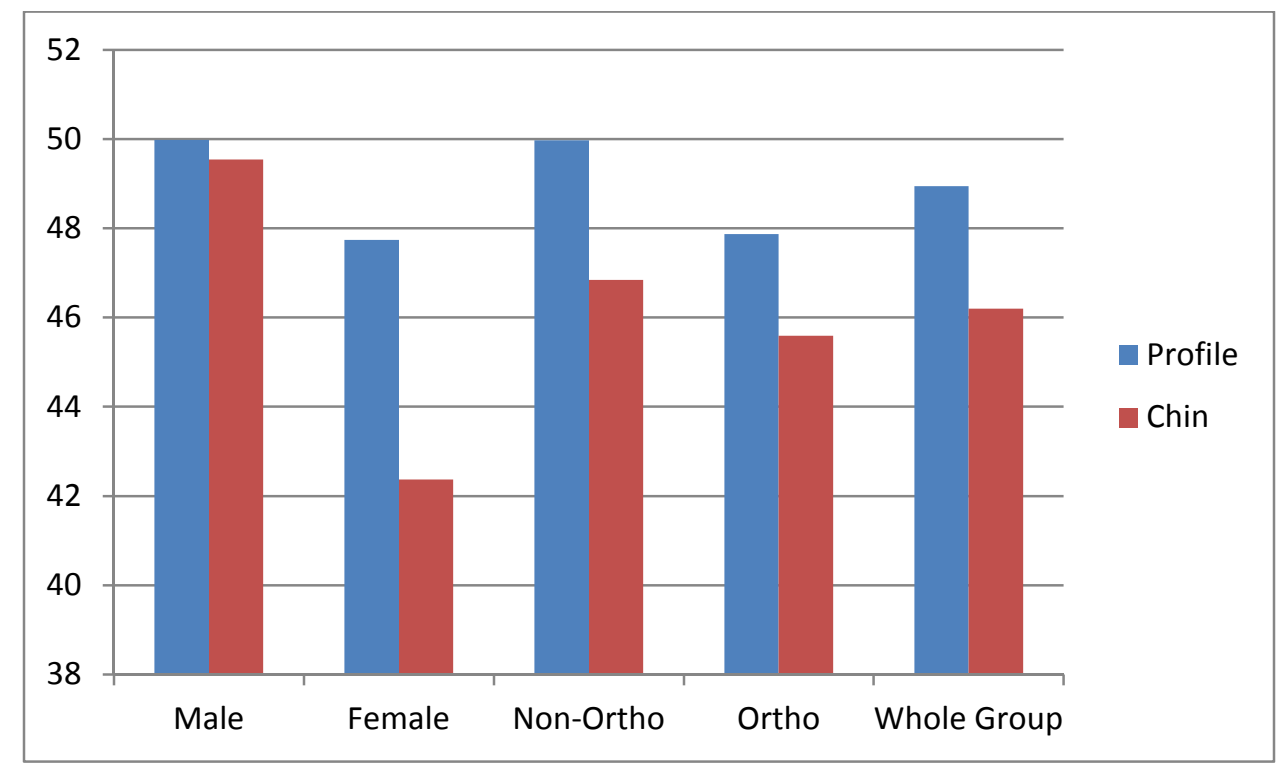

Chart 11: Average Esthetic Rating 


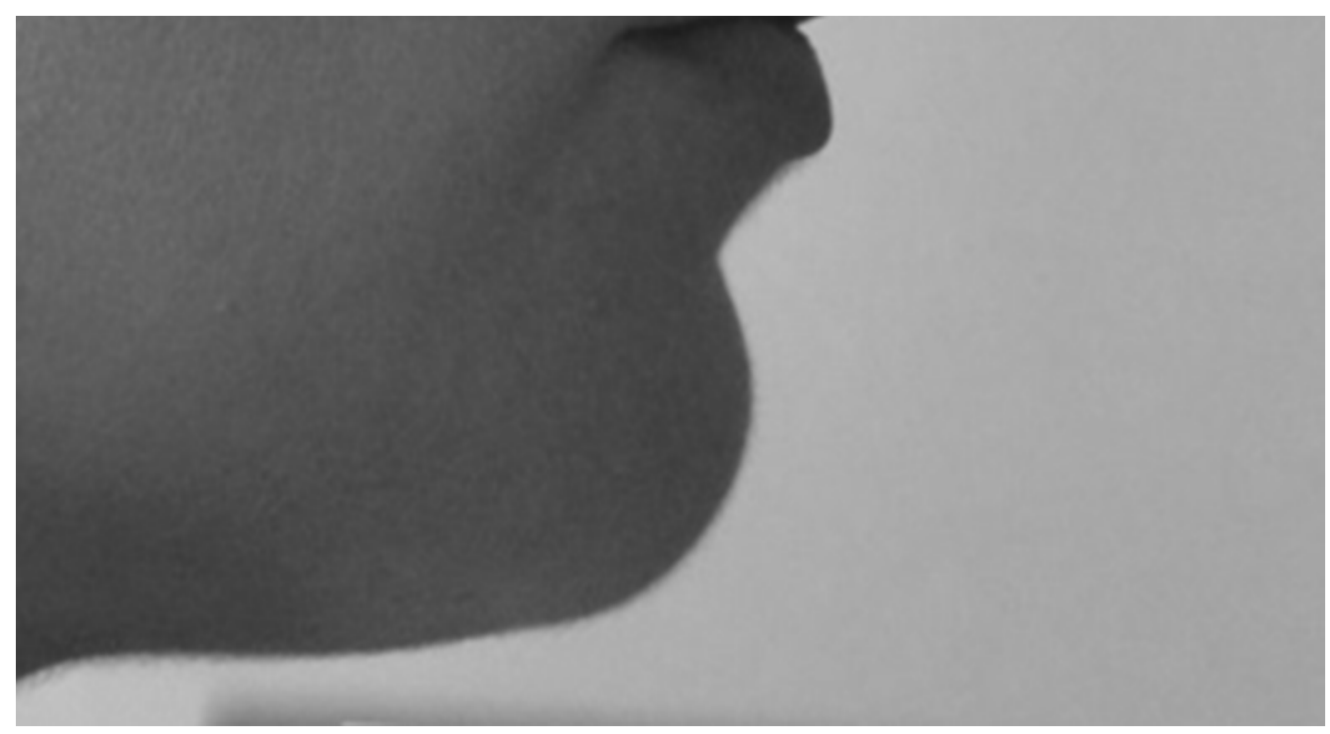

Figure 18: Highest Rated Chin

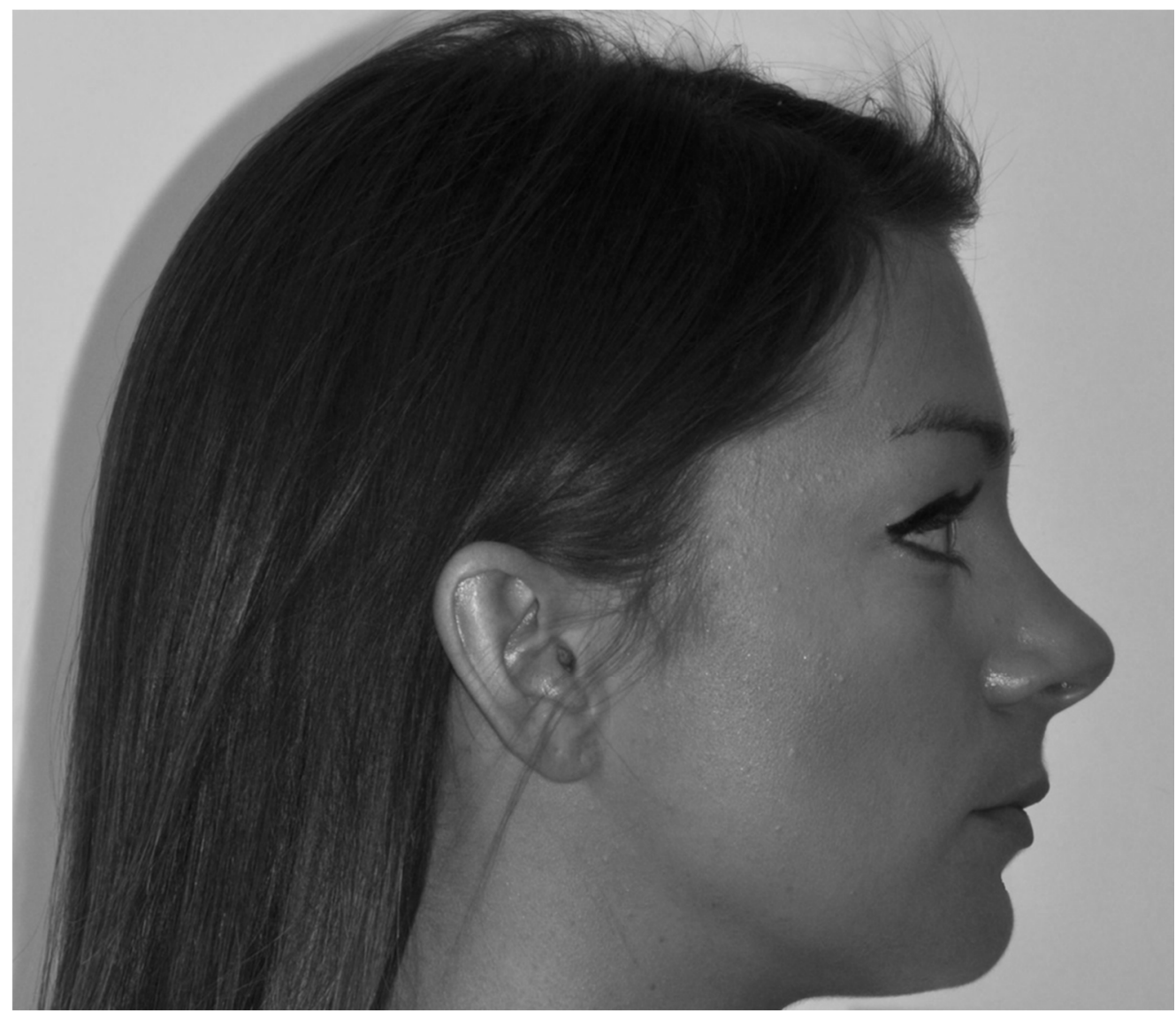




\section{Figure 19: Highest Rated Face}

\section{RELIABILITY COEFFICIENTS}

The repeatability of the survey participants ratings was tested by blindly repeating one image in both the chin and face groups. The first time the image was rated is labeled as Variable 1 while the second is labeled Variable 2. In the chin group there was a Pearson Coefficient of $0.715(p$-value $=0.077)($ Table 11). In the face group there was a Pearson Coefficient of $0.351(p$-value $=0.175)($ Table12 $)$.

\section{Table 13: Chin Alone Reliability}

\begin{tabular}{|c|c|c|}
\hline \multirow{2}{*}{$\begin{array}{l}\text { t-Test: Paired Two Sample for Means } \\
\text { Whole Group: Chin Reliability }\end{array}$} & \multirow[b]{3}{*}{ Variable 1} & \multirow[b]{3}{*}{ Variable 2} \\
\hline & & \\
\hline & & \\
\hline Mean & 42.48717949 & 39.23076923 \\
\hline Variance & 284.3616734 & 380.6032389 \\
\hline Observations & 39 & 39 \\
\hline Pearson Correlation & 0.714934565 & \\
\hline Hypothesized Mean Difference & 0 & \\
\hline df & 38 & \\
\hline t Stat & 1.457941371 & \\
\hline $\mathrm{P}(\mathrm{T}<=\mathrm{t})$ one-tail & 0.076536253 & \\
\hline t Critical one-tail & 1.68595446 & \\
\hline $\mathrm{P}(\mathrm{T}<=\mathrm{t})$ two-tail & 0.153072506 & \\
\hline t Critical two-tail & 2.024394164 & \\
\hline
\end{tabular}




\section{Table 14: Whole Face Reliability}

\begin{tabular}{|c|c|c|}
\hline \multirow{3}{*}{$\begin{array}{l}\text { t-Test: Paired Two Sample for Means } \\
\text { Whole Group: Face Reliability }\end{array}$} & & \multirow[b]{3}{*}{ Variable 2} \\
\hline & \multirow[b]{2}{*}{ Variable 1} & \\
\hline & & \\
\hline Mean & 70.33333333 & 72.92307692 \\
\hline Variance & 151.6491228 & 289.1781377 \\
\hline Observations & 39 & 39 \\
\hline Pearson Correlation & 0.350604856 & \\
\hline Hypothesized Mean Difference & 0 & \\
\hline $\mathrm{df}$ & 38 & \\
\hline t Stat & -0.943249035 & \\
\hline $\mathrm{P}(\mathrm{T}<=\mathrm{t})$ one-tail & 0.175756142 & \\
\hline t Critical one-tail & 1.68595446 & \\
\hline $\mathrm{P}(\mathrm{T}<=\mathrm{t})$ two-tail & 0.351512284 & \\
\hline t Critical two-tail & 2.024394164 & \\
\hline
\end{tabular}

\section{CHAPTER 5: DISCUSSION}

HARD TISSUE VS. SOFT TISSUE ANALYSIS

Most cephalometric analyses use hard tissue landmarks and measurements to define ideal. While facial esthetics are effected by skeletal structures the magnitude can vary based on the corresponding soft tissue thickness. The thickness of soft tissue covering the chin of patients in this study sample averaged $11.84 \mathrm{~mm}$ with a range of $5.22 \mathrm{~mm}$ to $18.19 \mathrm{~mm}$. The hard tissue measurements that were found to have significant 
correlation ( $p$-value $<.05$ ) with soft tissue chin thickness were N-Me $(0.24)$, Sn'-Me' (0.21), Pog'-GALL (-0.42), Pog-GALL (-0.29), and TVL-Pog' (-0.40). While statistically significant, the Pearson coefficients are not close to 1 thus showing a weak correlation. The stepwise regression also found weak correlation with hard tissue measurements.

Due to the variance seen in soft tissue thickness covering the chin and the lack of strong correlation with hard tissue cephalometric measurements, perhaps skeletal measurements are not good predictors of chin esthetics.

There has been research that supports upright head posture as a repeatable, reliable position ${ }^{12}$. Two analyses that use upright head posture to determine facial planes are Arnett's facial analysis ${ }^{16}$ and Andrew's Six Elements ${ }^{22}$. In Arnett's analysis, the True Vertical Line is used as a reference to measure soft tissue landmarks. It is a line dropped from subnasale perpendicular to the floor. Dr. Arnett's analysis provides a very thorough examination of soft tissue features of the face and is widely accepted.

Andrews Six Elements on the other hand uses a lined dropped from glabella that is used to determine ideal anteroposterior position of the maxillary incisors. The Six Elements teach that if all of the elements are optimal than an esthetic face will result. All the elements are hard tissue measurements. It would be interesting to use measurements made from the GALL line to the landmarks used in Dr. Arnett's analysis 
and see if ranges of normal could be determined. Would the ranges be smaller or more variable?

In this study sample, a measurement was made on each radiograph to determine the distance of subnasale to the GALL line. The average distance was $7.89 \mathrm{~mm}$ with a range of $-1.92 \mathrm{~mm}$ to $13.31 \mathrm{~mm}$. This variability shows clearly that use of these reference lines would result in the different measurements. More research is needed to determine which line would be a more reliable reference for facial esthetics.

When the sample was grouped based on skeletal class, there were significant differences seen in measurements from subnasale to the GALL. This again raises the point that there is a difference in the reliability of these reference lines do to the effects seen with change in skeletal class. Further research is need to determine which reference line is more reliable.

\section{CHIN VS. FACE ATTRACTIVENESS}

Comparisons were made between raters perceived attractiveness of varying chin positions. While changes were made in only $1 \mathrm{~mm}$ increments in the anteroposterior direction, there was a clear effect on the rated attractiveness. There was no statistical significant difference between the chin images and facial images average attractiveness ratings. Interestingly though, the graphs show a smoother bell curve in the facial group. 
Perhaps people are more conditioned to evaluate the attractiveness of ones face than just a chin alone.

There appears to be a "plateau" of $5 \mathrm{~mm}$ where the increase and decrease of perceived attractiveness is minimal. This means that while small changes are noticeable, they do not have drastic effects on facial attractiveness. Previous research has determined that protrusions greater than $6 \mathrm{~mm}$ and retrusions greater than $10 \mathrm{~mm}$ survey participants would elect surgery ${ }^{7}$. It is difficult to determine when surgery is justified, but these results show that small changes in chin prominence can have profound affects when outside of the $5 \mathrm{~mm}$ "window."

\section{CHIN ANALYSIS BASED ON SKELETAL CLASS}

A comparison of chin measurements between groups based on skeletal class was conducted to look for similarities. There was no significant difference seen in soft tissue chin thickness. This is further evidence that soft tissue chin thickness is independent of hard tissue structures. There were also no significant difference seen in symphyseal thickness or Element $\mathrm{V}$. This supports Dr. Andrews claim that Element $\mathrm{V}$ defines an optimal hard tissue chin regardless of anteroposterior mandibular position. There was significant difference seen in soft tissue chin prominence (Pog'-GALL) seen between all skeletal class groups. This means Pog'-GALL might be a useful soft tissue measurement to supplement an analysis. 
A comparison of chin measurements between groups based on skeletal categories was conducted to look for similarities. Similar to skeletal class, there was no significant difference between skeletal category groups in regard to soft tissue chin thickness. There was however significant difference seen in symphyseal thickness between categories Category I/ Category III and Category II/ Category III. There was no significant difference seen in Element $\mathrm{V}$ based skeletal category. As seen in groups based on skeletal class, there was significant difference between all groups and soft tissue chin prominence. This further raises the need for further research on the measurement Pog'-GALL and the significance to facial esthetics.

When comparing the ratings of males and females, there were no significant differences in the perceived attractiveness of the face images. Males were slightly more generous than females but not significantly. There was strong correlation $(R=0.96)$ so as males rating increased, so did the females and vice versa. For the chin images, however, there was significant difference between males and females. Males had an average rating of 49.54 while females were 42.37 . The correlation was still strong $(R=.96)$. In general, females tended to grade attractiveness more harshly than males. 
When comparing the ratings of orthodontists and non-orthodontists. There were no significant differences with both facial images and chin images. There was a higher correlation between the two in regard to facial images $(R=0.98)$. It is helpful knowing that orthodontist and non-orthodontist agree upon what is attractive. This supports conclusions from previous studies ${ }^{7}$. The fact that orthodontist do not display specialty bias helps justify treatment plans and objectives.

While there were no statistically significant differences between the ratings of orthodontists and non-orthodontists, comparison of the curves in Charts $4 \& 5$ shows that the orthodontist ratings seem more consistent. The non-orthodontist curve jumps up and down in the "plateau" range. 


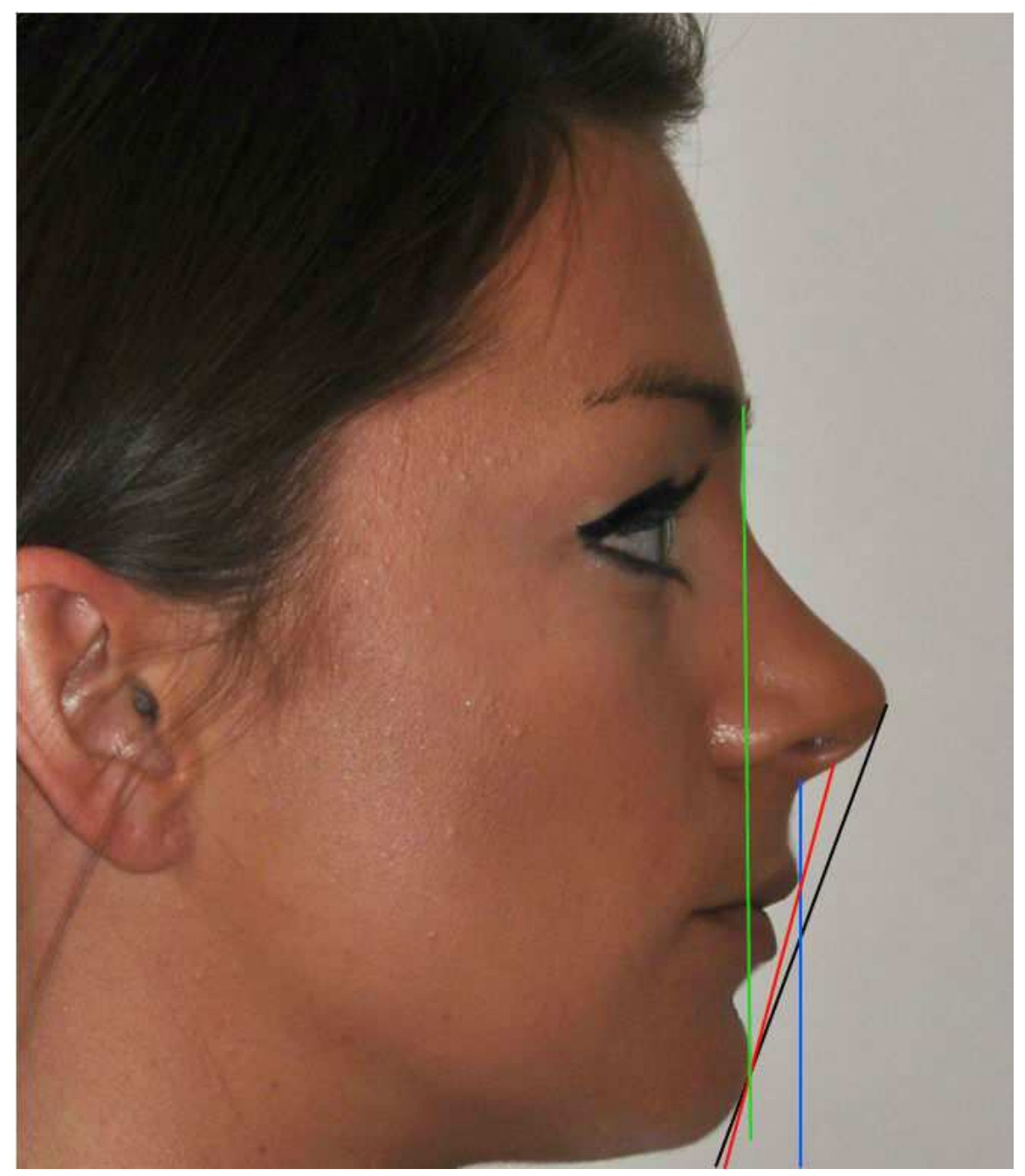

Figure 20: TVL (Blue), S-Line (Red), E-Plane (Black), GALL (Green)

Soft tissue analysis of the highest rated image can help evaluate reference lines (Fig. 20). When printed out in 1:1 ratio, the upper lip was found to be $-4 \mathrm{~mm}$ behind Rickett's E-plane while the lower lip was $-3 \mathrm{~mm}$ behind. This nearly corresponds with Rickett's norms for Caucasian Females of $-4 \mathrm{~mm}$ for the upper lip and $-2 \mathrm{~mm}$ for the lower. Steiner proposes that the upper and lower lip should fall on a line from the 
midpoint of the columella of the nose to soft tissue pogonion. For this image the upper and lower lip are $-1.5 \mathrm{~mm}$ behind this line which is pretty close.

Arnett's analysis tells us that the upper lip, lower lip and chin are all retrusive. The upper lip is $-1 \mathrm{~mm}$ behind TVL (normal $=2.5$ to $4.9 \mathrm{in}$ front). The lower lip is $-4 \mathrm{~mm}$ behind TVL (normal $=0.5$ to $3.3 \mathrm{~mm}$ in front). The chin is $-9 \mathrm{~mm}$ behind TVL (normal $=-$ 4.5 to -0.7 behind). In a case where there the upper and lower lips are more retrusive than ideal, it is important to note that a chin within the "normal" range would appear too prominent.

\section{CLINICAL IMPLICATIONS}

Soft tissue variability can be drastic and predictable. Soft tissue analysis should be performed in addition to hard tissue cephalometric analysis.

Chin prominence has a strong effect on perceived facial attractiveness. Clinicians and laypeople are sensitive to millimeter changes in anteroposterior prominence of the chin. There seems to a $5 \mathrm{~mm}$ "window" where the perceived attractiveness is best. Outside this window, the ratings drop more rapidly. 
The first objective of this study was to evaluate the relationships of soft tissue chin thickness with hard tissue cephalometric measurements. A sample of 105 pretreatment cephalometric radiographs, of subjects with various skeletal and dental morphological characteristics were analyzed. Correlations coefficients were determined to quantify relationships along with a stepwise regression analysis in attempt to create a method to predict soft tissue thickness.

The second objective of this study was to evaluate the effects of chin prominence on perceived profile attractiveness. Comparisons were made among orthodontists and non-orthodontists as well as males and females.

The following null hypotheses were able to be rejected:

1. Hard tissue lateral cephalometric measurements do not correlate with soft tissue chin prominence.

2. There is no correlation with soft tissue chin prominence and perceived attractiveness.

3. There is no difference between judge attractiveness perceived by males and females.

The following null hypotheses were able to be accepted:

1. There is no difference in soft tissue chin thickness based on skeletal class or category. 
2. There is no difference between perceived attractiveness of chin prominence alone and full facial profile.

3. There is no difference between judged attractiveness perceived by orthodontists and non-orthodontists.

\section{CONCLUSIONS}

The results of this study lead to the following conclusions:

1. There is weak correlation between chin soft tissue thickness and the following measurements: N-Me, Sn'-Me', Pog'-GALL, Pog-GALL, and TVL-Pog'.

2. Chin soft tissue thickness is highly variable.

3. There is no difference in soft tissue chin thickness based on skeletal class or category.

4. Perceived attractiveness of the profile is sensitive to millimeter changes in chin prominence.

5. Orthodontist and non-orthodontist agree on attractiveness.

6. Male and females agree on profile attractiveness but differ on chin attractiveness. Females in this study tended to rate images as less attractive as compared to males. 
There are several questions that are raised by this study. The following areas could be evaluated:

- The study could be repeated with a male patient for comparison.

- The study could be repeated with a smiling profile picture to compare smiling vs. repose.

- Research is needed to determine if the GALL line is a reliable landmark for soft tissue analysis.

- A comparison between TVL vs. GALL in defining ideal facial esthetics. 


\section{WORKS CITED}

1. Dobson SD, Trinkaus E. Cross-sectional geometry and morphology of the mandibular symphysis in middle and late pleistocene homo. J Hum Evol. 2002;43(1):67-67. doi: 10.1006/jhev.2002.0563.

2. Ichim I, Swain M, Kieser JA. Mandibular biomechanics and development of the human chin. J Dent Res. 2006;85(7):638-642. doi: 10.1177/154405910608500711.

3. Marshall SD, Low LE, Holton NE, et al. Chin development as a result of differential jaw growth. American Journal of Orthodontics and Dentofacial Orthopedics. 2011;139(4):456-464. doi: http://dx.doi.org/10.1016/i.ajodo.2009.05.038.

4. Khosravanifard B, Rakhshan V, Raeesi E. Factors influencing attractiveness of soft tissue profile. Oral surgery, oral medicine, oral pathology and oral radiology. 2013;115(1):29-37. doi: 10.1016/j.00oo.2012.03.021.

5. Maple JR, Vig KW, Beck FM, Larsen PE, Shanker S. A comparison of providers' and consumers' perceptions of facial-profile attractiveness. Am J Orthod Dentofacial Orthop. 2005;128(6):690-6; quiz 801. doi: 10.1016/j.ajodo.2004.09.030.

6. Johnston C, Hunt O, Burden D, Stevenson M, Hepper P. The influence of mandibular prominence on facial attractiveness. Eur J Orthod. 2005;27(2):129-133. doi: 10.1093/ejo/cjh093.

7. Naini FB, Donaldson AN, McDonald F, Cobourne MT. Assessing the influence of chin prominence on perceived attractiveness in the orthognathic patient, clinician and layperson. Int J Oral Maxillofac Surg. 2012;41(7):839-846. doi: 10.1016/j.ijom.2012.01.012; 10.1016/j.ijom.2012.01.012.

8. Hockley A, Weinstein M, Borislow AJ, Braitman LE. Photos vs silhouettes for evaluation of african american profile esthetics. American Journal of Orthodontics \& Dentofacial Orthopedics. 2012;141(2):161-168. doi: 10.1016/j.ajodo.2011.06.041. 
9. Wahl N. Orthodontics in 3 millennia. chapter 2: Entering the modern era. American Journal of Orthodontics and Dentofacial Orthopedics. 2005;127(4):510-515. doi: http://dx.doi.org/10.1016/j.ajodo.2005.01.002.

10. Downs WB. Analysis of the dentofacial profile. Angle Orthod. 1956;26(4):191-212.

11. Lundström A, Lundström F. The frankfort horizontal as a basis for cephalometric analysis. American Journal of Orthodontics and Dentofacial Orthopedics. 1995;107(5):537-540.

12. Lundström F, Lundström A. Natural head position as a basis for cephalometric analysis. American Journal of Orthodontics and Dentofacial Orthopedics. 1992;101(3):244-247. doi: http://dx.doi.org/10.1016/0889-

5406(92)70093-P.

13. Arnett GW, Bergman RT. Facial keys to orthodontic diagnosis and treatment planning. part I. American Journal of Orthodontics and Dentofacial Orthopedics. 1993;103(4):299-312.

14. Buschang PH, Gandini Júnior LG. Mandibular skeletal growth and modelling between 10 and 15 years of age. European journal of orthodontics. 2002;24(1):69-79. doi: 10.1093/ejo/24.1.69.

15. Holdaway RA. A soft-tissue cephalometric analysis and its use in orthodontic treatment planning. part I. Am J Orthod. 1983;84(1):1-28. doi: http://dx.doi.org/10.1016/0002-9416(83)90144-6.

16. Arnett GW, Bergman RT. Facial keys to orthodontic diagnosis and treatment planning-part II. American journal of orthodontics and dentofacial orthopedics. 1993;103(5):395-411.

17. Ewing M, Ross RB. Soft tissue response to mandibular advancement and genioplasty. American Journal of Orthodontics and Dentofacial Orthopedics. 1992;101(6):550-555.

18. Veltkamp T, Buschang PH, English JD, Bates J, Schow SR. Predicting lower lip and chin response to mandibular advancement and genioplasty. American journal of orthodontics and dentofacial orthopedics. 2002;122(6):627634. 
19. Spyropoulos MN, Halazonetis DJ. Significance of the soft tissue profile on facial esthetics. American Journal of Orthodontics and Dentofacial Orthopedics. 2001;119(5):464-471.

20. Ricketts RM. The biologic significance of the divine proportion and fibonacci series. Am J Orthod. $1982 ; 81(5): 351-370$.

21. Jahanbin A, Basafa M, Alizadeh Y. Evaluation of the divine proportion in the facial profile of young females. Indian J Dent Res. 2008;19(4):292-296.

22. Andrews LF, Andrews WA. Syllabus of the andrews orthodontic philosophy. U.S.: ; 2013.

23. Eppard $\mathrm{H}$. The occlusal plane inclination relative to craniofacial form: A cephalometric investigation. [Master of Science]. West Virgini University. 


\section{WestVirginiaUniversity. \\ Office of Research Integrity and Compliance}

\section{Approval Letter Expedited}

To

From

Action Date

Approval Period

Subject

Protocol Number

Title
Timothy Tremont

WVU Office of Research Integrity and Compliance

$02 / 10 / 2015$

02/10/2015 Exp iration Date 02/09/2016

Protocol Approval Letter

1411484386

Correlation of Chin Position and Facial Esthetics

The above-referenced research study was reviewed by the West Virginia University Institutional Review Board $\mathbb{R B}$ and was approved in accordance with 46 CFR $46.101 \mathrm{~b}$.

It has been determined that this study is of minimal risk and meets the criteria as defined by the expedited categories listed below:

" Category 6. Collection of data from voice, video, digital, or image recordings made for research purposes.

" Category 7. Research on individual or group characteristics or behavior (including, but not limited to, research on perception, cognition, motivation, identity, language, communication, cultural beliefs or practices, and social behavior) or research employing survey, interwiew, oral history, focus group, program evaluation, human factors evaluation, or quality assurance methodologies. [NOTE: Some research in this category may be exempt from the DHHS regulations for the protection of human subjects. See Exempt Categories and 45 CFR $46.101(\mathrm{~b})(2)$ and (b)(3). This listing refers only to research that is not exempt.]

Documents for use in this study are available in the WVUkc system in the Notes and Attachments section of your protocol.

The Office of Research Integrity and Compliance is here to provide assistance to you from the initial submission of an IRB protocol and all subsequent activity. Please feel free to contact us by phone at 304.293 .7073 with any question you may have. Thank you.

WVU Office of Research Integrity and Compliance

Date: $02 / 10 / 2015$ 
Signed:

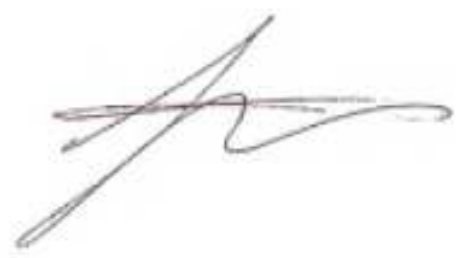

\section{Jonathan Young} Program Administrator

ct research, the following regulations apply:

1. Unanticipated or serious adverse events/side effects encountered in this research study must be reported to the IRB within five (5) days via the Notify IRB action.

2. Any modifications to the study protocol or informed consent form must be reviewed and approved by the $\mathbb{R B}$ prior to implementation via submission of an amendment.

3. You may not use a modified in formed consent form until it has been approved and validated by the IRB . 


\section{Instructions}

Please evaluate the attractiveness of the subject in each photograph using the scale provided. You may mark an " $X$ " anywhere between the zero and the ten. Ten is most attractive and zero is least attractive. Please only mark one " $X$ " per photograph and corresponding identification number. Make sure the photo you are evaluating matches the photo ID on the evaluation sheet. At the end of the survey, please answer the demographic questions. Thank you for your participation.

Examples:

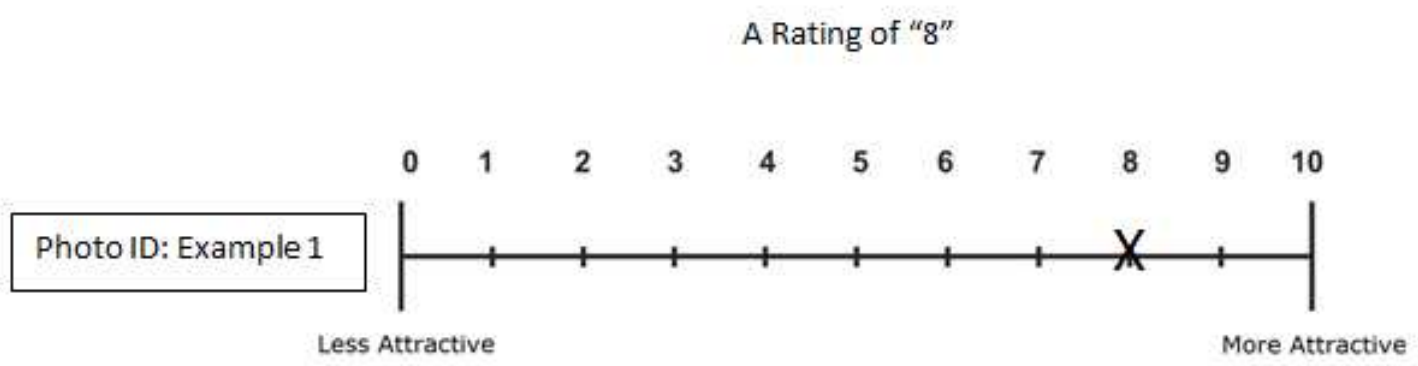

A Rating of " 6.7 "

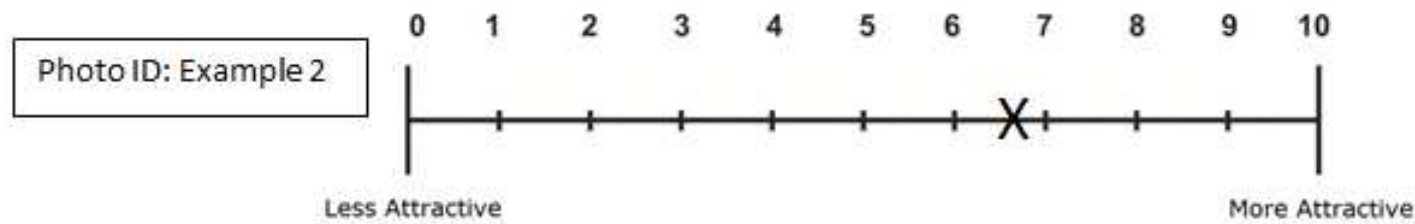

A Rating of " 4.2 "

Photo ID: Example 3

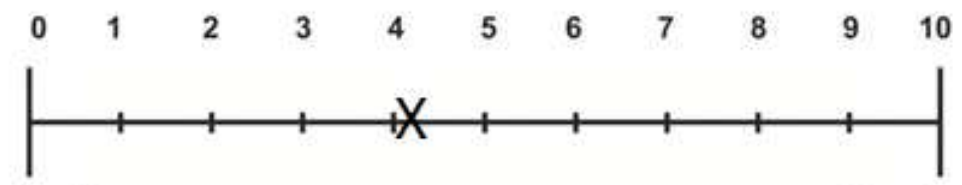


Evaluation Sheet

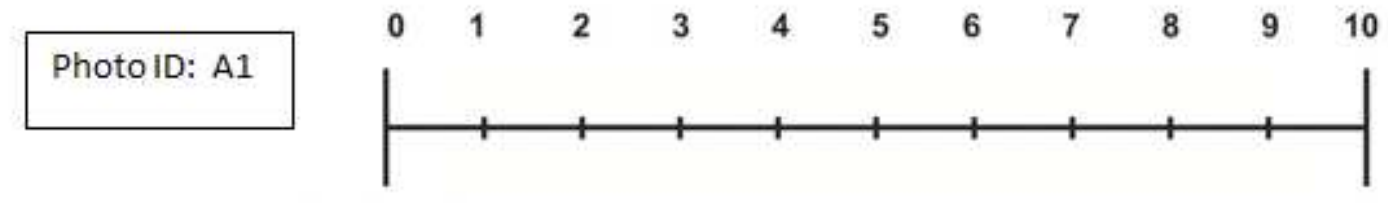

Less Attractive

More Attractive

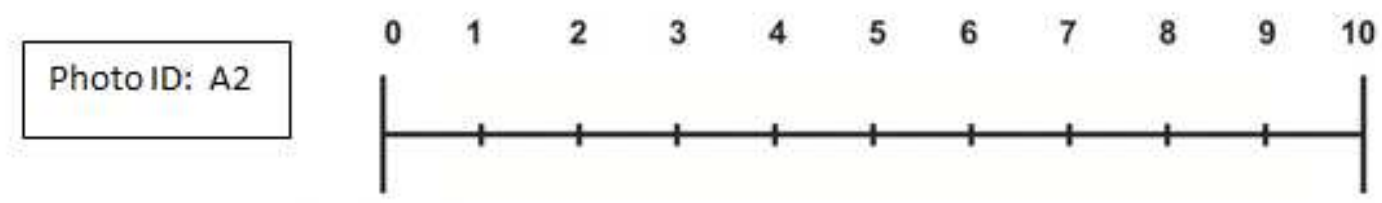

Less Attractive

More Attractive
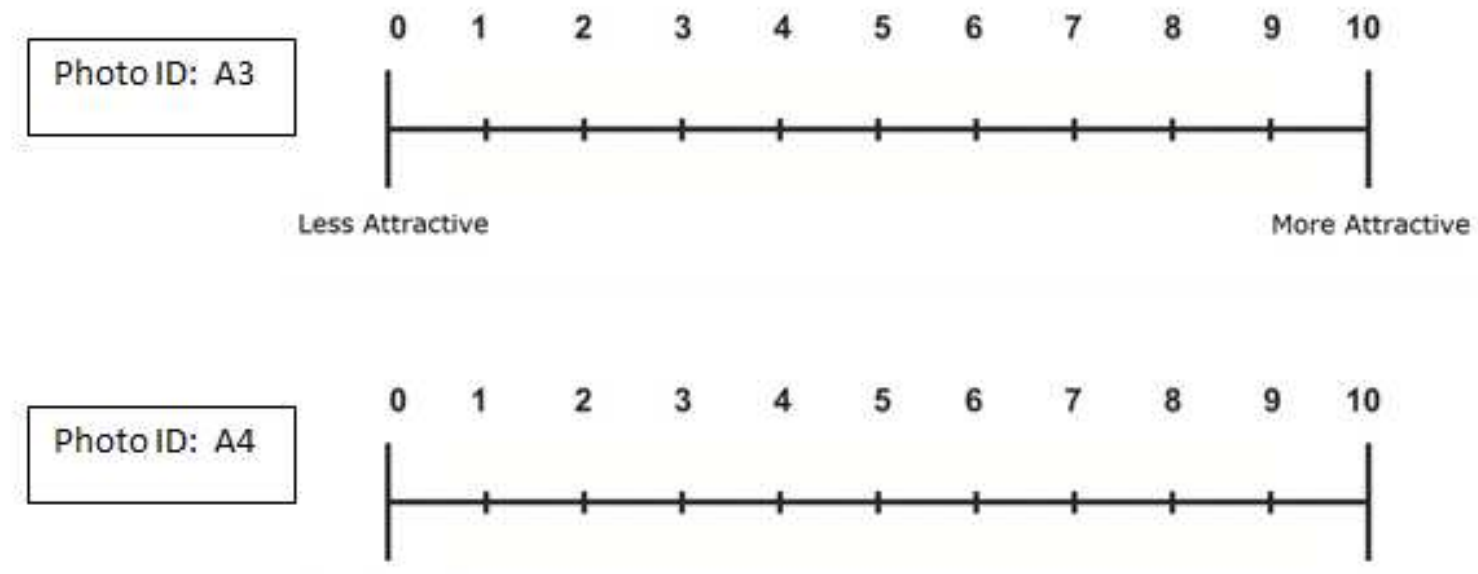

Less Attractive

More Attractive

PhotoID: A5

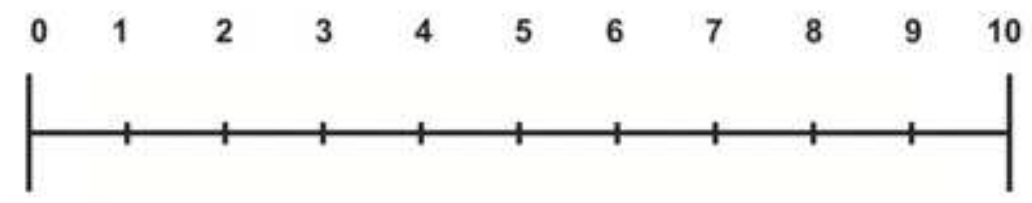

Less Attractive

More Attractive 


\begin{tabular}{|c|c|c|c|}
\hline Variable & $\begin{array}{l}\text { Correlations } \\
\text { by Variable }\end{array}$ & Correlation & P-value \\
\hline ANS-Me & N-ANS & 0.2133 & $0.0314^{*}$ \\
\hline $\mathrm{N}-\mathrm{Me}$ & N-ANS & 0.6466 & $<.0001^{*}$ \\
\hline $\mathrm{N}-\mathrm{Me}$ & ANS-Me & 0.8832 & $<.0001^{*}$ \\
\hline$C^{\prime}-S n^{\prime}$ & N-ANS & 0.6941 & $<.0001^{*}$ \\
\hline$G^{\prime}-S n^{\prime}$ & ANS-Me & 0.2199 & $0.0263^{*}$ \\
\hline$C^{\prime}-S n^{\prime}$ & $\mathrm{N}-\mathrm{Me}$ & 0.5049 & $<.0001^{\star}$ \\
\hline$S n^{\prime}-M e^{\prime}$ & $\mathrm{N}$-ANS & 0.2239 & $0.0237^{*}$ \\
\hline $\mathrm{Sn}^{\prime}-\mathrm{Me}^{\prime}$ & ANS-Me & 0.8960 & $<.0001^{*}$ \\
\hline$S n^{\prime}-M e^{\prime}$ & $\mathrm{N}-\mathrm{Me}$ & (1) Copy & $<001^{*}$ \\
\hline$S n^{\prime}-M e^{\prime}$ & $\mathrm{G}^{\prime}-\mathrm{Sn}^{\prime}$ & 0.1796 & 0.0709 \\
\hline$G^{\prime}-M^{\prime}$ & $\mathrm{N}$-ANS & 0.5450 & $<.0001^{*}$ \\
\hline $\mathrm{C}^{\prime}-\mathrm{Me}^{\prime}$ & ANS-Me & 0.7888 & $<.0001^{*}$ \\
\hline $\mathrm{C}^{\prime}-\mathrm{Me}^{\prime}$ & $\mathrm{N}-\mathrm{Me}$ & 0.9848 & $<.0001^{*}$ \\
\hline $\mathrm{C}^{\prime}-\mathrm{Me}^{\prime}$ & $\mathrm{C}^{\prime}-\mathrm{Sn}^{\prime}$ & 0.6785 & $<.0001^{*}$ \\
\hline $\mathrm{C}^{\prime}-\mathrm{Me}^{\prime}$ & $S n^{\prime}-M e^{\prime}$ & 0.8445 & $<.0001^{*}$ \\
\hline Co-Go & $\mathrm{N}$-ANS & 0.4262 & $<.0001^{*}$ \\
\hline Co-Go & ANS-Me & 0.3080 & $0.0016^{*}$ \\
\hline Co-Go & $\mathrm{N}-\mathrm{Me}$ & 0.4451 & $<, 0001^{*}$ \\
\hline Co-Go & $\mathrm{G}^{\prime}-\mathrm{Sn}^{\prime}$ & 0.4680 & $<.0001^{*}$ \\
\hline Co-Go & $S n^{\prime}-M e^{\prime}$ & 0.3185 & $0.0011^{*}$ \\
\hline Co-Go & $\mathrm{G}^{\prime}-\mathrm{Me}^{\prime}$ & 0.4926 & $<.0001^{*}$ \\
\hline Pog'-GALL & $\mathrm{N}$-ANS & -0.3108 & $0.0015^{*}$ \\
\hline Pog'-GALL & ANS-Me & -0.0562 & 0.5748 \\
\hline Pog'-GALL & $\mathrm{N}-\mathrm{Me}$ & -0.1931 & 0.0518 \\
\hline Pog'-GALL & $G^{\prime}-S n^{\prime}$ & -0.2035 & $0.0402^{*}$ \\
\hline Pog'-GALL & $\mathrm{Sn}^{\prime}-\mathrm{Me}^{\prime}$ & -0.0454 & 0.6504 \\
\hline Pog'-GALL & $\mathrm{G}^{\prime}-\mathrm{Me}^{\prime}$ & -0.1447 & 0.1468 \\
\hline Pog'-GALL & Co-Go & 0.0669 & 0.5044 \\
\hline Pog-GALL & N-ANS & -0.1895 & 0.0564 \\
\hline Pog-GALL & ANS-Me & -0.0693 & 0.4889 \\
\hline Pog-GALL & $\mathrm{N}-\mathrm{Me}$ & -0.1451 & 0.1457 \\
\hline Pog-GALL & $\mathrm{G}^{\prime}-\mathrm{Sn}^{\prime}$ & -0.2059 & $0.0379^{*}$ \\
\hline Pog-GALL & $S n^{\prime}-M e^{\prime}$ & -0.1350 & 0.1762 \\
\hline Pog-GALL & $\mathrm{C}^{\prime}-\mathrm{Me}^{\prime}$ & -0.2128 & $0.0317^{*}$ \\
\hline Pog-GALL & Co-Go & -0.0192 & 0.8480 \\
\hline Pog-GALL & Pog'-CALL & 0.5479 & $<.0001^{*}$ \\
\hline TVL-Pog' & N-ANS & -0.2150 & $0.0300^{*}$ \\
\hline TVL-Pog' & ANS-Me & 0.0402 & 0.6883 \\
\hline TVL-Pog' & $\mathrm{N}-\mathrm{Me}$ & -0.0718 & 0.4732 \\
\hline TVL-Pog' & $\mathrm{C}^{\prime}-\mathrm{Sn}^{\prime}$ & -0.0453 & 0.6515 \\
\hline TVL-Pog' & $\mathrm{Sn}^{\prime}-\mathrm{Me}^{\prime}$ & 0.0654 & 0.5134 \\
\hline TVL-Pog' & $\mathrm{G}^{\prime}-\mathrm{Me}^{\prime}$ & 0.0242 & 0.8089 \\
\hline TVL-Pog' & Co-Go & 0.0904 & 0.3665 \\
\hline
\end{tabular}




\begin{tabular}{|c|c|c|c|}
\hline Variable & by Variable & Correlation & P-value \\
\hline TVL-Pog' & Pog'-GALL & 0.7905 & $<.0001^{*}$ \\
\hline TVL-Pog' & Pog-GALL & 0.4744 & $<.0001^{*}$ \\
\hline MP-L1 & $\mathrm{N}$-ANS & 0.3769 & $<.0001^{*}$ \\
\hline MP-L1 & ANS-Me & 0.7649 & $<.0001^{*}$ \\
\hline MP-L1 & $\mathrm{N}-\mathrm{Me}$ & 0.7782 & $<.0001^{*}$ \\
\hline MP-L1 & $\mathrm{G}^{\prime}-\mathrm{Sn}^{\prime}$ & 0.3134 & $0.0013^{*}$ \\
\hline MP-L1 & $S n^{\prime}-M e^{\prime}$ & 0.6914 & $<.0001^{*}$ \\
\hline MP-L1 & $\mathrm{G}^{\prime}-\mathrm{Me}^{\prime}$ & 0.6869 & $<.0001^{*}$ \\
\hline MP-L1 & Co-Go & 0.4773 & $<.0001^{*}$ \\
\hline MP-L1 & Pog'-GALL & -0.0985 & 0.3247 \\
\hline MP-L1 & Pog-GALL & -0.1278 & 0.2006 \\
\hline MP-L1 & TVL-Pog' & -0.0169 & 0.8658 \\
\hline $\mathrm{Go}^{\circ}$ & $\mathrm{N}$-ANS & ก 1173 & ? 2402 \\
\hline $\mathrm{Go}^{\circ}$ & ANS-Me & Copy & 0.6749 \\
\hline $\mathrm{Go}^{\circ}$ & $\mathrm{N}-\mathrm{Me}$ & -0.0235 & 0.8146 \\
\hline $\mathrm{Go}^{\circ}$ & $G^{\prime}-S n^{\prime}$ & -0.1083 & 0.2786 \\
\hline $\mathrm{Go}^{\circ}$ & $S n^{\prime}-M e^{\prime}$ & 0.0066 & 0.9473 \\
\hline $\mathrm{Co}^{\circ}$ & $\mathrm{G}^{\prime}-\mathrm{Me}^{\prime}$ & -0.0540 & 0.5899 \\
\hline $\mathrm{Co}^{\circ}$ & Co-Go & -0.3871 & $<.0001^{*}$ \\
\hline $\mathrm{Go}^{\circ}$ & Pog'-GALL & 0.0672 & 0.5021 \\
\hline $\mathrm{Go}^{\circ}$ & Pog-GALL & 0.1694 & 0.0888 \\
\hline $\mathrm{Go}^{\circ}$ & TVL-Pog' & 0.1281 & 0.1995 \\
\hline $\mathrm{Go}^{\circ}$ & $M P-L 1$ & -0.2067 & $0.0371^{*}$ \\
\hline$M P^{\circ}$ & $\mathrm{N}$-ANS & 0.1269 & 0.2038 \\
\hline $\mathrm{MP}^{\circ}$ & ANS-Me & 0.1067 & 0.2858 \\
\hline $\mathrm{MP}^{\circ}$ & $\mathrm{N}-\mathrm{Me}$ & 0.1442 & 0.1481 \\
\hline$M P^{\circ}$ & $\mathrm{C}^{\prime}-\mathrm{Sn}^{\prime}$ & 0.1419 & 0.1547 \\
\hline$M P^{\circ}$ & $S n^{\prime}-M e^{\prime}$ & 0.0471 & 0.6386 \\
\hline $\mathrm{MP}^{\circ}$ & $\mathrm{C}^{\prime}-\mathrm{Me}^{\prime}$ & 0.1124 & 0.2607 \\
\hline $\mathrm{MP}^{\circ}$ & Co-Go & -0.1429 & 0.1518 \\
\hline $\mathrm{MP}^{\circ}$ & Pog'-GALL & -0.2000 & $0.0438^{*}$ \\
\hline $\mathrm{MP}^{\circ}$ & Pog-GALL & -0.1290 & 0.1963 \\
\hline $\mathrm{MP}^{\circ}$ & TVL-Pog' & 0.1000 & 0.3171 \\
\hline $\mathrm{MP}^{\circ}$ & MP-L1 & 0.0601 & 0.5486 \\
\hline $\mathrm{MP}^{\circ}$ & $\mathrm{Go}^{\circ}$ & 0.1847 & 0.0631 \\
\hline Op & $\mathrm{N}$-ANS & 0.0195 & 0.8459 \\
\hline$O p^{\circ}$ & ANS-Me & 0.0301 & 0.7642 \\
\hline Op ${ }^{\circ}$ & $\mathrm{N}-\mathrm{Me}$ & 0.0328 & 0.7432 \\
\hline Op ${ }^{\circ}$ & $\mathrm{G}^{\prime}-\mathrm{Sn}^{\prime}$ & 0.0197 & 0.8440 \\
\hline Op ${ }^{\circ}$ & $S n^{\prime}-M e^{\prime}$ & -0.0099 & 0.9211 \\
\hline$O p^{\circ}$ & $\mathrm{G}^{\prime}-\mathrm{Me}^{\prime}$ & 0.0033 & 0.9735 \\
\hline Op ${ }^{\circ}$ & Co-Go & -0.0624 & 0.5332 \\
\hline Op ${ }^{\circ}$ & Pog'-GALL & -0.2001 & $0.0437^{*}$ \\
\hline$O p^{\circ}$ & Pog-GALL & -0.0899 & 0.3690 \\
\hline
\end{tabular}




\begin{tabular}{|c|c|c|c|}
\hline Variable & by Variable & Correlation & $\mathrm{P}$-value \\
\hline$O p^{\circ}$ & TVL-Pog' & -0.1586 & 0.1112 \\
\hline Op ${ }^{\circ}$ & MP-L1 & -0.0377 & 0.7069 \\
\hline$O p^{\circ}$ & $\mathrm{Go}^{\circ}$ & 0.0000 & 1.0000 \\
\hline$O p^{\circ}$ & $\mathrm{MP}^{\circ}$ & 01.177 & 0.1385 \\
\hline Pog-Pog' & $\mathrm{N}$-ANS & & 0596 \\
\hline Pog-Pog' & ANS-Me & 0.1932 & 0.0517 \\
\hline Pog-Pog' & $\mathrm{N}-\mathrm{Me}$ & 0.2407 & $0.0148^{*}$ \\
\hline Pog-Pog' & $G^{\prime}-S n^{\prime}$ & 0.0398 & 0.6916 \\
\hline Pog-Pog' & $S n^{\prime}-M e^{\prime}$ & 0.2074 & $0.0365^{*}$ \\
\hline Pog-Pog' & $\mathrm{C}^{\prime}-\mathrm{Me}^{\prime}$ & 0.1765 & 0.0760 \\
\hline Pog-Pog' & Co-Go & -0.0152 & 0.8797 \\
\hline Pog-Pog' & Pog'-GALL & -0.4202 & $<.0001^{*}$ \\
\hline Pog-Pog' & Pog-GALL & -0.2862 & $0.0035^{*}$ \\
\hline Pog-Pog' & TVL-Pog' & -0.3985 & $<.0001^{*}$ \\
\hline Pog-Pog' & MP-L1 & 0.1405 & 0.1590 \\
\hline Pog-Pog' & $\mathrm{Go}^{\circ}$ & -0.0100 & 0.9206 \\
\hline Pog-Pog' & $\mathrm{MP}^{\circ}$ & 0.0685 & 0.4942 \\
\hline Pog-Pog' & Op ${ }^{\circ}$ & 0.0574 & 0.5664 \\
\hline Sn-GALL & $\mathrm{N}$-ANS & 0.1444 & 0.1475 \\
\hline Sn-GALL & ANS-Me & 0.0010 & 0.9917 \\
\hline Sn-GALL & $\mathrm{N}-\mathrm{Me}$ & 0.0701 & 0.4836 \\
\hline Sn-GALL & $G^{\prime}-S n^{\prime}$ & -0.0373 & 0.7100 \\
\hline Sn-GALL & $S n^{\prime}-M e^{\prime}$ & -0.0037 & 0.9706 \\
\hline Sn-GALL & $G^{\prime}-M e^{\prime}$ & -0.0230 & 0.8182 \\
\hline Sn-GALL & Co-Go & -0.0416 & 0.6778 \\
\hline Sn-GALL & Pog'-GALL & -0.0812 & 0.4172 \\
\hline Sn-GALL & Pog-GALL & 0.0308 & 0.7586 \\
\hline Sn-GALL & TVL-Pog' & -0.4531 & $<.0001^{\star}$ \\
\hline Sn-GALL & MP-L1 & 0.0386 & 0.7000 \\
\hline Sn-GALL & $\mathrm{Go}^{\circ}$ & -0.0137 & 0.8915 \\
\hline Sn-GALL & $\mathrm{MP}^{\circ}$ & -0.0312 & 0.7555 \\
\hline Sn-GALL & Op & 0.0650 & 0.5162 \\
\hline Sn-GALL & Pog-Pog' & 0.1229 & 0.2185 \\
\hline $\mathrm{Co}-\mathrm{Gn}$ & N-ANS & 0.2478 & $0.0120^{*}$ \\
\hline $\mathrm{Co}-\mathrm{Gn}$ & ANS-Me & 0.5006 & $<.0001^{*}$ \\
\hline Co-Gn & $\mathrm{N}-\mathrm{Me}$ & 0.5098 & $<.0001^{*}$ \\
\hline $\mathrm{Co}-\mathrm{Cn}$ & $G^{\prime}-S n^{\prime}$ & 0.3806 & $<.0001^{*}$ \\
\hline $\mathrm{Co}-\mathrm{Gn}$ & $S n^{\prime}-M e^{\prime}$ & 0.4938 & $<.0001^{*}$ \\
\hline $\mathrm{Co}-\mathrm{Gn}$ & $\mathrm{G}^{\prime}-\mathrm{Me}^{\prime}$ & 0.5760 & $<.0001^{\star}$ \\
\hline Co-Gn & Co-Go & 0.6531 & $<.0001^{*}$ \\
\hline $\mathrm{Co}-\mathrm{Gn}$ & Pog'-GALL & 0.3585 & $0.0002^{\star}$ \\
\hline $\mathrm{Co}-\mathrm{Gn}$ & Pog-GALL & 0.1770 & 0.0751 \\
\hline $\mathrm{Co}-\mathrm{Gn}$ & TVL-Pog' & 0.4207 & $<.0001^{*}$ \\
\hline Co-Gn & MP-L1 & 0.4624 & $<.0001^{*}$ \\
\hline
\end{tabular}




\begin{tabular}{|c|c|c|c|}
\hline Variable & by Variable & Correlation & P-value \\
\hline $\mathrm{Co}-\mathrm{Gn}$ & $\mathrm{Go}^{\circ}$ & -0.0323 & 0.7469 \\
\hline $\mathrm{Co}-\mathrm{Gn}$ & $\mathrm{MP}^{\circ}$ & -0.0490 & 0.6251 \\
\hline Co-Gn & Op ${ }^{\circ}$ & -0.1297 & 0.1939 \\
\hline $\mathrm{Co}-\mathrm{Gn}$ & Pog-Pog' & -0.0377 & 0.7071 \\
\hline $\mathrm{Co}-\mathrm{Gn}$ & Sn-GALL & -0.1754 & 0.0778 \\
\hline Pog-Pog" & $\mathrm{N}$-ANS & 0.0875 & 0.3817 \\
\hline Pog-Pog" & ANS-Me & 0.0882 & 0.3778 \\
\hline Pog-Pog" & $\mathrm{N}-\mathrm{Me}$ & 0.1109 & 0.2671 \\
\hline Pog-Pog" & $\mathrm{G}^{\prime}-\mathrm{Sn}^{\prime}$ & 0.1013 & 0.3112 \\
\hline Pog-Pog" & $S n^{\prime}-M e^{\prime}$ & 0.0759 & 0.4483 \\
\hline Pog-Pog" & $\mathrm{C}^{\prime}-\mathrm{Me}^{\prime}$ & 0.1118 & 0.2632 \\
\hline Pog-Pog" & Co-Go & Copy & $0.007^{*}$ \\
\hline Pog-Pog" & Pog'-GALL & $0.1 / 08$ & 0.0860 \\
\hline Pog-Pog" & Pog-GALL & 0.0716 & 0.4744 \\
\hline Pog-Pog" & TVL-Pog' & 0.1157 & 0.2468 \\
\hline Pog-Pog" & MP-L1 & 0.3073 & $0.0017^{*}$ \\
\hline Pog-Pog" & $\mathrm{Co}^{\circ}$ & -0.0214 & 0.8307 \\
\hline Pog-Pog" & $\mathrm{MP}^{\circ}$ & -0.0641 & 0.5222 \\
\hline Pog-Pog" & $O p^{\circ}$ & -0.1733 & 0.0816 \\
\hline Pog-Pog" & Pog-Pog' & -0.0541 & 0.5890 \\
\hline Pog-Pog" & Sn-GALL & 0.0887 & 0.3754 \\
\hline Pog-Pog" & $\mathrm{Co}-\mathrm{Gn}$ & 0.2746 & $0.0052^{*}$ \\
\hline U1-L1 & $\mathrm{N}$-ANS & -0.0435 & 0.6644 \\
\hline U1-L1 & ANS-Me & -0.2986 & $0.0023^{*}$ \\
\hline U1-L1 & $\mathrm{N}-\mathrm{Me}$ & -0.2540 & $0.0100^{*}$ \\
\hline U1-L1 & $\mathrm{G}^{\prime}-\mathrm{Sn}^{\prime}$ & -0.0299 & 0.7651 \\
\hline U1-L1 & $S n^{\prime}-M e^{\prime}$ & -0.2466 & $0.0125^{*}$ \\
\hline U1-L1 & $G^{\prime}-M^{\prime}$ & -0.2005 & $0.0434^{\star}$ \\
\hline U1-L1 & $\mathrm{Co}-\mathrm{Go}$ & 0.0434 & 0.6647 \\
\hline U1-L1 & Pog'-GALL & -0.1271 & 0.2030 \\
\hline U1-L1 & Pog-GALL & -0.2055 & $0.0382^{*}$ \\
\hline U1-L1 & TVL-Pog' & -0.1642 & 0.0991 \\
\hline U1-L1 & MP-L.1 & 0.1405 & 0.1590 \\
\hline U1-L1 & $\mathrm{Go}^{\circ}$ & -0.1861 & 0.0611 \\
\hline U1-L1 & $\mathrm{MP}^{\circ}$ & -0.0169 & 0.8659 \\
\hline U1-L1 & $\mathrm{Op}^{\circ}$ & -0.0278 & 0.7819 \\
\hline U1-L1 & Pog-Pog' & -0.2121 & $0.0324^{*}$ \\
\hline U1-L1 & Sn-GALL & 0.1660 & 0.0954 \\
\hline U1-L1 & Co-Gn & -0.2702 & $0.0060^{\text {t }}$ \\
\hline U1-L1 & Pog-Pog" & 0.3121 & $0.0014^{k}$ \\
\hline L1'-Pog & N-ANS & -0.0169 & 0.8660 \\
\hline L1'-Pog & ANS-Me & -0.1424 & 0.1534 \\
\hline L1'-Pog & $\mathrm{N}-\mathrm{Me}$ & -0.1193 & 0.2324 \\
\hline L1'-Pog & $G^{\prime}-S^{\prime}$ & 0.0538 & 0.5914 \\
\hline
\end{tabular}




\begin{tabular}{|c|c|c|c|}
\hline Variable & by Variable & Correlation & P-value \\
\hline L1'-Pog & $\mathrm{Sn}^{\prime}-\mathrm{Me}^{\prime}$ & -0.1913 & 0.0541 \\
\hline L1'-Pog & $\mathrm{C}^{\prime}-\mathrm{Me}^{\prime}$ & -0.1136 & 0.2556 \\
\hline L1'-Pog & Co-Go & 0.2647 & $0.0072^{*}$ \\
\hline$L^{\prime}-P o g$ & Pog'-GALL & 0.2312 & $0.0194^{*}$ \\
\hline L1'-Pog & Pog-GALL & ก 2160 & $n \cap 285^{*}$ \\
\hline L1'-Pog & TVL-Pog' & Copy & (4) $182^{*}$ \\
\hline L1'-Pog & MP-L1 & 0.1325 & 0.1843 \\
\hline LI'-Pog & $\mathrm{Co}^{\circ}$ & -0.0568 & 0.5706 \\
\hline LI'-Pog & $\mathrm{MP}^{\circ}$ & -0.1117 & 0.2639 \\
\hline L1'-Pog & Op ${ }^{\circ}$ & 0.0067 & 0.9463 \\
\hline L1'-Pog & Pog-Pog' & -0.0421 & 0.6741 \\
\hline L1'-Pog & Sn-GALL & -0.1520 & 0.1272 \\
\hline L1'-Pog & Co-Gn & 0.2451 & $0.0130^{*}$ \\
\hline L1'-Pog & Pog-Pog" & 0.6048 & $<.0001^{*}$ \\
\hline L1'-Pog & U1-L1 & 0.3353 & $0.0006^{*}$ \\
\hline L1"-Pog & $\mathrm{N}$-ANS & 0.0199 & 0.8425 \\
\hline $\mathrm{L1} 1^{\prime \prime}-\mathrm{Pog}$ & ANS-Me & -0.0623 & 0.5337 \\
\hline L1"-Pog & $\mathrm{N}-\mathrm{Me}$ & -0.0391 & 0.6963 \\
\hline L1"-Pog & $G^{\prime}-S n^{\prime}$ & 0.0170 & 0.8653 \\
\hline L1"-Pog & $S n^{\prime}-M e^{\prime}$ & -0.0592 & 0.5547 \\
\hline L1"-Pog & $\mathrm{G}^{\prime}-\mathrm{Me}^{\prime}$ & -0.0349 & 0.7275 \\
\hline L1"-Pog & Co-Go & 0.0144 & 0.8862 \\
\hline L1"-Pog & Pog'-GALL & 0.0181 & 0.8566 \\
\hline L1"-Pog & Pog-CALL & 0.0026 & 0.9795 \\
\hline L1"-Pog & TVL-Pog' & -0.0314 & 0.7537 \\
\hline L1"-Pog & MP-L1 & 0.0069 & 0.9451 \\
\hline L1"-Pog & $\mathrm{Go}^{\circ}$ & 0.0339 & 0.7351 \\
\hline L1"-Pog & $\mathrm{MP}^{\circ}$ & -0.0346 & 0.7297 \\
\hline L1"-Pog & $O p^{\circ}$ & 0.0178 & 0.8589 \\
\hline L1"-Pog & Pog-Pog' & 0.0007 & 0.9942 \\
\hline L1"-Pog & $\mathrm{Sn}-\mathrm{GALL}$ & 0.0715 & 0.4755 \\
\hline L.1"-Pog & $\mathrm{Co}-\mathrm{Gn}$ & -0.0230 & 0.8187 \\
\hline L1"-Pog & Pog-Pog" & 0.0949 & 0.3426 \\
\hline L1"-Pog & $\mathrm{U} 1-\mathrm{L} 1$ & 0.1866 & 0.0604 \\
\hline L1"-Pog & L1'-Pog & 0.1701 & 0.0874 \\
\hline L1-Me & $\mathrm{N}$-ANS & 0.3927 & $<.0001^{*}$ \\
\hline L1-Me & ANS-Me & 0.8286 & $<.0001^{*}$ \\
\hline L1-Me & $\mathrm{N}-\mathrm{Me}$ & 0.8355 & $<.0001^{*}$ \\
\hline L1-Me & $G^{\prime}-S n^{\prime}$ & 0.3458 & $0.0004^{\star}$ \\
\hline L1-Me & $S n^{\prime}-M e^{\prime}$ & 0.7593 & $<.0001^{*}$ \\
\hline L1-Me & $\mathrm{G}^{\prime}-\mathrm{Me}^{\prime}$ & 0.7553 & $<.0001^{*}$ \\
\hline L1-Me & Co-Go & 0.3839 & $<.0001^{*}$ \\
\hline L1-Me & Pog'-GALL & -0.2821 & $0.0041^{*}$ \\
\hline L1-Me & Pog-GALL & -0.2524 & $0.0105^{*}$ \\
\hline
\end{tabular}




\begin{tabular}{|c|c|c|c|}
\hline Variable & by Variable & Correlation & P-value \\
\hline L1-Me & TV́-Pog' & -0.1818 & 0.0675 \\
\hline L1-Me & $\mathrm{MP}-\mathrm{LI}$ & 0.9203 & $<.0001^{*}$ \\
\hline L1-Me & $60^{\circ}$ & -0.0918 & 0.3590 \\
\hline L1-Me & $\mathrm{MP}^{\circ}$ & 0.1015 & 0.3102 \\
\hline L1-Me & $O p^{\circ}$ & -0.0180 & 0.8572 \\
\hline $\mathrm{L} 1-\mathrm{Me}$ & Pog-Pog' & 0.2650 & $0.0071^{*}$ \\
\hline L1-Me & Sn-GALL & Copy & 2995 \\
\hline L1-Me & $\mathrm{Co}-\mathrm{Gn}$ & 0.3656 & $0.0002^{*}$ \\
\hline L1-Me & Pog-Pog" & 0.2310 & $0.0195^{\circ}$ \\
\hline L1-Me & $\mathrm{U} 1-\mathrm{L} 1$ & 0.1007 & 0.3141 \\
\hline L1-Me & L1'-Pog & -0.0481 & 0.6311 \\
\hline L1-Me & L1"-Pog & -0.0508 & 0.6118 \\
\hline L1-MP & N-ANS & 0.0418 & 0.6765 \\
\hline L1-MP & ANS-Me & -0.0279 & 0.7810 \\
\hline L1-MP & $\mathrm{N}-\mathrm{Me}$ & -0.0017 & 0.9866 \\
\hline L1-MP & $\mathrm{G}^{\prime}-\mathrm{Sn}^{\prime}$ & -0.0135 & 0.8931 \\
\hline L1-MP & $S n^{\prime}-M e^{\prime}$ & 0.0031 & 0.9752 \\
\hline L1-MP & $\mathrm{G}^{\prime}-\mathrm{Me}^{\prime}$ & -0.0050 & 0.9602 \\
\hline L1-MP & Co-Go & 0.2750 & $0.0052^{*}$ \\
\hline L1-MP & Pog'-GALL & -0.3267 & $0.0008^{*}$ \\
\hline L1-MP & Pog-GALL & -0.2044 & $0.0394^{*}$ \\
\hline L1-MP & TVL-Pog' & -0.4457 & $<.0001^{*}$ \\
\hline L1-MP & MP-L1 & -0.0367 & 0.7145 \\
\hline L1-MP & $\mathrm{Go}^{\circ}$ & -0.2957 & $0.0025^{*}$ \\
\hline L1-MP & $\mathrm{MP}^{\circ}$ & -0.1865 & 0.0605 \\
\hline L1-MP & Op & 0.0825 & 0.4098 \\
\hline L1-MP & Pog-Pog' & 0.0985 & 0.3248 \\
\hline L1-MP & Sn-GALL & 0.3423 & $0.0004^{*}$ \\
\hline L1-MP & $\mathrm{Co}-\mathrm{Gn}$ & -0.1950 & $0.0495^{*}$ \\
\hline L1-MP & Pog-Pog" & 0.1574 & 0.1141 \\
\hline L1-MP & $\mathrm{U} 1-\mathrm{L} 1$ & 0.1393 & 0.1626 \\
\hline L1-MP & L1'-Pog & -0.1502 & 0.1318 \\
\hline L1-MP & L1"-Pog & -0.0548 & 0.5841 \\
\hline L1-MP & L1-Me & 0.0984 & 0.3253 \\
\hline LI'-MP & $\mathrm{N}$-ANS & -0.0259 & 0.7960 \\
\hline L1'-MP & ANS-Me & -0.5166 & $<.0001^{*}$ \\
\hline L1'-MP & $\mathrm{N}-\mathrm{Me}$ & -0.4158 & $<.0001^{\star}$ \\
\hline L1'-MP & $\mathrm{C}^{\prime}-\mathrm{Sn}^{\prime}$ & 0.0355 & 0.7234 \\
\hline L1'-MP & $S n^{\prime}-M e^{\prime}$ & -0.4486 & $<.0001^{*}$ \\
\hline L1'-MP & $\mathrm{C}^{\prime}-\mathrm{Me}^{\prime}$ & -0.3157 & $0.0012^{*}$ \\
\hline L1'-MP & Co-Go & 0.2957 & $0.0025^{*}$ \\
\hline L1'-MP & Pog'-GALL & 0.0325 & 0.7457 \\
\hline L1'-MP & Pog-GALL & -0.0515 & 0.6070 \\
\hline L1'-MP & TVL-Pog' & -0.0745 & 0.4569 \\
\hline
\end{tabular}




$\begin{array}{llrr}\text { Variable } & \text { by Variable } & \text { Correlation } & \text { P-value } \\ \text { L1'-MP } & \text { MP-L1 } & -0.2729 & 0.0055^{*} \\ \text { L1'-MP } & \text { Go }^{\circ} & -0.4368 & <.0001^{*} \\ \text { L1'-MP } & \text { MP }^{\circ} & -0.1724 & 0.0832 \\ \text { L1'-MP } & \text { Op }^{\circ} & 0.0388 & 0.6986 \\ \text { L1'-MP } & \text { Pog-Pog' } & -0.1490 & 0.1349 \\ \text { L1'-MP } & \text { Sn-GALL } & 0.1062 & 0.2882 \\ \text { L1'-MP } & \text { Co-Gn } & -0.1478 & 0.1383 \\ \text { L1'-MP } & \text { Pog-Pog" } & 0.3005 & 0.0021^{*} \\ \text { L1'-MP } & \text { U1-L1 } & 0.3663 & 0.0002^{*} \\ \text { L1'-MP } & \text { L1'-Pog } & 0.4194 & <.0001^{*} \\ \text { L1'-MP } & \text { L1"-Pog } & 0.1277 & 0.2008 \\ \text { L1'-MP } & \text { L1-Me } & -0.3658 & 0.0002^{*} \\ \text { L1'-MP } & \text { L1-MP } & 0.3394 & 0.0005^{*}\end{array}$

Stepwise Regression Analysis 


\begin{tabular}{|c|c|c|c|c|c|c|}
\hline \multicolumn{7}{|c|}{ Response Pog-Pog' } \\
\hline \multicolumn{7}{|c|}{ Whole Model } \\
\hline \multicolumn{5}{|c|}{ Summary of Fit } & & \\
\hline \multicolumn{4}{|c|}{$\begin{array}{l}\text { RSquare } \\
\text { RSquare Adj } \\
\text { Root Mean Square Error } \\
\text { Mean of Response } \\
\text { Observations (or Sum Wgts) }\end{array}$} & $\begin{array}{r}29702 \\
82818 \\
59164 \\
84353 \\
102\end{array}$ & & \\
\hline \multicolumn{7}{|c|}{ Analysis of Variance } \\
\hline $\begin{array}{l}\text { Source } \\
\text { Model } \\
\text { Error } \\
\text { C. Total }\end{array}$ & $\begin{array}{r}\text { DF } \\
2 \\
99 \\
101\end{array}$ & $\begin{array}{r}S \\
144 \\
342 \\
486\end{array}$ & $\begin{array}{l}\text { Sum of } \\
\text { Squares } \\
4.58151 \\
.19262 \\
.77413\end{array}$ & $\begin{array}{r}\text { Mean Squ } \\
72.29 \\
3.45\end{array}$ & $\begin{array}{l}\text { are } \\
308 \\
665\end{array}$ & $\begin{array}{r}\text { F Ratio } \\
20.9145 \\
\text { Prob }>\text { F } \\
<.0001\end{array}$ \\
\hline \multicolumn{7}{|c|}{ Parameter Estimates } \\
\hline $\begin{array}{l}\text { Term } \\
\text { Intercept } \\
\text { Sn'-Me' } \\
\text { TVL-Pog' }\end{array}$ & $\begin{array}{l}\text { Estim } \\
1.8324 \\
0.1618 \\
0.1009\end{array}$ & $\begin{array}{l}\text { late } \\
372 \\
482 \\
298\end{array}$ & $\begin{array}{l}\text { Std Error } \\
2.023696 \\
0.030374 \\
0.030502\end{array}$ & $\begin{array}{r}\text { t Ratio } \\
0.91 \\
5.33 \\
3.31\end{array}$ & $\begin{array}{r}\text { Prot } \\
0.3 \\
<.0 \\
0.0\end{array}$ & $\begin{array}{l}b>|t| \\
3674 \\
0001 \\
0013\end{array}$ \\
\hline$S n^{\prime}-M e^{\prime}$ & \multicolumn{2}{|c|}{ TVL-Pog' } & & & & \\
\hline
\end{tabular}



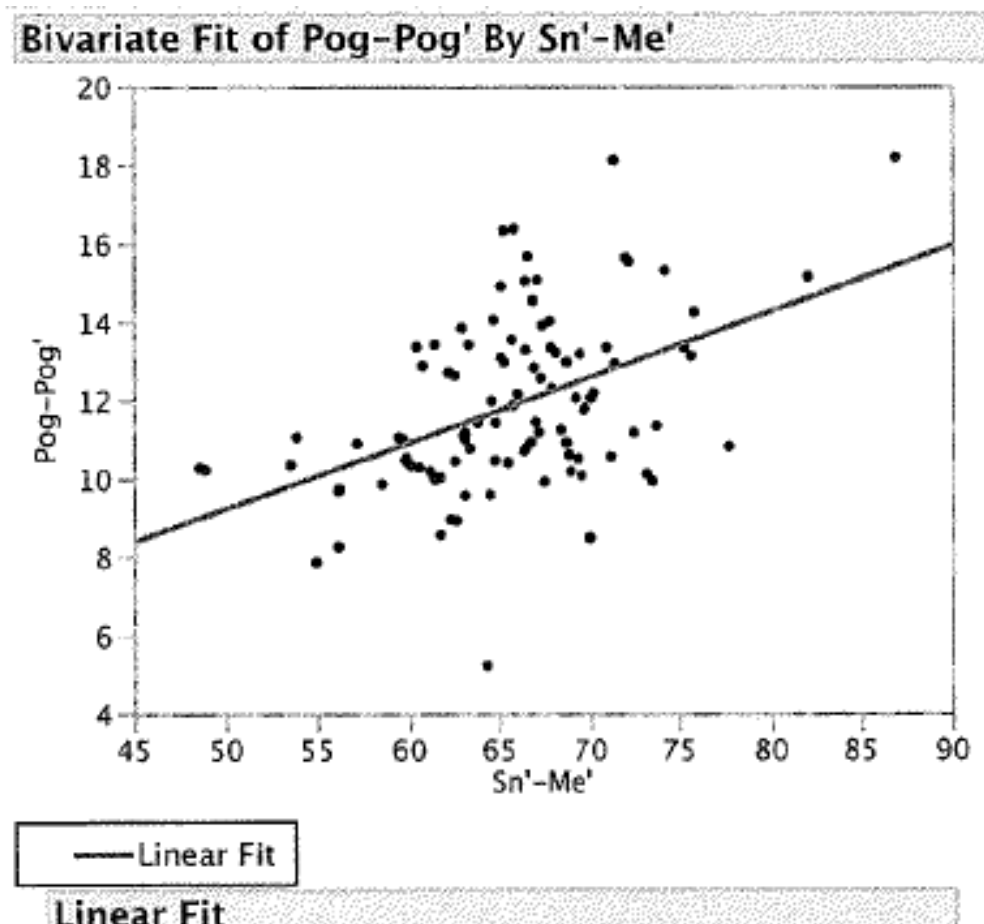

Linear Fit

Pog-Pog' $=0.7838534+0.1684257^{\star}{ }^{-5} n^{\prime}-M^{\prime}$

Summary of Fit

$\begin{array}{lr}\text { RSquare } & 0.219272 \\ \text { RSquare Adj } & 0.211465 \\ \text { Root Mean Square Error } & 1.949456 \\ \text { Mean of Response } & 11.84353 \\ \text { Observations (or Sum Wgts) } & 102\end{array}$

Analysis of Variance

$\begin{array}{lrrrrr}\text { Source } & \text { DF } & \begin{array}{r}\text { Squm of } \\ \text { Squares }\end{array} & \text { Mean Square } & \text { F Ratio } \\ \text { Model } & 1 & 106.73614 & 106.736 & 28.0856 \\ \text { Error } & 100 & 380.03799 & 3.800 & \text { Prob }>\text { F } \\ \text { C. Total } & 101 & 486.77413 & & <.0001 \text { i }\end{array}$

\section{Parameter Estimates}

Term Estimate Std Error t Ratio Prob $>|t|$

$\begin{array}{llllll}\text { Intercept } & 0.7838534 & 2.095801 & 0.37 & 0.7092\end{array}$

$\begin{array}{llllll}S^{\prime} n^{\prime}-\mathrm{Me}^{\prime} & 0.1684257 & 0.031781 & 5.30 & <.000 I^{\prime}\end{array}$ 


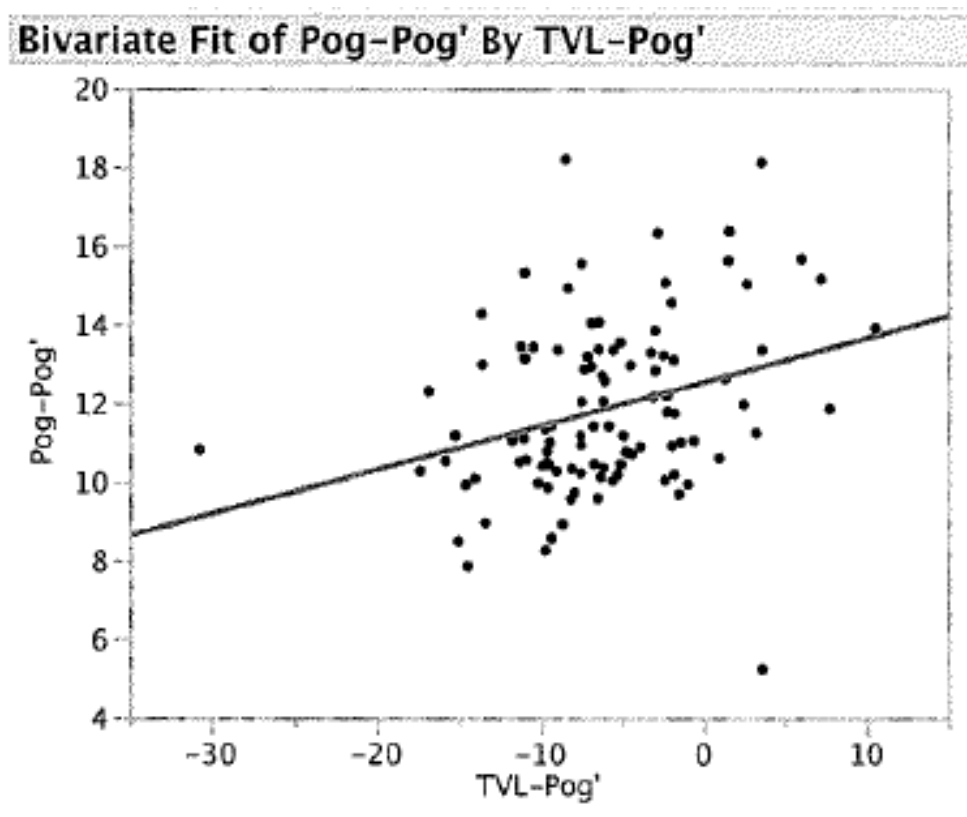

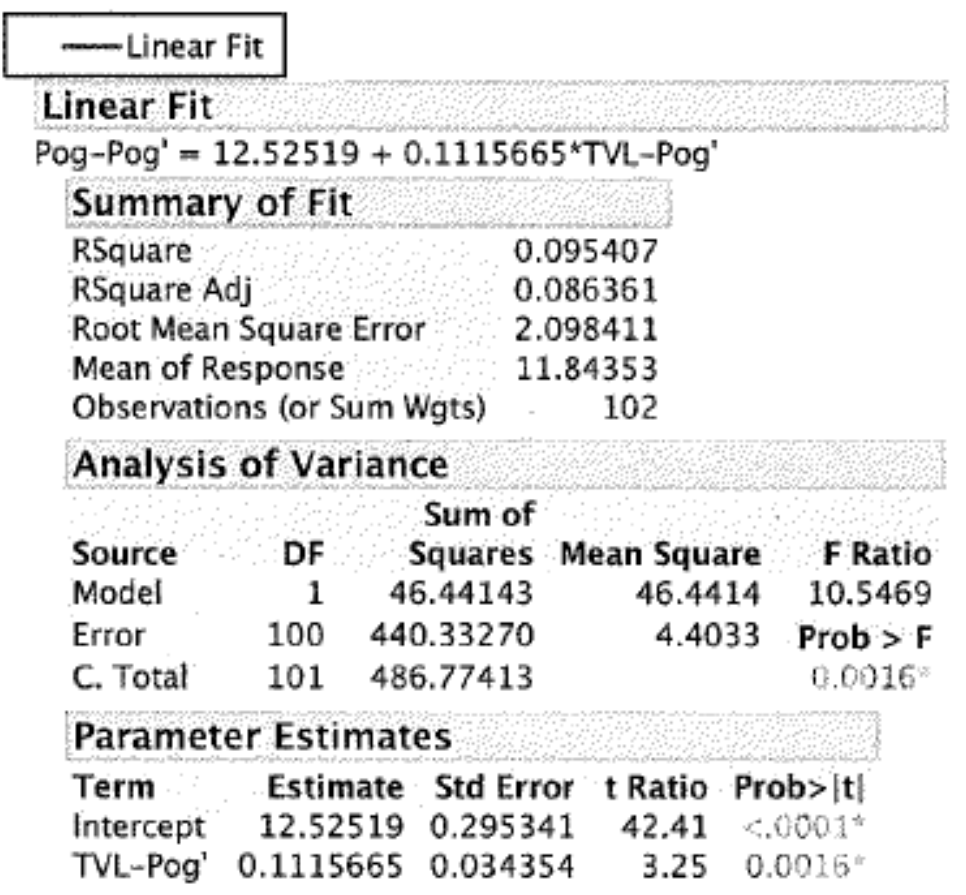

